\title{
A Pound of Flesh:
}

\section{Human Remains, Ethics and Museums in Tertiary Education}

\author{
by \\ Paulette Ruth McFarland Milnes
}

\begin{abstract}
A thesis submitted to
Victoria University of Wellington

in fulfilment of the requirements for the degree of

Master of Arts in Museum and Heritage Studies
\end{abstract}

Victoria University of Wellington

2017 


\section{Contents}

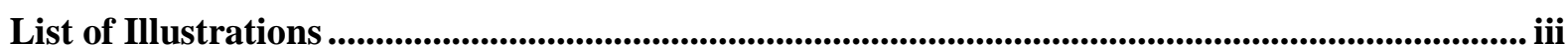

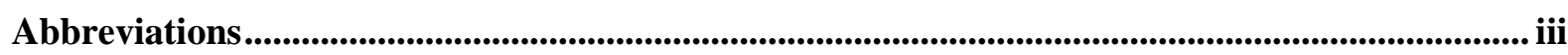

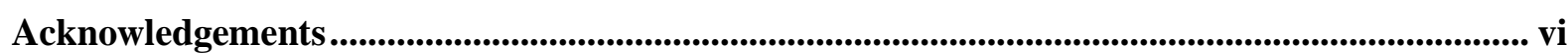

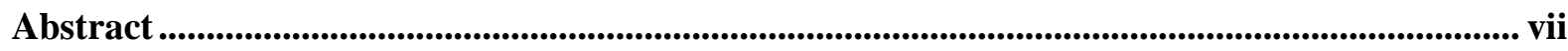

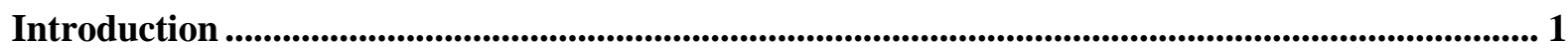

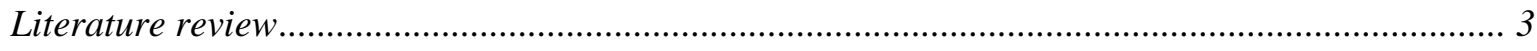

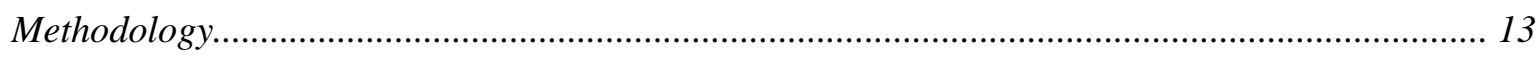

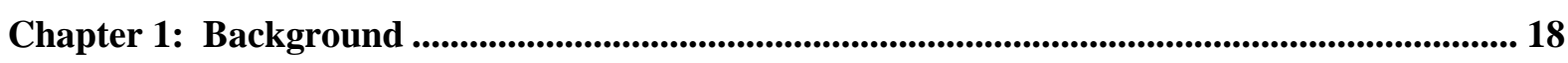

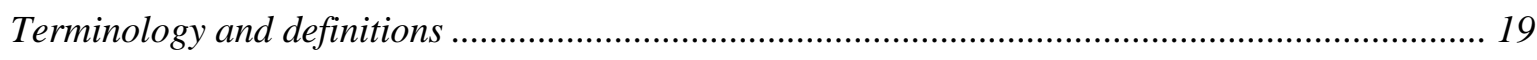

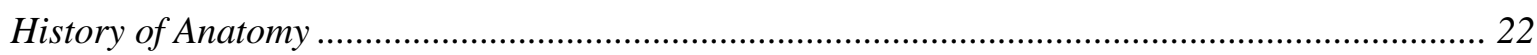

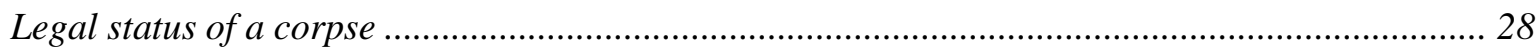

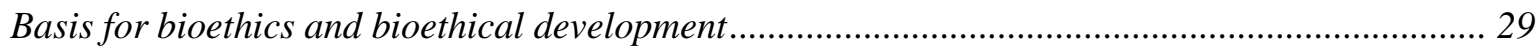

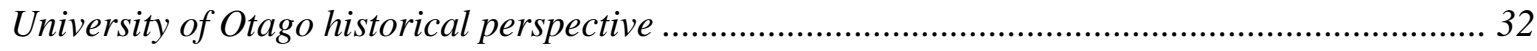

Chapter 2: Sources .......................................................................................................................................... 35

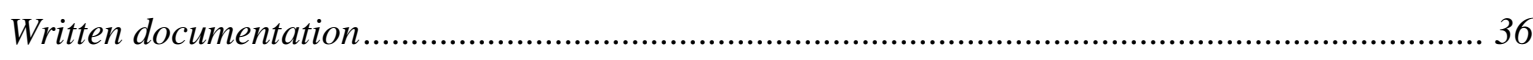

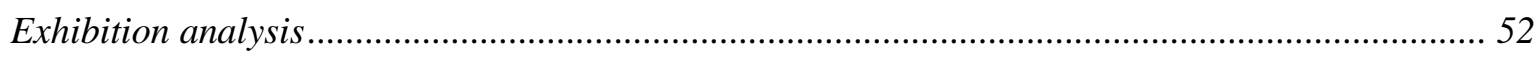

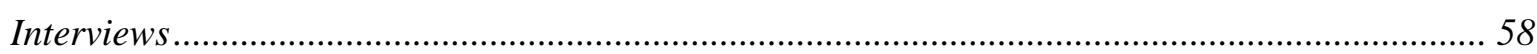

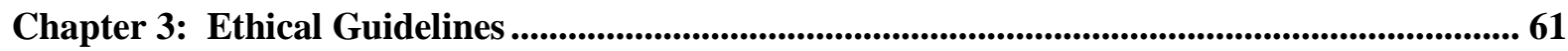

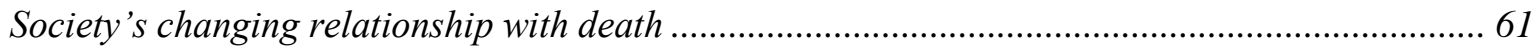

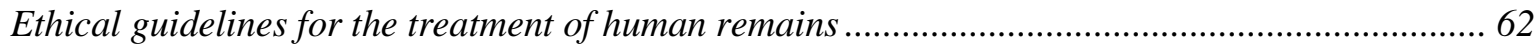

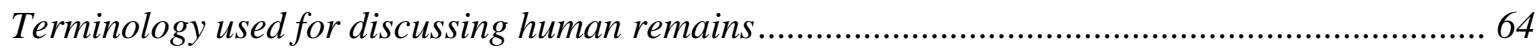

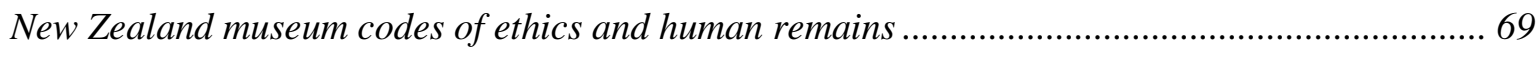

Tensions between different types of ethics in health science museums ........................................... 70

Guidelines for working with human remains at Otago University .............................................. 70

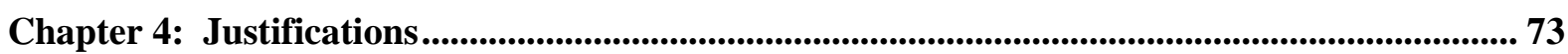

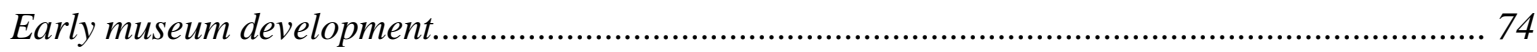

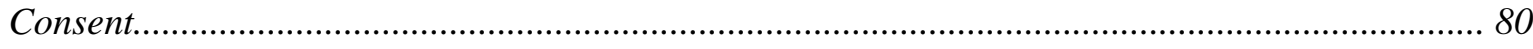

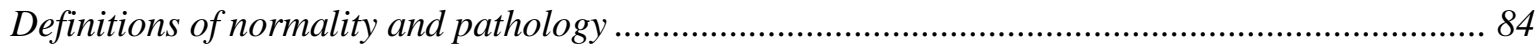

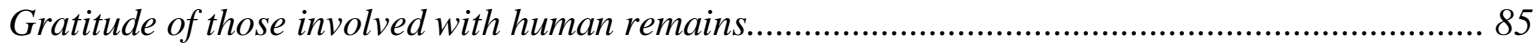

Chapter 5: Tertiary Museums and Health Science Education........................................................... 87

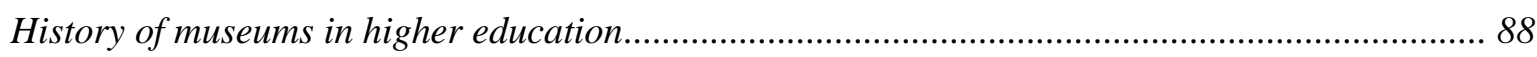




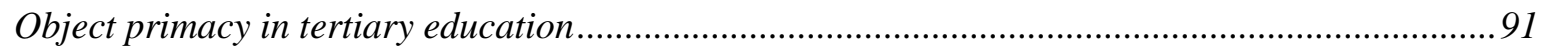

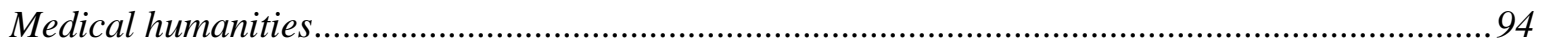

Emotional response in health science education .............................................................................95

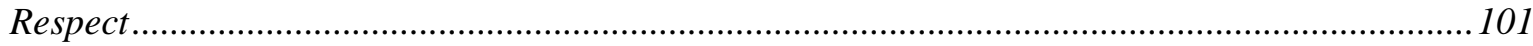

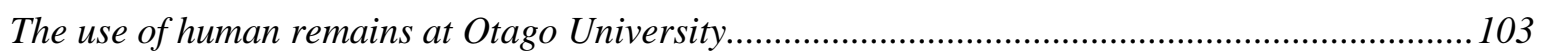

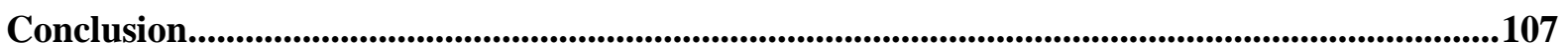

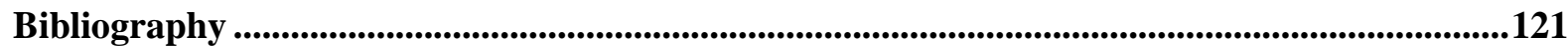

\section{List of Illustrations}

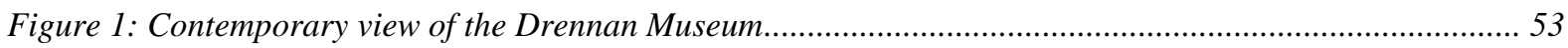

Figure 2: Contemporary view of the Trotter Museum ………………….................................................... 55

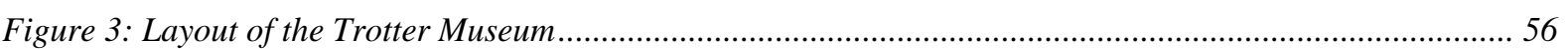

All images () University of Otago. Used with permission.

\section{Abbreviations}

AAM

BABAO

CAUMAC

CDC

Code of Patients Rights

CMA

DCMS

HNZ

HTANZ

HTAUK

ICOM

IFAA

MA
American Alliance of Museums, United States of America

British Association for Biological Anthropology and Osteoarchaeology, United Kingdom

Council of Australian University Museums and Collections

Centre for Disease Control and Prevention, United States of America

Code of Health \& Disability Services Consumers' Rights

Canadian Museums Association

Department of Culture, Media and Sport, United Kingdom

Heritage New Zealand

Human Tissue Act 2008 (NZ)

Human Tissue Act 2004 (UK)

International Council of Museums

International Federation of Associations of Anatomists

Museums Aotearoa, New Zealand 
MAUK

MAus

MCNZ

MEG

MSCNZ

NAGPRA

NZHPT

OBL

QS

ROC

Te Papa

UCL

UMAC

UNESCO Convention

UNIDROIT Convention

WAC

WGEHCE

WGHRM

WHO

WMA
Museums Association, United Kingdom

Museums Australia

Medical Council of New Zealand

Museum Ethnographers' Group

Medical Sciences Council of New Zealand

Native American Graves Protection and Repatriation Act 1990 (USA)

Historic Places Trust Pouhere Taonga, New Zealand

Object-based learning

Quacquarelli Symonds

Retained Organs Commission

Museum of New Zealand Te Papa Tongarewa

University College London, United Kingdom

International Committee for University Museums and Collections

United Nations Educational, Scientific and Cultural

Organization Convention on the Means of Prohibiting and Preventing the Illicit Import, Export and Transfer of

Ownership of Cultural Property (1970)

International Institute for the Unification of Private Law

Convention (1995)

World Archaeological Congress

Working Group from English Heritage and the Church of England, United Kingdom

Working Group on Human Rights in Museum Collections, United Kingdom

World Health Organisation

World Medical Association 


\section{Acknowledgements}

I must begin these acknowledgements with thanks to my supervisors, Dr Conal McCarthy, Victoria University of Wellington, and Professor D. Gareth Jones, University of Otago. While studying off site has had its challenges it was always good to know that you were both an email or a Skype call away, with sound advice and the ability to point me in just the right direction that I needed to find. And thank you for not being too concerned when I went into silent mode for months as I chipped away at things. Being on staff at the University of Otago while working on my thesis has allowed me the privilege of benefiting from the intellectual generosity of the staff and students. In particular I would like to thank Thelma Fisher (Library), Claire Gallop (Dentistry), Barbara Lee (Hunter Centre), Professor Nicola Peart (Law), Professor Peter Skegg (Law), Kate Thompson (Library), Dr Davinia Thornley (Media, Film and Communication), Katie Young (Pathology) and countless others who have allowed me to twist their ear. I have also benefited from the intellectual and collegial generosity and support of people outside of Victoria University of Wellington and the University of Otago. I would like to thank Sam Alberti (previously Hunterian), Ken Arnold (Wellcome Institute), Laura Balcells Sintado (Royal College of Surgeons), Martyn Cooke (Royal College of Surgeons), Jean McIntyre (Open Palace Programme), and people from Museums Aotearoa, EMPNZ, and the OPP.

I would like to thank my friends and family, especially as I've been a bit MIA for the last couple of years. The Mid-life (Crisis) group at Highgate Presbyterian Church, Erika Pearson, Matthew and Jackie Pitchforth, Jason and Judy Goroncy, Felicity McLeod, Patrick Harsveldt, Anthony Wade and Rosie Creighton.

Special thanks to Dr Warwick Johnson, proof reader and grammar checker extraordinaire! Thank you for pulling me on track when sentences made perfect sense to me but no-one else, and I was too far down the rabbit hole to know quite what I had said, hadn't said, or even meant.

Extra special thanks must go to two people: Amanda Mills and John Milnes. Amanda without your support, acting as a listening board, and allowing me to be a bit crazy every now and again I don't think I would have survived. I can never express quite how much your support has meant over the last couple of years, and I thank you from the bottom of my tootsies. 
Dr Dickon John Milnes - When one partner works full-time and does postgrad part-time it's a bit crazy-making. When both of you do it, it really is a special kind of crazy.

Between us we have managed a doctorate, a postgraduate diploma, a masters degree, and I know more about the First World War than I think I ever wanted to, although I know I've subjected you to 'squishy things in jars' too. Now we have time to watch Netflix without feeling guilty. Thank you for your love and unending belief that I could get this done and that it would be good. Can we get a dog now? 


\begin{abstract}
The collection and display of human remains has long been accepted within many cultures and religions. However, in contemporary Western society the practice has become contentious, and acquisition by museums has all but ceased. Among academic and museum communities, debate and discussion on the problem have been centred almost entirely on indigenous repatriation claims and Body Worlds exhibitions, to the exclusion of other aspects of what is in fact a much broader issue. The purpose of this thesis is to reflect on the question of whether human remains can ever justifiably be collected and held by museums. The focus of the study is the situation of health science disciplinary museums within tertiary education, with specific and detailed reference to the W.D. Trotter Anatomy Museum and the Drennan Pathology Museum at the University of Otago, Dunedin, New Zealand.
\end{abstract}

Three interconnected aspects of the topic are considered in order to answer the primary question. The first is an examination of the codes of ethics and professional practice that govern the treatment of human remains; the second reviews the justifications commonly given for the use of human remains; and the third aspect considers the role museums play in tertiary education. Documentary sources, exhibitions and interviews were analysed to address these issues and corroborate evidence. Examined together, these three areas of investigation bring a fresh perspective to whether the acquisition and retention of human remains can be justified, at least within certain parameters.

This study concludes that in the particular educational context of the health science teaching museum there is a strong justification for continued acquisition and display, albeit in a highly regulated and clearly defined ethical environment, of human remains. A key outcome of the research is that the most important consideration across all three areas of investigation, and for all groups working with human remains, was the concept of respect. Definitions and expressions of respect differed depending on context and professional boundaries, but within specific ethical parameters it is possible to determine that the collection and retention of human remains can be justified. 
Therefore prepare thee to cut off the flesh.

Shed thou no blood; nor cut thou less nor more

But just a pound of flesh: if thou cutt'st more

Or less than a just pound, - be it but so much

As makes it light or heavy in the substance,

Or the division of the twentieth part

Of one poor scruple, nay, if the scale do turn

But in the estimation of a hair, -

Thou diest, and all thy good are confiscate.

Portia, The Merchant of Venice, Act 4, 1, 324-332 


\section{Introduction}

Acquisition and display of human remains has been a widely accepted cultural or religious practice within many communities around the world. However, recent developments in Western society have raised ethical questions concerning the holding and exhibiting of human remains. This results from the growing political status of indigenous communities and public reaction to ethically dubious collection of human remains in clinical settings. The general reaction of the museum sector has been to recognise the special status of human remains, prohibit further acquisition, and consider repatriation where possible. This thesis investigates whether there are justifiable reasons for museums to collect and hold collections of human remains, with specific reference to health science museums in tertiary education institutions. ${ }^{1}$ This first introductory chapter is intended to provide a broad context and overview of what will be more closely examined and developed in later chapters.

Three interconnected areas are examined: what codes of ethics and professional practice govern the treatment of human remains; what justifications are given for their use; and what is the place of museums in tertiary education. These issues are explored more specifically in relation to the W.D. Trotter Anatomy Museum and the Drennan Pathology Museum at the University of Otago, Dunedin (commonly known as Otago University). Examining how these museums are utilised for teaching and research, as well as documentation which governs practice, allows for assessment of museums' ethical basis for behaviour. These directives are compared to established museum codes of ethics and professional practice to gauge the extent of similarity between the case study museums and the wider museum sector.

Debate regarding human remains in museums largely disregards museums teaching health sciences. The primary focus is on two main issues: Indigenous repatriation claims; and the Body Worlds exhibitions developed by the Institute for Plastination, Heidelberg. Limitation of the debate to these specific issues restricts wider discussion. Significant amounts of remains in museum collections relate to neither indigenous remains nor Body Worlds exhibitions, and research undertaken on tertiary collections predominantly examine issues

\footnotetext{
${ }^{1}$ The term "health science museum" is used in preference to the more common "medical museum" to acknowledge that these are utilised for teaching more than just medical programmes.
} 
surrounding anthropological contexts rather than health science collections. This thesis investigates health science collections to draw them into the wider debate and develop more nuanced understandings of the subject.

The majority of literature focusing on using museums' human remains collections to educate about the body is centred on Body Worlds rather than specialised disciplinary museums. ${ }^{2}$ Body Worlds exhibitions are comprised of plastinated donated bodies. The technique of plastination, where plastic replaces liquid in tissue, is not controversial and is used internationally by medical schools, including Otago. Although the technique itself is not contentious, Body Worlds exhibitions have caused significant controversy and debate.

A basic assumption of this thesis is that all institutions and individuals work within a framework of acceptable practice provided by their community. The community may be comprised of disciplinary academics, professional practitioners, specific cultural groups or geographically defined communities. The framework may be defined by legislation, professional standards, religious beliefs, cultural identity or societal norms. This thesis considers how different frameworks of acceptable practice interact to produce an individual, contextualised set of ethics within tertiary health science museums, and it examines how these mediated ethics are viewed in respect of their more established predecessors.

This research aims to add to current academic debate around museological ethics, human remains in museums, and museums in tertiary education, where it potentially has implications for health science instructors, medical personnel and consequently their patients. The shaping of how health science students are taught and, hence, what they are taught, is a tangible expression of the development of ethical thought and behaviour, with real world manifestations within health care practice. As noted above, there is a significant gap in the literature concerning human remains in museums, in that attention is mostly limited to indigenous remains and Body Worlds. Examining human remains in museums only through the oppositional frameworks of indigeneity and spectacles of plastination ignores other contexts which can provide nuance to the discussion. This thesis will help to fill the present conceptual gap.

\footnotetext{
${ }^{2}$ This refers primarily to exhibitions of full and partial plastinates (remains that have been plastinated are usually referred to as 'plastinates'), likened to Victorian freak shows and the concept of freakery, rather than use of plastinated human remains within purely educational contexts.
} 


\section{Literature review}

There is a very large body of academic and professional work on the broad topic of this thesis, and a full examination is beyond the scope and physical limitations of this work. However, narrowing the focus shines a brighter light on the essential area of the present research. Despite the historical popularity of human remains as objects of display, and more recent concerns around this practice, beyond the two topics of indigenous remains and Body Worlds, the question of human remains as objects of contemporary display is largely unexplored. It is a field of enquiry which more broadly incorporates the place of disciplinary-specific museums in higher education, as well as the divergence between academic museums and museums in the wider sector.

Due to this significant gap in museum studies literature, material from a breadth of disciplines must be considered to understand the treatment of human remains in museums and society. The literature on this subject falls into four main areas: general discussion of human remains in museums and society, use of museums in tertiary education, guidelines for the treatment of remains, and justification for uses of remains.

\section{General discussion}

Examination of how the body itself is, and has been, viewed and how health and death are contextualised is important in discussions of human remains in museums. Among the fundamental works on this topic, Ruth Richardson (1988) outlines the historical place of the body within anatomical education and law in the United Kingdom. This is important due to New Zealand's historical links with the UK and Otago University's close association with Edinburgh University. Gareth Jones \& Maja Whitaker (2009) discuss the role of the human body within current scientific thought, including ideas of what constitutes death and delineating boundaries of the human body. Tiffany Jenkins (2011) examines the problematising of holding and using human remains within the clinic and the museum, and Georges Canguilhem (1978) explores theoretical conceptions of health and pathology. While Jenkins' work investigates how holding remains became problematic, J. L. Foltyn's work (2008) on death in modern Western societies allows for contextualisation of these concerns within the current cultural experience of death as disconnected from general experience except through trauma or fiction. Sanchita Balachandran (2009) is only one of a number of authors who have explored understandings of "human remains" and the duality 
of the nature:culture interpretation which limits other non-Western understandings of the body and objects. Human remains as sacred have often been contextualised within Western ideology rather than within beliefs of originating communities.

There is an extensive body of work on the challenges to the cultural authority of the museum and responses to it. Whether authors have investigated the museum as an agent or as a respondent to change, these challenges have been met with a variety of intellectual and professional responses, with Jenkins, Balachandran and Gary Edson (1997) prominent. Science has also not been immune to changing perceptions of its authority. Richardson (1988) has explored the murky origins of anatomy, its involvement in grave-robbing, and how anatomy and the medical profession became increasingly respectable. Charles Darwin's On the Origin of Species had profound effects on the place and authority of natural history, having a significant impact on separating the natural world from theology. It has been argued (Conn 2006; Wikler \& Barondess, 1993) that the development of atomic weaponry and Nazi scientific excesses had significant impacts on science's reputation. The impact of the Nazis is crucial as it lies at the heart of the development of modern bioethics, and incorporates issues such as the complicity of medical personnel, eugenics, racial hygiene, sexual and political deviance, and society rather than individuals as the base unit of health.

In more recent times scandals in hospitals and clinics worldwide have impacted on how human remains are discussed in all contexts, including museums. The impetus for this was the discovery of organ retention without informed consent at Royal Liverpool Children's Hospital (Alder Hey) and Bristol Royal Infirmary in the UK (discussed below, Chapter 1). This triggered international reviews of accepted practice regarding the retention of body parts, including those held by museums. As a number of writers have demonstrated, these events played a significant role in the way human remains in museums have been conceptualised and legislated for (Jenkins 2011; Jones \& Whitaker 2009; Mason \& Laurie 2001).

This present study of remains in health science museums aims to explore themes of ethics involved in collecting and displaying any human remains, but it cannot ignore the fact that the historical context is complicated by racism, sexism, and ableism within imperial, economic, class-based and patriarchal power structures. While these factors are acknowledged as significant aspects of the history of human remains in museums, it is not 
the focus of this research to fully explore these themes. Human remains, body boundaries, health and death are all concepts that are generally accepted intuitively as static and stable. However, literature around these concepts demonstrates that this is not the case. In discussions of remains in museums teaching health science, these concepts need further exploration to ensure clarity about what exactly is under discussion.

\section{Tertiary museums}

Literature regarding human remains in tertiary museums must be positioned within a larger examination of museums within tertiary institutions. Historically museums were fundamental to higher education and delineating disciplinary boundaries. Museums were the primary site of research and discovery, whereas universities were places for teaching established knowledge (Conn 1998). With the shift from observational to experimental science, emphasis for knowledge creation largely moved to universities. Museums came to be seen as outdated and it is only recently that there has been a resurgence of interest in tertiary museums. In their recent publication Museums and Higher Education, Boddington et al. (2013) draw together current research on modern links between museums and tertiary education. In the introduction Speight et al. (2013) note that while there is room for partnerships to develop between museums and tertiary institutions, these relationships are significantly limited by power relations that exist between and within each institution and their pedagogical approaches to information and learning.

Much of the literature surrounding health science museums has a historical focus rather than viewing them as part of modern curricula. In Samuel Alberti's thorough examination of medical museums in the UK it is only in his concluding chapter that he comments on the state of contemporary collections (Alberti 2011). He notes that with increasing importance placed on microbiology and biochemistry, collections and teaching have moved away from gross specimens. Trudy Turner (2014) has examined how cross-disciplinary borrowing from museum studies can aid the organisation and running of biobanks and other academic scientific collections. Biological anthropology departments also collect human remains but discussions regarding these collections often focus on repatriation.

Other discussions of relationships between museums and tertiary institutions consider the development of a dual purpose for tertiary museums. Supporting teaching and research is only one role tertiary museums are expected to play. Increasingly they are used to promote 
the tertiary institution. Some authors, among them Stanbury (2001), Mack (2001) and Yerbury (2001), see this role as being of more immediate importance than museums' pedagogical role.

Limited awareness of collections affects access. Stanbury noted that many Australian university collections were unknown outside their academic department. Jane Weeks (2000) explored the dynamics surrounding management of tertiary collections. She found that academics often assumed primary responsibility for tertiary collections, alongside their normal duties, when they often had little, if any, training in collection care. Graeme Were (2010) commented that interactions between academics and museum staff could be complicated. In research institutions knowledge creation and dissemination is the raison d'être of academic careers and status. Academics outside of Museum Studies departments do not usually have experience or skills in exhibition development and interpretation, which can lead to conflict when specialist skills of museum professionals are not recognised.

This highlights the disconnect between the practices and management of tertiary museums and those of wider sector museums. Tertiary museums must service the needs of two very different professional communities, academic and museological, which cater to audiences with different expectations. Within tertiary institutions, museums may be viewed as a noncore activity, with different needs and goals from those of their institution or their disciplinary department, affecting professional advancement and networking opportunities (Weeks 2000). Under-resourcing is another significant issue which follows on from consideration of tertiary museums as a non-core function (Stanbury 2001). Some curators are discouraged from engaging with the wider museum sector because museum underresourcing is recognised, which may damage the wider institution's reputation. Museum staff may feel unable to rectify matters and subsequently isolate themselves to avoid discussing their collections.

A major review of Australian museums was undertaken in 1975, recommending greater support of tertiary museums. A major step towards increased support was the establishment in 1992 of the Council of Australian University Museums and Collections (CAUMAC) (Yerbury 2001). In 1996 the CAUMAC report Cinderella Collections was released. The report found over 260 tertiary collections in Australia, with 'Medicine, Dentistry, Nursing, Pharmacy' being the second largest collection type (Yerbury). A second review fifteen years later identified 403 university collections. However, this 
reflected methodological change more than collection growth (Simpson 2012). Health science collections are part of 'Science and Technology collections' in this review and reflect declining use due to pedagogical changes within curricula (Simpson). There is a resurgence of interest in museums within tertiary education and connections between institutions but as an emerging field there is little literature to support it. One of the key areas of interest is object-based learning (OBL). OBL's value is recognised within primary and secondary education but within tertiary education it is only beginning to be explored and is discussed in chapter 5 (Hannan et al. 2013; Chatterjee 2008; Noble 2010).

As Hudson and Legget (2000) have pointed out, among New Zealand's best resourced and used tertiary collections are the health science collections at Auckland and Otago Universities. However, there is little literature on their use, although Dorothy Page's (2008) history of Otago Medical School is invaluable for contextualising the case study museums. Penelope Baines' (2015) thesis examines the use of university art collections in New Zealand but to examine literature on tertiary health science museums one must look further afield. Denis Wakefield (2007) explores declining use of museums in modern medical education in Australia and possible developments for continuing relevance and use, while Douglas Waugh (1990) laments the decline of Canadian medical museums. Alberti $(2011,202)$ notes that medical collections are becoming 'increasingly distanced from the rest of the heritage sector, and records of their use and even their existence [have] become sparse.' He acknowledges the importance of growing microscopic collections but notes that gross collections have become less useful and that 'the use and display of human remains has very different meanings in recent years.' The destruction or sale of many of the medical collections in the UK led him to conclude that the 'death knell for medical museums' has rung. Although he does not assert that this is universal, the pessimism he demonstrates may be attributed more to their loss of prominence than to their complete eradication.

Despite the examples cited above and other individual pieces on health science education, the majority of literature discussing museums and tertiary education focuses on other disciplines, with particular attention given to art and history (Marreez et al. 2010). Where health science collections are discussed it is often in regard to archaeology and anthropology. Even Linda Friedlaender's (2013) research with medical students discusses the use of art in medical education rather than the use of health science collections. 
It is not just in museum studies literature that health science museums are infrequently discussed. Very little is written in medical education literature regarding health science museums in modern curricula. Literature focused on Body Worlds does not focus specifically on human remains in health science museums, but provides an avenue for academics to contemplate historical and contemporary debates around remains in medical education and museums. Authors have raised a number of concerns about Body Worlds, including concerns about the exhibits themselves and how they relate to wider medical education. As Jones \& Whitaker (2009) have pointed out, plastinate poses reflect aesthetic values rather than providing the best views of anatomical structures. For human remains in museums there is a fine line between object and artefact, and plastinates further complicate this. When large percentages of the composition of remains are replaced by synthetic material the question is whether these can still be regarded as human remains. Plastinates occupy a place in between, neither fully human or fully object (Belling 2011).

One of the issues under discussion is that of mediating interactions between human remains and audiences. There were concerns with the initial Body Worlds exhibition that real dead bodies would cause visitors distress. However, visitors were easily able to view plastinates dispassionately raising concerns over psychological effects of breaking societal taboos (Belling). In medical schools clinical detachment is considered an 'important professional competency' necessary for breaking societal taboos regarding the body (Corradini \& Bukowski 2012). Health professionals and students are empowered to break these taboos due to their explicitly stated commitment to treat patients (Cherryson 2010). Although it is important developing detachmen can have a significant emotional toll. Students face peer pressure to deny feelings of discomfort for fear of being labelled 'sentimental' or to question their place in highly competitive courses (Hildebrandt 2014). Staff implement mediating processes to aid students in finding balance between developing appropriate clinical skills and the effects of violating accepted social norms in order to become both 'neutral observers and compassionate helpers' (Hildebrandt 2016, 41).

Museum exhibits of human remains contain few mediating processes to provide balance for the public. The ease with which the general public are able to objectify remains in museum exhibits raises concerns over the implications this has for ethical use of human tissue in wider society (Curlin 2011). It has been argued (Jenkins 2011; Walter 2004) that clinical detachment separates medical professionals from the lived experience of their own body, 
and marginalises patients' experiences of health and disease. For museum visitors who have no need to develop clinical detachment, they are able to relate to remains on display in other ways, including development of a partial 'medico-scientific gaze', and approaching exhibited bodies with awe (Walter). In contrast to the above concerns, other authors have commented on the sentimentality surrounding human remains, lamenting moves to disperse collections and subsequent loss of data (Weis 2008; Quigley 2001).

Tertiary museums have played an important historical role in delineating disciplinary boundaries, teaching and creating knowledge. Although the historical role of museums is well established, much less attention has been paid to the role of contemporary tertiary museums. There are, however, some exceptions. Academic literature regarding Body Worlds addresses some of the wider intellectual and ethical debates involving human remains acquisition and display. Body Worlds causes debate by contextualising plastinates as pieces of art and is often interpreted as a development of Victorian freak-shows.

\section{Guidelines}

The most important guidelines for the treatment of human remains are the relevant laws. In New Zealand the key statute is the Human Tissue Act (2008) (HTANZ). An extensive international body of work exists on the human body within legislation and the status of a corpse. New Zealand adheres to the long-standing principle that there is no property in a corpse, although issues exist in interpreting this precept (Peart 2015). Modifications made to cadavers, including dissection and preservation of specimens, may be considered sufficient application of skill to change remains from a natural to manufactured state, changing their status from "human remains" to "object" which can then be viewed as a form of property. The amount of skill necessary to change the status is unclear (Canterbury Museum 1998; Te Papa 2010). Lesley Sharp (2000) explores how the body is commodified and re-imagined as property, especially within the medical-scientific context, and the implications this has on objectification of the living and deceased body. Richardson (1988) examines this in depth in her exploration of the UK Anatomy Act (1832). This Act was extremely influential in the New Zealand context. New Zealand had only been settled as a British colony in 1840 and its legislative foundations were based on the British model. With the establishment of the Otago Medical School in 1875 a specific New Zealand Anatomy Act became necessary and legislation was enacted shortly after (Page 2008, 21). 
The second set of guidelines governing treatment of human remains are the professional guidelines within both museology and scientific areas. For museums these include the Codes of Ethics from the International Council of Museums (ICOM) (2013), national professional bodies such as Museums Aotearoa (MA) (2013), Museums Association (MAUK) (2008) and Museums Australia (MAus) (1999). For scientists these would include bodies such as the Medical Council of New Zealand (MCNZ), Medical Science Council of New Zealand (MSCNZ), World Medical Association (WMA), and World Archaeological Congress (WAC). Tertiary museums need to consider wider institutional policies. At Otago University these include the Māori Strategic Framework, the Discipline Statute and the Teaching and Learning Plan. (University of Otago 2006; 2011; 2013). These documents form the body of primary sources for this research and as such they need not be discussed further in this literature review.

There has been a movement to have museum work classified as a profession, and a code of ethics is a key characteristics of this. (Edson 1997; Nicholson \& Williams 2002.) Within the context of disciplinary tertiary museums, there is a tension between professional recognition for museum work and ad hoc collection management by academics with different professional priorities, guidelines and ethics. This tension was the seed for this present thesis and generates a series of critical questions:

- In what ways can tertiary museums cater to both the professional needs of museum staff and academic requirements?

- Should tertiary museum directors/curators be museum or disciplinary academics?

- Should the daily operation of tertiary museums be left to subject or museum specialists?

These questions are all founded on the assumption that tertiary museums should be professionally managed by trained staff, which is frequently not the case. If collections are managed by non-professional staff, then what is the place of museum theory, practice or ethics within tertiary museums?

It is important to draw distinctions between ethical codes and codes of professional practice. Ethical codes provide clarity on ethical issues but they not necessarily advise on practical matters, hence the importance of codes of professional practice. In some cases these two documents are combined, although they focus on two separate areas and should 
be taken separately. Codes of both ethics and professional practice frequently provide criteria for membership, another key professional characteristic (Edson). Institutions have been encouraged to develop individualised ethical codes in line with those of professional bodies (Nicholson \& Williams).

Ethical guidelines are necessary but debate exists about the need for them to be codified and set, rather than fluid and adaptive to different situations (Marstine et al. 2015). Nicholson \& Williams (2002) argue that the multitude of professional ethical codes has caused confusion and damaged effectiveness. Marstine et al. argue that codified ethics are insufficient to respond to changing realities of modern museums because they are not updated often enough. They suggest that dynamic engagement with invested parties would be more effective than written codes. The development of these New Museum Ethics, as these are commonly named, is shaped by cross-disciplinary collaboration, theories of postcolonialism, feminism and neo-Marxism, and by current changes within museum theory and practice.

Much of the literature surrounding museum ethics has focused on case studies, which are useful for seeing the application of ethics, although they have limited value in exploring the specific theoretical foundations for ethical principles, especially when juxtaposing museum and disciplinary ethics (Holm 2011; Tapsell 2011; Butts 2007). In the case of health science museums, bioethics and museum ethics must be considered alongside each other to find commonalities and ways to bridge the very different approaches and base assumptions of the sciences and humanities. Both museum studies and bioethics are relatively new disciplinary areas. Museum ethics has developed within the wider scope of museum studies while bioethics has developed as a discipline in its own right. One of the key areas of interest for this research is the synthesis of these two viewpoints and how they interact within the case study museums.

Both Hedley Swain (2002) and John Lantos (2011) have explored disquiet in specific uses of human remains in museums but there is general acceptance within bioethical and scientific literature that using human remains is necessary and justifiable, without avoiding the reality that human remains are the physical remains of individuals. This acknowledgment means that it is not undertaken lightly and strict guidelines ensure that use of human participants, cadavers or tissue is undertaken ethically. Bioethical strictures apply to research and teaching with human participants and how museums handle human 
remains. If one sector of society must justify its use of human remains, then all other sectors using them should also.

One of the key issues of contention around human remains in museum collections is acquisition. Historically this was intimately connected with issues of social inequality, race and imperialism (Jenkins 2011; Fforde 2004; Richardson 1988). As Harold Jackson (1997) and others have shown (Hallam 2013; Blakely \& Harrington 1997; Curtis-Richardson 1997), repatriation debates often focus on indigenous communities but other marginalised communities have also been targeted. African-Americans have been conceptualised through frames of race, theories of creation and evolution, and have been treated as separate and inferior to people of European descent. Destitute individuals, prisoners, itinerant workers and unclaimed bodies are other sources of human remains. Acquisition of modern remains is a contentious issue with varying approaches from medical/scientific communities internationally, and is influenced by historic practices (Jones 2014).

\section{Justifications}

Changes to museum ethical principles has resulted in fewer museums accepting human remains than before, but there continue to be situations where acquisition is considered appropriate. Swain (2002) and Heather Edgar \& Anna Rautman (2014) have discussed contemporary museum acquisition policies for human remains which exist to facilitate their proper care. These two cases, discussed below, provide examples where collecting remains is justified by wider ethical principles, highlighting that a blanket ethical policy against collecting human remains is simplistic.

Questions have been raised over whether greater ethical obligations exist for scientists to repatriate human remains or to retain them for further investigation for benefit of the wider community (Jones \& Whitaker 2009; 2013; Morris 2007; Quigley 2001). Repatriation is viewed in some sectors as a loss of valuable information and in others as the rightful return of individuals to their homes (Jones \& Whitaker 2009; Weis 2008; Quigley). Both arguments have merit but warrant further scrutiny. To "repatriate" remains implies a specific home to return them to exists. This is not always the case and repatriation claims must be validated and authenticated. Advocates of the scientific position often claim that human remains are used to advance science for the benefit of all. However, benefits derived from research on human remains are not necessarily universally available, 
especially in marginalised communities which are often the source of human material (Andrews 1986; Skloot 2010).

\section{Methodology}

Human remains are 'substantially different' (Cassman et al. 2007, 1) from other things that museums collect and debate stirs around whether they are artefacts, objects, people, or something in between. Large numbers of remains have been, and are, held by institutions for teaching and research. However, the literature review demonstrates that little research explores this. Debates that focus on human remains in museums largely fail to take note of their use in teaching biological sciences, modern acquisition, or the importance of human remains in developing knowledge about the body. Discussions of human remains in medical education largely focus on dissection, with retention for museum collections only mentioned in passing. Both Body Worlds and the debate surrounding indigenous repatriation make significant contributions to consideration of human remains in museums but the limitation of the debate stifles more nuanced understanding of the broader issues and understanding of the need for human remains for the teaching of health science at tertiary level. As both museum studies and bioethics are relatively new disciplines it is understandable that not much research has considered these issues.

Both museums and universities have established frames of reference for ethical behaviour but the research interests of this thesis lie in where these ethics meet, where they differ, where they are similar, and how differences are negotiated. After considering the gaps in the existing literature, the specific focus of this research is on how tertiary museum practitioners utilise their collections within ethical frameworks, what professional communities and cultures guide the development of these ethical frameworks, and their interpretation for health science museums. The aim is to draw museums teaching health science into the discussion concerning human remains in museums to extend the debate beyond the two focus points established. This thesis considers the ethical use of human remains in a different context, in order to illuminate other aspects of the debate, such as ethical acquisition of remains for teaching and research, and use, rather than return, of remains. 
This research utilised a mixed methods approach, applied to case studies of the W.D. Trotter Anatomy Museum and Drennan Pathology Museum, Otago University. It took a transformative/emancipatory perspective for the qualitative methods, a postpositivist approach for quantitative methods, and focused on primary document analysis, exhibition analysis, and interviews (Hesse-Biber 2010; DeCuir-Gunby 2008; Maykut \& Morehouse 2002).

The research is based upon three assumptions:

1. All institutions and organisations referred to in the study want to act ethically and legally.

2. Communities/cultures of practice involve individuals from a range of backgrounds. The in-group ethics of these communities will be influenced by these individuals. As such, ethnic cultural sensibilities and ideas will be considered as part of wider institutional practice as appropriate.

3. All human remains involved in the research will be considered legitimately acquired.

Although these assumptions may be individually problematic, they allow for research to be conducted without widening the focus beyond the scope of a Masters-level thesis. It is acknowledged that there may be questions regarding the legitimacy of historical acquisitions, and that legitimate acquisitions may not fit within contemporary ideas of ethical acquisition.

The Trotter and Drennan were chosen as case studies through purposive sampling for a number of reasons: both fit the definition of a bounded unit for case study analysis; both are available for use within the tertiary environment; both belong to the same university, providing some similarity in external influences and wider institutional policy; Otago University is one of two universities in New Zealand teaching medical sciences; and Otago University has an international five star plus Quacquarelli Symonds (QS) ranking for tertiary education (with a ranking of 64 for Life Sciences and Medicine in 2016). ${ }^{3}$ As this research falls within a substantial gap in the literature an emergent research design approach was utilised to consider any specific developments that occurred while conducting research (Maykut \& Morehouse 2002). Data were analysed through a concurrent mixed

\footnotetext{
${ }^{3}$ QS rankings are a well-respected annual publication of university rankings by educational advice company Quacquarelli Symonds.
} 
analysis model which facilitated the integration of data from both qualitative and quantitative analyses throughout the project (DeCuir-Gunby 2008). This thesis examines three sources of data: written documentation; exhibition analysis; and user interviews. Utilising these three sources of data allowed the validity and trustworthiness of the results to be triangulated and corroborated.

A phenomenological approach was taken to compare pertinent documents (Maykut \& Morehouse). This included:

- local body, national and international legislation and treaties;

- codes of ethics and codes of practice from associated professional communities of practice; and

- institutional documents from Otago University and other relevant parties.

These documents were used to assess how important the treatment of human remains was to these bodies; whether or not best practice was established; and what constituted best practice. They were also assessed against the documentary and interview material (Davies \& Hughes 2014; Maykut \& Morehouse; Jenkins 2011). Content analysis of these documents examined a number of factors, including the use of language in relation to human remains within different professional contexts; clauses on how remains are to be ethically treated; what percentage of the documents pertain to the treatment of human remains; and what differences exist between treatment of material from living and deceased individuals.

The case study museums were analysed in terms of their arrangement and interpretation. The analysis took into account what objects are not on display or have restricted access, and why. A statistical analysis of the medium of objects was undertaken to consider the percentage of human remains within exhibitions, indicating the importance of guidelines. Concurrent consideration of wider ethical concerns allowed for an exploration of how these concerns play out in specific situations (Burns 2000). Comparisons between two museums within one institution allowed for differences between the museums to be highlighted without requiring consideration of wider institutional differences.

Interviews from previous projects within the Otago Medical School, Donated to Science (Trotman 2009b) and Practising Medicine (Trotman 2012), are publicly available and were 
utilised for this research. These interviews do not specifically address guidelines for use of human remains within the case study museums but have provided insight into the use of human remains within the wider health science programme at Otago University. Interviews allow for written sources and exhibition analysis to be verified and further explored, considering what differences exist between best practice and daily practice within the case study museums (Davies \& Hughes 2014; Maykut \& Morehouse 2002; Tolich \& Davidson 1999).

This evidence was used to draw conclusions about the relative importance of guidelines, their implementation, and how remains in collections are perceived. Utilising three types of data increases the validity of the conclusions. Each form of data includes inherent strengths and weaknesses. Written documentation is developed by experts and evolves over time to provide best practice from a wide field of experience. Exhibitions demonstrate curatorial best practice, connoisseurship, scholarship and display. User interviews provided insight into the way exhibits are perceived and how wider issues surrounding human remains and mortality are addressed. However, written documentation can be divergent from living practice, exhibitions can be limited by practical considerations rather than reflecting theoretical principles, and interviews provide individuals with a voice which may not reflect the thoughts of the wider group. Original interviews with museum staff were initially incorporated into the research design to complement recorded interviews but were unable to be conducted due to time constraints. The recorded interviews focus on dissection within Otago's medical curriculum rather than the museums. However, as modern acquisition of remains is linked to dissection data can be extrapolated from these interviews. Conclusions drawn from a single form of data are liable to reflect the intrinsic biases of that medium. By utilising three different forms of data it is possible to corroborate or refute assumptions, and to see convergent and divergent patterns develop, which in turn provides more compelling evidence to support the accuracy of the conclusions.

This research examines three separate but entwined aspects of the use of human remains in health science museum collections. Consideration of a breadth of academic literature and primary data sources provides not only triangulation of the data, but also of the research question. By examining these three points the overarching question of whether or not there are justifiable reasons for museums to collect and display human remains is explored. The 
acquisition and display of human remains has become essentially polarised between two positions, with little consideration of alternative contexts. The place of health science museums in tertiary education has been largely overlooked except as a historical anachronism. However the continued use of health science collections for teaching Anatomy and Pathology at Otago University challenges these entrenched positions. An examination of these specific situations provides insight into potential advantages of OBL, the benefit of utilising collections of remains, and a possible basis for development of ethical practice for other health science collections.

The following chapters explore some of the key points surrounding the use of human remains in health science contexts. Chapter one provides background material to the wider debate. It considers terminology used and the legal status of human remains. It outlines the history of anatomical science, bioethics and tertiary education in New Zealand, focusing on Otago University. Chapter two discusses the evidence used to draw conclusions about the treatment of human remains in New Zealand's tertiary health science museums. It investigates national and international legislation, government advice, and professional organisations' guidance before focusing on Otago University's information and policies. Exhibition analysis of the Trotter and Drennan demonstrates their implementation and use, and the interviews are evaluated. Chapter three assesses ethical guidelines with reference to wider society, theories regarding ethical guidelines, and how these are implemented in the case study museums. Chapter four determines whether the ethical guidelines justify the use and objectification of human remains and scrutinizes the importance of real objects. The primary issue of consent is considered, as well as expressions of gratitude towards body donors. Chapter five briefly covers the history of museums in higher education. It outlines the differences between tertiary and wider sector museums, and how object primacy fits within tertiary pedagogical frameworks. It also considers some of the key issues for health science museums and the use of real human material in teaching, including student emotional responses and the emergence of medical humanities. 


\section{Chapter 1: Background}

This chapter clarifies the key terminology employed in areas of concern in this study. It also considers the history of Anatomy, examines the legal status of a corpse, and challenges definitions of ethics and legality. Finally it outlines Otago University's Medical School's history, and it examines the School's association with the relevant museum and scientific communities.

Clarification of terms is essential for understanding the concepts in this thesis, as they possess specialised meanings which do not necessarily equate with general understanding. The three areas of examination for this thesis -codes of ethics, justifications for use of human remains, and remains in health science tertiary museums - must be considered within these specific linguistic contexts. Differences between definitions have arisen with advances in science and polarised views of the human body between scientific and cultural groups.

The broad history of anatomy, bioethics and museums significantly impacts current behaviour, sensitivities and the legal status of the human body and of institutions. All medical advancement is based on foundations of anatomical knowledge, gathered through close examination of the deceased human body. The historical importance of museums for medical education ensures that museums must be included in the history of Anatomy and health science education. Wider contemporary legal and ethical challenges to any use of human remains must also be considered to provide perspective on their retention within museum collections.

The history of the Otago University Medical School has ongoing interconnectedness with the international academic community, particularly that of the UK. This association necessitates exploration of international best practice, especially with countries with a similar cultural heritage. Examining how the case study museums are integrated into their host departments, the wider university and the wider museum sector is essential to understanding their use and the pedagogy of utilising human remains within education. 


\section{Terminology and definitions}

What constitutes the "body" is not clearly defined. The body is often conceived as a biological machine, made up of its requisite parts. Medical techniques have advanced to the point where these parts can be substituted, enhanced and exchanged (Jenkins 2011). Issues of organ transplantation are further complicated when xenotransplantation or genetically modified tissues is included, and the replacement tissue can no longer be considered "natural" or even "human" (Jones \& Whitaker 2009). Mechanical replacements modify the biological nature of the body, providing yet further complication to simple definitions and boundaries. These medical advances are designed to return individuals back to health or "normality". However, ideas of posthumanism/transhumanism take the human body beyond health/normality (which are themselves problematic terms), developing intellectual and physical abilities beyond the limits of the natural human form (Jones \& Whitaker). Although most readily found within science fiction, these ideas cannot be entirely dismissed. Scientific framing of the body as object allows for research and display, and postmodern development of therapeutic culture has centred the body as the focus for individual sense of identity and wider understanding of the world. These ideas have combined to form the concept of self-eugenic (or newgenic) behaviour of bodily self improvement. This involves enhancing an individuals physical and mental capacity through biotechnological intervention, including genetic manipulation (Stafford 2011). It must also be remembered that all discussions of the "body" are discussions of an abstraction, as every body is that of an individual (Jones \& Whitaker).

"Health" is also not as straightforward as generally considered. The living experience of the individual and the scientific understanding of health professionals differ. Canguilhem (1978) notes that until the development of modern empirical science, concepts of disease were based on the appearance of symptoms and their subsequent impact (Boorse 1977). Now, however, an individual can feel well but medical tests can reveal disease within the asymptomatic body. This changes the patient from an individual into an object of health and disease. Society has become medicalised and every individual a patient and object. Empiricism has also changed definitions of "normality." If normality is defined as being within a certain range then anything outside of that range is no longer normal, and anything within it is. For example, blood sugar levels within a certain range are healthy, outside that range diabetes is diagnosed. However, these ranges are based on statistical data, applying 
the concept of "normality" within a population rather than for an individual, and as such "normal" is an abstracted rather than concrete concept (Canguilhem, 73, 77). In certain historical periods and cultures, the health of the State was considered more important than that of its constituent individuals (Hildebrandt 2009b). Ideas of racial hygiene led to the disease metaphor being interpreted literally in regard to the State. Wikler \& Barondess's (1993) example of the application of this theory is the purge in Germany of undesirable classes of people prior to, and during, World War II:

The regime fastened onto a trio of images: "the Jew as disease, the German people as patient, and National Socialism (qua Hitler) as physician," with Hitler portrayed in posters and in speeches as the doctor who rescues the German volk. (Wikler \& Barondess, 44)

In New Zealand there is no legal definition of 'death'; it is a matter of legal and medical debate (Skegg 2015). It was not until the late twentieth century that this became an issue, when death could be challenged by technological advances. Debates around brain-stem death, persistent vegetative states and locked-in syndrome added further complications. As Skegg points out, in New Zealand medical and legal circles death is widely accepted as brain-stem death, but this does not necessarily equate to societal understandings. Death can no longer be seen as a purely medical issue as it has significant legal ramifications. The point at which death occurs also has implications for the use of human remains in medical education and museums. If death occurs at the point of brain-stem death then patients who have reached this point, but are being artificially sustained by technology, could conceivably be used for display and teaching (Rees 2011). Although considered legally and medically dead, the individuals would still possess some key attributes of life, such as breathing, even if artificially maintained. This would pose significant ethical problems and would challenge common conceptions of death. If current uses of human remains are controversial, then the use of brain dead cadavers is likely to be untenable at this time.

Definitions of "human remains" also need clarity. Literature most commonly describes 'human remains' as bodily material after death, or tissue removed from living bodies. However, within this definition there is room for debate. Human remains are given a special, sometimes sacred, status, but different types of remains are afforded different levels of status (Balachandran 2009). Hair and nails are undoubtedly of human origin but they are considered quite differently from donations of blood, bones, and tissue, or organs taken from the body at death. There is a range of opinions on the status of foetuses, whether they are entities in and of themselves, or merely part of the mother until birth (Peart 2015). In 
New Zealand law, specifically under the provisions of HTANZ (s8), unborn foetuses are not considered human remains (Peart). Size of the body part also needs consideration. It is now possible to explore the DNA of an individual from microscopic specimens, and hence the microscopic sample can be considered the full individual. Microscopic and gross specimens are both undoubtedly of human origin, but are conceptualised differently. To some extent the process of preservation can be viewed as changing all preserved human remains to hybrid states, no longer fully human (Alberti 2011). This argument is most commonly discussed in relation to plastination. While plastinated remains are, again, undoubtedly of human origin, the plastination process renders them no longer easily recognisable as human. Approximately $70 \%$ of human tissue is liquid which is replaced in this process (Jones \& Whitaker 2009, 93-94). This raises questions over whether there is enough human material left to still consider them human remains, especially as plastic is 'widely seen as a symbol of the artificial' (Walter 2004, 464-88).

Within museums, definitions of human remains are further refined based on age and ethnicity, although definitions are not consistently applied. Remains may not be defined as humans if they are sufficiently old and there is extensive fossilisation. Dates of between 1000 and 5000 years have been used to classify bodily material as no longer "human remains" (Palmer 2003, 43; Jones \& Harris 1997, 15-16). Legislation, such as the United States Native American Graves Protection and Repatriation Act (NAGPRA) 1990, or policies (Te Papa 2010; NZHPT 2010) may have been expressly written to manage the remains of specific ethnic groups, and as such do not apply, or have minimal application, to other remains.

An understanding of "human remains" as purely "bodily remains" is formulated within Western scholarship and does not account for other understandings of the body or sacredness (Peters et al. 2007). In some cultures the dead body continues to play an active role in the life of the community, whereas this is not usual within Western secular society. A number of authors have commented on the importance of grave goods and other artefacts closely associated with an individual during life. These objects may have religious connotations or be indicators of what it means to live as a human being (Balachandran 2009, 200; Sofaer 2006). The theoretical distinction between living beings and objects is a product of Western philosophy, and this duality of nature:culture limits understandings of indigenous conceptions of the body (Curtis, 2003, 27). Despite varying definitions of 
"human remains" and the difficulty that poses for some authors, Jenkins (2011) has proposed that what is understood as "human remains" is inherently stable within the Western context.

Terminology surrounding human remains is also important. As Winkelmann (2016, 70-77) has pointed out, conceptions of human remains as "object", "specimen", or "loved one" reflect how the remains, and the individual they came from, are framed. How the deceased body and its parts are described implies certain meanings that reflect the intellectual tension between the abstracted body and the personalised body. Framing the body as "object" gives viewers the permission to stare at the body not normally permissible (Durbach 2014, 52; Sandell, 2007). However, as Trotman demonstrates (2009a, 2009b), conceiving the body as "object" creates an inherent tension for viewers who continue to experience the duality of the body as both "object" and "individual". Viewing the body as "object" is essential for the development of 'clinical detachment' which will be discussed in more detail in chapter 3.

This thesis refers to all parts of the human body as 'human remains', irrespective of size, age, modifications or preservation type, although different terms are used to specify particular types of human remains. This may not be the preferred terminology for all readers, but it is maintained that all human remains discussed are considered with due respect and dignity.

\section{History of Anatomy}

Over time there have been many reasons for acquiring human remains and a variety of procurement methods. The intellectual and cultural shift of collections from cabinets of curiosities to systematic displays based on taxonomic classifications has led to increasing numbers of human remains being acquired for collections. Many remains were added to collections in ways that may or may not have been ethical at the time, but are certainly not considered ethical now. However, it must not be assumed that all remains in collections were collected in ways that would be considered unethical by contemporary standards.

A primary reason for collecting human remains during the modern period was to provide anatomical instruction in medical schools. New Zealand's history as a British colony means that the history of anatomy in the UK is synonymous with that of New Zealand. 
From the seventeenth century onwards there were a number of private medical schools in the UK, all utilising dissection and museum teaching collections (Alberti 2011, 14, 29, 37; Richardson 1988, 39). Medical schools which could not provide corpses and anatomical specimens for instruction were at a significant disadvantage, and a thriving market for specimens as gifts or goods between the different schools developed (Cherryson, 2010, 142-43). Although dissection was utilised in medical education during the classical period, it came to be viewed as a crime against God and State and was superseded by medieval concepts of health. In the sixteenth century there was renewed interest in the internal workings of the body, and dissection once again became legal in the British Isles. Royal patronage from James IV of Scotland in 1506, followed in 1540 by Henry VIII of England, allowed a small number of convicted murderers per year to be dissected for advancement of medical knowledge. ${ }^{1}$ During the seventeenth century legal dissection was limited to six convicted murderers per year. Dissection was viewed as the ultimate penalty, beyond execution, fragmenting the body and denying offenders a grave, and as such was reserved for the worst offenders (Richardson; Hildebrandt 2008). Religious convictions of the period held to the physical resurrection of the body and thus dissection imperilled a person's immortal soul (Blakely \& Harrington 1997, 169). ${ }^{2}$

The small number of legally obtainable bodies was woefully insufficient. Obtaining bodies legally was further complicated by interference from friends and families of the deceased who attempted to prevent bodies being taken for dissection. The difficulty of obtaining bodies legally, along with the growing number of medical schools, led to the emergence of an illicit market for recently deceased bodies (Richardson 1988). Grave-robbing became an established, if illicit, part of medical education. Initially students and teachers undertook grave-robbing, but this was eventually taken over by grave-robbers (resurrectionists) who supplied thousands of bodies per year (Jones \& Whitaker 2009, 25). Public objection to grave-robbing led to significant changes to burial practices to thwart the resurrectionists. This included the introduction of metal coffins, deeper burials, community watches over graveyards, and the erection of "dead-houses" where corpses were securely stored until the

\footnotetext{
${ }^{1}$ Henry VIII granted the right to dissect four convicted felons per year. The number had risen to six per annum by 1663 , in the reign of Charles II.

${ }^{2}$ These religious beliefs refer to the specific mix of Christian, pagan, and superstitious beliefs of the period. (Richardson 1988, 7-8). In the United States of America relevant religious beliefs were a mix of Christian and African beliefs.
} 
bodies were too putrefied to be dissected (Richardson, 81-83). Grave-robbing broke societal taboos but it could not technically be considered theft as the body was not considered property, with the "no property rule" being fully established by this period (Peart 2015). Resurrectionists were charged with desecration of a grave or theft of burial goods rather than theft of the body. The lucrative market for cadavers led to people being worth more dead than alive. People sold their corpses prior to death in order to have enough money to live, and taken to the extreme, murders were conducted to ensure supply.

It required no extraordinary sagacity to forsee, that the worst consequences must inevitably result from the system of traffic between resurrectionists and anatomists, which the executive government has so long suffered to exist (Lancet 1829, cited in Richardson, 1988, 131).

Increasing numbers of medical schools, paucity of legal supply of bodies for dissection, and the advent of murder for illicit supply, particularly the Burke and Hare case in Edinburgh, led to calls for legislative reform to provide a sustainable, legal supply of cadavers for medical schools. This resulted in the Anatomy Act (1832) (Richardson). There was a significant amount of political wrangling required for the Act to be passed. As part of this, objections were raised against using criminals for dissection. This clause was removed from the Bill, leaving only unclaimed bodies eligible for dissection.

In the USA there is evidence of some murders for supply, but slaves were the most easily obtainable supply of human material (Blakely 1997; Jackson 1997, 196; Jones \& Whitaker 2013). With the classification of humanity within the natural order, ideas concerning racial difference and superiority were framed within constructs of scientific authority (Fforde 2004, 1). Slavery was inherently intertwined with these ideas of racial difference. Theories regarding the origin of racial difference included degeneration from a primordial original, and multiple creations. Publication of Darwin's On the Origin of Species led to a melding of monogenist and polygenist views into a theory of human evolution via natural selection. African slaves were disproportionately used for dissection in the southern USA, despite perceived racial anatomical differences which classified them as inferior and subhuman. As Blakely $(1997,163)$ has commented:

Although southern physicians of the nineteenth century held the same racist notions about the inferiority of blacks as the rest of southern society and went so far as to teach that blacks and whites differed anatomically, they nevertheless used black cadavers to teach medical students human anatomy and performed medical experiments on living black people to benefit mainly their white patients. 
Slave owners had power over whether or not slaves were dissected, which in turn helped to control and subjugate their property (Jackson 1997). After slavery was banned graverobbers persisted in exploiting burial grounds of vulnerable groups. Religious beliefs regarding burial and resurrection were similar to those in the UK, and had a corresponding punitive aspect. Disturbance of graves was a common fear, but belief that body disturbance allowed spirits to escape and harm the living was unique to African-Americans (Blakely \& Harrington 1997).

During European imperial expansion, racial evolutionary theory had significant impact on interactions between Europeans and indigenous peoples. From the seventeenth century onwards scientists attempted to classify humanity. Based on biblical traditions of lineages from the descendants of Noah - Ham, Shem and Japheth - humanity was divided into four or five groups, resulting in François Bernier's explicit 'racial' divisions (Fforde 2004). Further taxonomic classifications were undertaken by a number of scholars, including Carl von Linnaeus, who significantly placed humanity within the animal kingdom (Morris 2007). Ideas surrounding purity of races, and interactions with more advanced races led to human remains from indigenous peoples being actively collected while they still existed. This was framed as altruistically preserving remnants of dying cultures (Palmer 2003, 23; Sully 2007, 29; Watt 1995, 78) These remains provided evidence for the scientific basis for human diversity, and significant collections were accumulated (Quigley 2001). Scientific studies of human diversity led to the development of cerebral localisation (phrenology) and eugenics (Fforde 2004, 23; Quigley, 2). While early work on museum collections, such as Samuel Morton's craniometric research on the hierarchy of racial types, reinforced ideas of racial difference and superiority, later work by Franz Boas, based on strict empirical data from the Field Museum collection, found that many fundamental assumptions of race were false. Despite racial difference no longer being considered accurate it is still employed for ease of differentiation and classification (Fforde, 35-36; Quigley, 102).

Human remains are still collected by museums, albeit with more ethical consideration. The Maxwell Museum of Anthropology, University of New Mexico, accepts all human remains it is offered and assumes responsibility for their care within NAGPRA regulations and state laws (Edgar \& Rautman 2014, 237-9). This enables remains to be taken out of private hands and provided for appropriately. Historically, acquisition of human remains resulted from fieldwork undertaken by the University, and following the USA's enactment of the 
NAGPRA the Museum developed consultative relationships with indigenous groups, aimed at facilitating return of remains. Implementation of NAGPRA has resulted in a variety of ethical responses from museums, with some like the Maxwell Museum taking an active role in facilitating return, while others have decided to distance themselves from any activities involving human remains, excluding legislative obligations.

The Museum of London continues to ethically collect human remains. Thousands of years of continuous habitation and urban development in London has necessitated regulation of archaeology on building sites (Swain 2002). The Museum of London has traditionally undertaken archaeological consultation for contractors to ensure proper care of sites, including assuming responsibility for the disturbance and excavation of burial sites. Contemporary collections are also being created by so-called Body Farms. The original Body Farm is the University of Tennessee's Anthropological Research Facility, established in 1971 to conduct research on human decomposition, utilising unclaimed or donated bodies (Jones \& Whitaker 2013; Quigley 2001). Other Body Farms have been established in a small number of other centres to provide forensic evidence on decomposition rates in different environmental conditions; these include Australasia's only Body Farm, University of Technology, Sydney, which opened in 2016 and uses donated bodies (Forbes \& Heaven 2016). As the whole genetic code can be found in a single cell, collections of samples taken for scientific study comprise another avenue of contemporary acquisition, especially with the advent of reliable freezing technology (Radin 2014, 250). Scientific researchers are drawing on museum theory and practice in managing the large collections of human remains their research amasses (Turner 2014).

Another significant twentieth century source of human remains was retention of material from patients in care. Donated bodies were the primary source for New Zealand schools of anatomy, although the Human Tissue Act (1964) allowed for the use of unclaimed bodies from mental institutions and prisons. HTANZ repealed this legislation, but using unclaimed bodies continues overseas (Jones 2011; Jones \& Whitaker 2013). In the 1990s and 2000s there were a number of international scandals involving retention of organs with dubious, or no, consent. In 1991 it was discovered that the University of Pennsylvania was receiving brains from the medical examiner without consent. Although this practice was defended on grounds that it was providing benefit to both parties, it was stopped due to objections from next of kin (Jones \& Whitaker, 50). An investigation into the paediatric 
unit at Bristol Royal Infirmary led to the discovery of significant issues with the collections of retained organs at Alder Hey (Kennedy 2001). The retention of organs through postmortems was not unusual, but the extent and manner in which the collection at Alder Hey had been amassed certainly was (Chief Medical Officer 2000; 2001; Redfern, Keeling and Powell 2001). Professor Dick van Velzen, Chair of Foetal and Infant Pathology, Alder Hey, requested the retention of every organ from every child who died between 1988 and 1995 (Redfern et al., 41:8.2). The Chief Medical Officer undertook a census of organ collections in the UK, finding significant collections of contemporary and archival material (Chief Medical Officer, 2000, s3). Paternalistic attitudes of the medical profession led to the development of these collections, often without consent (Redfern et al., 1.3). Where consent was obtained it was gathered through unclear consent forms and could not be considered informed consent. However this did not breach the Human Tissue Act (1961). When the situation at Alder Hey became public in 1999 there was a significant public outcry, with considerable distress for parents involved (Redfern et al., 19:1.4, 23:6.1; Chief Medical Officer 2001, 1.5). Parents were given the opportunity during the subsequent enquiry to provide feedback. Comments on the emotional impact of this discovery were included in the report prepared by Redfern et al. (p.19:1.4) for the House of Commons:

It feels like body snatching. The hospital stole something from me. They have taken us back 11 years in our healing process.

I feel devastated... I am wondering how much of her body was left.

I have learnt to live with my daughter's death and now I have found out that they removed her heart. It is like losing her all over again.

This grief was further exacerbated by the realization that organs had been retained but not used. As one parent commented:

Studying her brain would help explain why her brain did not form properly and it might help treat the next child born with a similar condition. Unfortunately her brain has not been studied. Instead it sits in a jar in a storeroom somewhere.

The ramifications were felt internationally. In New Zealand an internal review at Auckland's Green Lane Hospital discovered a collection of over 1300 specimens of paediatric heart tissue amassed since 1950 . The specimens had been acquired through postmortem examinations, and while legal, many parents were unaware that their child's heart had been retained. Although the collection had been of immense use in advancing paediatric cardiac surgery it caused considerable public backlash when the Hospital took 
steps to notify parents and return tissue in 2002. The review showed that the Hospital had acted within the law, irrespective of public reaction (Jones \& Whitaker 2009, 51). Many of the hearts had been retained for detailed pathological examination to determine cause of death, which could mean a delay of six weeks. It was thought inappropriate to return organs to families so long after the funeral, and retention of the heart was legal. These discoveries highlighted a disconnect between legislation and public expectations, leading to of legislative change in both the UK and New Zealand, as well as changing standards of practice while the law was reconsidered (Jones \& Whitaker, 52; Peart 2015, 713-4).

\section{Legal status of a corpse}

In New Zealand there is no property in a body. Founded on British legal antecedents, this principle is well established but its origins are unclear (Peart, 707). It has been upheld in New Zealand courts as recently as $2015 .^{3}$ Despite the well established nature of this there are exceptions (Peart, 708; Mason \& Laurie 2001, 721). The first of these is the right to legal possession, especially for conducting funerary rites (Skegg 1991, 345; Peart, 708-9; Mason \& Laurie, 715-9). This is the most widely accepted exception, and pertains to limited possession. There is debate over whether the rule only applies to the whole body, or if it is applicable to fragmented parts (Andrews 1986, 29). As noted in the Introduction, the application of skill, transferring remains from a natural to manufactured state, is another significant consideration. There is debate as to whether the no property rule is appropriate, especially as bodies already hold a quasi-property status, and are to a certain extent being commodified (Mason \& Laurie, 721-3).

People retain bodily autonomy but are unable to own their own body or treat it as a commodity. Bodies only convert to quasi-property upon death, when individuals are unable to benefit from any property rights held by their body (Mason \& Laurie, 719, 725; Andrews, 28). The exceptions to this are existing markets for non-vital body parts, such as hair or non-vital organs (Campbell 2009, 49-51). The gift language used to discuss organ donation and body bequests also frames the body as property (Mason \& Laurie, 725; Sharp 2000, 303-04). Legal protections enacted to govern the treatment of human remains are similar in nature to property rights but there is hesitancy to identify them as such, possibly

\footnotetext{
${ }^{3}$ Mackenzie v Attorney General [2015] NZHC19.
} 
due to inappropriate application of property law. Arguments exist both for and against a market for human material. Proponents argue that markets provide greater freedom for individual control over the marketable worth of bodies, and more compatible donor matches. There are a number of arguments against a market for tissue, including increasing pressure on vulnerable populations, and a decrease of community altruism.

\section{Basis for bioethics and bioethical development}

Alongside changes in the treatment of human remains in museums there has been a corresponding shift in the field of bioethics. The rise of National Socialism in Germany had a profound effect on subsequent understandings of bioethics. Although easily dismissed as hyperbole, in the context of this thesis the impact of Nazism cannot be overstated (Wikler \& Barondess 1993, 40-42, 49). Prior to World War II there were significantly different ideas about health and well-being compared to those existing today. Ideas regarding racial theory, eugenics and evolution were widespread but under the Nazi regime were taken to the extreme. Wikler \& Barondess claim that twentieth century eugenics were 'not essentially racist' (p.43), and the large numbers of deaths through Aktion T4 support this. Aktion T4 was the systematic euthanisation of children with impairments, often at the request of their parents. It is estimated that between 5,000 and 8,000 children died (Kershaw 2008, 532). This programme was extended to include patients in mental institutions. Certain officials outside the programme took its enactment as authority to shoot patients (Kershaw, 534). Over 200,000 individuals were killed. Aktion T4 was a forerunner of the mass murders during World War II as it showed the Reich that mass extermination of citizens was permitted by society (Wikler \& Barondess, 43). Only a small number of medical personnel were tried for these deaths, which could not have been undertaken without the implicit and explicit cooperation of the German medical community (Shirer 1998, 979; Wikler \& Barondess, 45-9; Hildebrandt 2009a; $2009 b ; 2009 c)$.

The eugenic obsession of the regime involved and implicated ordinary physicians in many ways. The Nazis' plan for the master race was of such grandiosity that it required a highly detailed map of the (supposedly) genetic endowment of virtually every German capable of reproduction. This information could only be gleaned by physicians. (Wikler \& Barondess, 46).

The participation of medical staff in these actions is understandable within the context of German medicine during the period. In 1939 doctors were one of the highest paid 
professions, and medicine accounted for approximately a third of all academic positions. By 1945 nearly half of university students were medical students. Skilled doctors and researchers were in demand in industry, the military, and in academia. Established academics continued their research and teaching as usual, but debate exists over the continuing quality of medical education (Evans 2005). Medical historians, notably Hildebrandt (2009c, 910) have noted the lack of research into anatomy in the Third Reich:

... the history of anatomy in the Third Reich was generally not talked about in German and Austrian universities until the last decade of the $20^{\text {th }}$ century, when most of the anatomists from this period had retired or passed away.

Despite the suspected drop in quality, as well as German isolation from international academic networks, some significant research did continue, with eugenic ideology prompting major investigations in preventive medicine for the health of society, such as discovering links between smoking and lung cancer. Society became increasingly medicalised. Deviance in behaviour or thought, such as political or sexual deviance, came to be viewed as a biological complaint. It is estimated that over two-thirds of medical personnel in Germany were connected to the Nazi Party (Evans, 446). Within this context it is hardly surprising that forced sterilisation, medical experimentation, and eventually murder were inflicted upon those deemed unfit.

At the end of World War II information about Nazi biomedical experiments and the Holocaust emerged, shocking the world. Eugenics had been widely accepted prior to the war but the excesses of the Nazi regime complicated any further consideration. During the subsequent prosecution of prominent Nazi doctors, the Nuremberg Code was developed to lay foundations for ethical medical experimentation using human subjects (Trials of War Criminals 1949).

\section{Challenges to definitions of what is ethical versus what is legal}

Through the remainder of the twentieth century there continued to be challenges to established norms of practice in many professional communities, and in society as a whole. The axiom of "what is legal must be ethical" was challenged on a number of points. Ethics are founded on moral ideas of wrong and right, differ between communities and gradually change over time. As legislation is the embodiment of the beliefs and mores that govern society, and is made by parliamentarians, it is subject to change by parliamentarians. Large 
scale social changes relating to feminism and civil rights have also changed societal attitudes towards many things previously taken as writ.

The exposure of previously secret scientific experiments and practices has affected how the general population thinks about what is, and is not, acceptable. While the experiments undertaken by Nazi scientists are often decried, it is naive to think that Germany was the only place that experimentation, now considered unethical, occurred. The US Public Health Service conducted a major syphilis study in Alabama between the 1930s and 1970s, known as the Tuskegee study. African-American men, both with and without syphilis, were monitored to study the effects of syphilis within the population (Jones \& Whitaker 2009,81 ). While there was no effective cure it was not necessarily unethical to observe the development of symptoms within a large population. However, by the 1940s penicillin became the recommended treatment for syphilis, but was withheld from study participants. Withholding treatment was unethical (CDC website).

In New Zealand, as part of an experiment Associate Professor Herbert Green withheld appropriate treatment for women with cervical cancer at National Women's Hospital (Coney \& Bunkle 1987). Referred to as the "Unfortunate Experiment," this led to a Ministerial Committee of Inquiry during the late 1980s that resulted in the development of the Code of Health and Disability Services Consumers' Rights (Code of Patients' Rights) (Paterson 2015; Manning 2015; Peart 2015; Jones \& Whitaker 2009). Issues regarding informed consent and greater autonomy for individuals also came to the fore after the organ retention scandal in the UK and New Zealand, leading to subsequent changes in legislation and practice (Peart; Jones \& Whitaker).

These challenges to the ethical basis for law were contemporaneous with a challenge to the established authority of science and museums. These challenges lay primarily within two areas: the right to a single truth, and in science's case, that all scientific discoveries were progress. Nazi scientific experimentation and proliferation of nuclear weaponry are two examples of instances which have undermined the belief of all scientific discoveries as progress. The politicisation of indigenous groups challenged empirical scientific knowledge as the only interpretation of the natural world, noticeable in New Zealand with the incorporation of mātauranga Māori and biculturalism in academia and museums (Otago 2006; UN 2007; Jahnke 2006; Conn 2006; Clarke 2002). 
Within this context, Māori repatriation claims of taonga and kōiwi tangata from domestic and international museums has increased. Repatriation claims are channelled through the Karanga Aotearoa Repatriation Programme at Te Papa, which is recognised overseas as a legitimate governmental agency acting on behalf of Māori (Te Papa 2010, 7.3.1;

Bienkowski 2015, 437; O’Hara 2012). This has relieved the need for overseas institutions to verify that iwi making claims are legitimate, and has allowed for consistency of claims. Te Papa has also provided a culturally sanctioned repository for unprovenanced kōiwi tangata, acting as kaitiaki until they can be repatriated (Watt 1995, 78). Repatriation was initially controversial for a number of institutions. In order to strengthen the possibility of a successful claim the focus was often on human remains where it was believed there were stronger moral and legal cases for return. Attempts to stop repatriation from the UK often focused on legislative impediments and failed to recognise legislation could be changed.

\section{University of Otago historical perspective}

The history of Otago University must be considered within this wider historical and cultural context described above. The University was established in Dunedin in 1869 and is New Zealand's oldest university. Otago's close association with British tertiary institutions influenced the University's development of teaching collections as 'integral' to several subjects (Hudson \& Legget 2000, 21). Between 1876 and 1955 Otago Museum was administered by Otago University, with ongoing University representation on the board after it was repurposed as a regional museum by Act of Parliament (K.W. Thomson 1981, 82; Hudson \& Legget, 23). ${ }^{4}$ This close association with the local provincial museum benefited both institutions, with increased access to collections and scholarship for both parties. The Pathology and Anatomy Collections at Otago University were utilised as key teaching resources, and the Professor of Biology was curator of Otago Museum for approximately 60 years (K.W. Thomson, 82).

The Otago School of Anatomy was opened at Otago University in 1875 and the Anatomy Museum was established in 1881. The Medical School initially offered only the foundation years of a medical degree but was recognised as a full medical school in 1883. Prior to this, students were required to complete their training overseas. Otago had close associations

\footnotetext{
${ }^{4}$ Otago Museum Trust Board Act 1955 (NZ).
} 
with the University of Edinburgh and many students completed their degree there. The Medical Library was established in 1917, thirty-six years after the Anatomy Museum, highlighting the importance of museum resources, as opposed to textbooks, for tertiary education during this period.

The donation of a portion of the archives of Alexander Monro tertius, the last of three prominent doctors of the same name, was the culmination of close associations between Otago and Edinburgh. This donation elevated Otago as a medical archive of international importance (Page, 2008, 100-1). ${ }^{5}$ Currently health sciences at Otago are important on a number of different levels. Otago has consistently rated highly for health sciences and related disciplines in the QS world university rankings and is one of the most prestigious universities in New Zealand. It has one of only two medical schools nationally, one of two physiotherapy schools, and the only dental school.

Museums have played a significant part in tertiary education in New Zealand, with major collections being either founded or gifted through universities (Hudson \& Legget, 2000, 23). At Otago University there are a number of collections used for teaching, with the Hocken Collections being the most well known. The University also has memoranda of understanding with Otago Museum and Te Papa. The Otago Museum Classical collection is used for university teaching, and the Museum offers scholarships for students undertaking research on its collections. The current Otago Museum director, Dr Ian Griffin, an astronomer by academic training, holds an honorary academic position in the Physics Department at Otago University.

$* * * * *$

These key philosophical and historical considerations set out in the foregoing chapter are essential for understanding the specific contexts surrounding the acquisition, retention and use of human remains within biomedical and museum settings. The history of anatomy is filled with disreputable and distasteful events. With such a history it is understandable that modern biomedical scientists wish to distance themselves from such actions and portray their deeds as respectable endeavours. However, to portray their behaviour as such they

\footnotetext{
${ }^{5}$ These archives were donated to the Otago Medical Library by Dr Charles Hector, a previous staff member of the Otago Medical School, who was a descendant of Alexander Monro.
} 
need to ensure that their practices are ethical and reputable. Clarification of the legal status of human material is a necessary starting point for further development of ethical behaviour, both in scientific and museum settings. Strict adherence to legalities does not ensure that practice is ethical, however. Ethical norms must be set within legal parameters but not limited by them. The following chapters explore the guidelines that exist for the ethical treatment of human remains, how the actions directed by these guidelines can be justified, and the place of human remains in health science education and museums in tertiary education more broadly. 


\section{Chapter 2: Sources}

The contemporary focus on human remains in museums as either indigenous remains or plastinates ignores other contexts. Many museums internationally continue to hold human remains. It is only by extending the debate around human remains in museums beyond these polarised positions that more general guidelines and sophisticated ethics can be considered. If human remains continue to hold the special status they are often afforded then ethical guidelines for their treatment must be more widely applicable.

The literature review above highlights the paucity of information and analysis of museum contexts for human remains outside of the two positions specified. Without acknowledgement of other contexts it is impossible to develop more nuanced guidelines to direct practice in a range of settings. The starting point for any further consideration of human remains in museums must be the existing guidelines of museums and the communities they serve. For this research those communities include professional scientific organisations and tertiary institutions, particularly Otago University. The development of wider guidelines will be based on the junction of best practice of each group. Where conflicting ideas meet negotiation will be necessary to find a mutually acceptable compromise. If compromise cannot be found the interests of the more influential group are likely to shape practice.

This chapter explores what information currently exists to guide practice relating to human remains. It examines international and domestic legislation and governmental guidelines, ethical guidance provided by professional organisations, and the specific instructions provided by Otago University. This documentation was assessed for points of commonality. An exhibition analysis was conducted in each of the case-study museums to evaluate layout, access, type of object and accompanying information. Information from interviews was also reviewed.

This evidence was used to draw conclusions about the relative importance of guidelines, their implemention, and how human remains in collections are perceived. Utilising three different types of data increases the validity of the conclusions. Each form of data includes inherent strengths and weaknesses. Written documentation is developed by experts providing best practice from wide experience. Exhibitions demonstrate curatorial connoisseurship, scholarship and display. User interviews provide insight into how 
exhibits are perceived and how wider issues surrounding human remains and mortality are addressed. However, written documentation can be divergent from living practice, exhibitions can be limited by practical considerations rather than reflecting best practice, and interviews provide individuals a voice which may not be representative. Conclusions drawn from a single form of data are liable to reflect the intrinsic biases and assumptions of that medium. By utilising three different forms of data it is possible to corroborate or refute assumptions and hypotheses, and to see patterns develop, which in turn provides more compelling evidence to support the accuracy of conclusions.

$$
* * * * *
$$

\section{Written documentation}

There are five primary types of relevant written documentation. They form a hierarchy of regulations and subsequent penalties for breaches. They govern general practice when dealing with remains and include international and national law and treaties, governmental agency reports and guidelines, professional organisation guidelines, and institutional documents for the case study museums.

\section{International legislation}

International regulation of human remains is subject to several conventions. The United Nations has issued a number of pertinent resolutions relating to tissue from both living and deceased individuals. These include the Declaration on the Rights of Indigenous People (UN 2007), and the Global Plan of Action to Combat Trafficking in Persons (UN 2010). Article 12 of the Declaration on the Rights of Indigenous People explicitly states that indigenous peoples should be able to access or repatriate remains through 'fair, transparent and effective mechanisms developed in conjunction with indigenous peoples concerned.' The United Nations Educational, Scientific and Cultural Organization Convention on the Means of Prohibiting and Preventing the Illicit Import, Export and Transfer of Ownership of Cultural Property (UNESCO Convention) (1970) and the International Institute for the Unification of Private Law Convention (UNIDROIT Convention) (1995) are concerned with the illegal movement of cultural objects and are supported by a network of legislation, understandings and treaties (Prott 2012; Nafziger 2007; Greenfield 2007; Fox 1993; Lenzner 1994; McIntosh 2002; Boos 2011; Posner 2006; Vernon 1994). Depending on 
how modified remains are defined, the UNESCO and UNIDROIT Conventions may apply to cultural artefacts comprised of modified human remains. Both Conventions require domestic legislation for enactment (Greenfield, 224). New Zealand's Protected Objects Act (1975) enacted in 2006 ratifies New Zealand's commitment to these conventions (Paquette 2012, 135; Barker 2006, 145-7; Boos, 4).

\section{National legislation}

The primary focus of this thesis is the situation in New Zealand but the subject cannot be examined in isolation. In other jurisdictions legislation has been developed which helps to understand the development of guidelines and laws for ethical treatment of human remains in New Zealand. Legislation is developed, interpreted and implemented through government agencies. As such the exploration of human tissue legislation needs to be considered alongside government agencies. The UK's Human Tissue Act (2004) (HTAUK) and the USA's NAGPRA are two influential pieces of legislation, indicative of the two main issues concerning human remains: ethical use of human tissue for research and education; and recognition of indigenous rights.

HTAUK was enacted subsequent to a major review of legislation and practice after the organ retention scandals of the late 1990s. These scandals triggered international reviews, including that undertaken at Green Lane Hospital, Auckland. However, events in New Zealand, such as the Cartwright Enquiry, had already led to greater awareness surrounding patients' rights and informed consent than was the case in the UK (Jones \& Whitaker 2009, 52). The Code of Patients' Rights governs tissue retention from living individuals and HTANZ was enacted to clarify issues of tissue retention from corpses (Peart 2015, 729).

NAGPRA invested ownership and control of Native American cultural objects, including human remains, in lineal descendants, or recognised cultural organisations. The purchase and sale of these cultural objects without appropriate rights was criminalised. NAGPRA legislation states (section 12) that it was developed to reflect the 'unique relationship' between the Federal government and indigenous peoples and should not be viewed as a precedent for interactions with other parties. In New Zealand, indigenous rights are based on the Treaty of Waitangi and subsequent legislation, integrating biculturalism into society.

The Treaty of Waitangi (1840), the Protected Objects Act (1975), the Coroners Act (2006), and HTANZ are New Zealand's pertinent legislative documents. The Treaty does not 
specifically speak to the treatment of human remains but its principles are incorporated into legislation and practice at all levels (Butts 2007; McCarthy 2011). HTANZ's purpose is to ensure respectful collection and use of human tissue from cadavers, including consideration of cultural, ethical and spiritual implications, and the public good associated with such collection (s3). It does this by specifying circumstances in which tissue can be collected from corpses, how it is used and makes it an offence to stray outside these constraints. Much of the Act is dedicated to issues surrounding informed consent or objection, and who has the right to make those decisions (pt 2). HTANZ (s77 \& 80) authorises the GovernorGeneral to establish Schools of Anatomy in connection with a university or school of medicine, and empowers them to appoint Inspectors of Anatomy, generally senior members of the New Zealand Police. Inspectors are obligated to inspect schools and report irregularities in the treatment of human remains (s84-5). HTANZ lists the Schools of Anatomy in New Zealand, the superseded legislation they were established under, and brings them under the authority of HTANZ (s96.2). Of the four Schools of Anatomy in New Zealand three are attached to Otago University, at Dunedin, Wellington, and Christchurch.

\section{Government agencies}

Documentation created by government agencies is important as these agencies scope and set parameters for legislation and its interpretation. As HTAUK and NAGPRA have proved influential on the current issue it is important to consider documentation developed by US and UK government agencies.

\section{United Kingdom}

In 2001 the Working Group on Human Remains in Museum Collections (WGHRM) was established in the UK to examine the status of remains within publicly funded museums. WGHRM was tasked with determining whether a statement of principles and guidance relating to human remains was desirable for UK museums (Palmer 2003). WGHRM narrowed the scope of their report to public funded archival collections in England, specifically those remains obtained prior to 1948. This did not include remains acquired through biopsy, surgery or post-mortem, which fell under the purview of the Retained Organs Commission (ROC). Increased public scrutiny after the organ retention scandals led to all discussion of human remains in collections being considered within this frame of 
reference (Jenkins 2011). The majority of human remains within the in-scope collections were sourced in the UK. Although there was little contention about their retention and treatment, a working group from English Heritage and the Church of England (WGEHCE) reviewed this in detail. The WGEHCE report focused on burials from Christian burial grounds dating from the seventh to nineteenth centuries in England, considering the treatment of human remains, associated artefacts and grave markers during archaeological digs and subsequent research (Historic England 2005, 4). By excluding remains being considered by ROC and WGHECE, WGHRM substantially narrowed its focus to those human remains from outside the British Isles. The subsequent report is of particular interest to the New Zealand context as Māori are specifically listed as one of the most commonly affected indigenous peoples.

Limitation of the report to non-domestic remains effectively realigned it as guidleines for indigenous remains, while still maintaining its supposed applicability to all remains in museums. This is reflected in the Statement of Dissent included in the report from Neil Chalmers (Palmer 2003). Chalmers agrees with several key points of the report but he registers specific dissent from several other aspects:

My reasons for dissent fall into three main areas. First, the Report and Recommendations do not provide a proper balance between the public benefits deriving from medical, scientific and other research on the one hand and the wishes of claimant communities on the other. The Report is slanted heavily, both in tone and in substance, in favour of the latter. Second, some of the Recommendations are disproportionately complicated and cumbersome in relation to the problems they are seeking to resolve. Third, some of the Recommendations are unworkable. (Palmer, 220:1.2)

The Department of Culture, Media and Sport (DCMS) was the lead agency for the WGHRM report and the development of guidance documents in conjunction with HTAUK. The guidance documents constituted a code of practice rather than a code of ethics. Parlimentarians agreed that museums listed in the draft Act would be provided with advice on treatment of human remains, and given new powers for deaccession (DCMS 2005; HTAUK sect 47). DCMS developed a guidance document for the nine museums listed, which was available to all museums in England, Wales, and Northern Ireland, not solely those listed in HTAUK. The guidelines did not apply to museums in Scotland, where separate guidance was being considered. Although they are not statutory the guidelines refer to Acts which are, and represent best practice at the time of writing. Acknowledgement was given to significant variation in size and type between organisations 
that held human remains, stating that application of the guidelines will necessarily be proportionate to the needs of each institution. Collections kept 'purely for medical teaching' are specifically exempt.

The report covers the legal and ethical framework, curation, care and use of remains, and a framework for dealing with repatriation claims. Human remains are defined as either whole or parts of bodies from Homo sapiens, including osteological material, soft tissue, embryos and slide preparations, irrespective of whether or not they had been submitted to modification. Hair and nails were explicitly excluded in line with the provisions of HTAUK. Matters of consent apply to remains 100 years old or younger, and as many museum holdings are older than this they largely fall under exemptions in the Act, limiting the application of consent principles. Development of ethical foundations for the DCMS guidance was complex and the guidelines specifically state that they are meant as a 'starting point' and that there is expectation 'that museums will wish to develop their own ideas on ethics and how these can be used as principles to guide actual actions.' Building on the WGHRM report the guidelines indicate that consideration of indigenous claims are further complicated by the lack of recognition in UK legislation for group rights, recommending that consultation be considered the main principle for resolution of repatriation claims.

\section{United States of America}

The focus for governmental agencies in the USA has been quite different from that in the UK. Partly this is a result of the nature of a federal political system, with responsibility in the USA devolved to state governments. There has been a paucity of evidence of federal responses to the treatment of human remains in museums, which limits exploration of the governmental response. While not specifically focusing on human remains, the Interagency Working Group on Scientific Collections explored the importance of federally held scientific collections to infrastructure, aiding national and international scientific enterprise (Interagency Working Group 2009). Despite not specifically mentioning remains, the rhetoric around scientific collections is equally applicable to collections of human remains. Another significant governmental contribution to the treatment of remains came from the National Commission for the Protection of Human Subjects of Biomedical and Behavioural Research in the mid-1970s. The Commission's purpose was to consider boundaries between therapy and research, criteria of risk-benefit for determining the appropriateness of research on human subjects, guidelines for selecting human participants for research, and 
the nature and definitions of informed consent in research (Belmont Report 1979). The task given to the Commission was to develop a series of recommendations for implementation; however, it requested that their report be adopted in its entirety as ethical best practice and it was made widely available. The Belmont Report as it is known has become a foundational document for bioethics. Responsibility for the implementation of NAGPRA has largely fallen on the museum sector rather than governmental agencies.

\section{New Zealand}

Heritage New Zealand Pouhere Taonga (HNZ) is the lead government agency for identifying, protecting, and preserving New Zealand's historical and cultural heritage, including any discovery of historic human remains (NZHPT 2010). ${ }^{1}$ The majority of human remains found in New Zealand are Māori, and guidelines focus on providing culturally appropriate ways to handle these. The guidelines apply to accidental and unexpected discovery of human remains, not existing burial grounds. The Mataatua Declaration on Cultural and Intellectual Property Rights of Indigenous Peoples, endorsed June 1993, is an indigenous initiative to protect their cultural and intellectual heritage, including rights over human remains. Clause 2.12 identifies human remains as 'cultural objects' and states museums must return them (Mataatua Declaration 1993). The Mataatua Declaration is important for protecting indigenous cultural property but is not legally enforceable (Hakiwai 2007).

\section{Professional organisations}

The fourth source of written evidence is publications of professional organisations. Because of the nature of the case study museums, there are a number of professional communities to be considered, including health professionals, archaeologists, biomedical research scientists, and museum professionals. These are all international communities of practice so guidelines from a number of geographical locations need to be considered.

\section{Museum Professional Organisations}

ICOM is the primary international professional museum organisation. Its Code of Ethics is viewed as a minimum standard for museums which reflects generally accepted principles of

\footnotetext{
${ }^{1} \mathrm{HNZ}$ became the lead agency after the Heritage New Zealand Pouhere Taonga Act 2014 replaced the Historic Places Act 1993. HNZ have retained the NZHPT guidelines for the treatment of human remains.
} 
the international museum community and is available in a range of languages. ICOM (2013) recognises that in some countries minimum standards are set by legislation, while in others accepted standards are confirmed by accreditations schemes. The intention is that the ICOM Code of Ethics be used as a minimum standard to be further developed in reference to specific cultural circumstances by member countries' professional organisations. The ICOM Code of Ethics acknowledges that collections of human remains are culturally sensitive and should be treated accordingly.

The International Committee for University Museums and Collections (UMAC) is a special committee of ICOM. Recognising the special needs of university collections, it was founded in 2000 to preserve and provide access to these collections. The UMAC database lists University collections from around the world. Thirty-five New Zealand collections are listed, including eight collections at Otago University. The Trotter is listed (as theAnatomy Museum) but the Drennan is not. The Council of Europe has also articulated the importance of university heritage and museums (2005). Other professional museum organisations include MA, MAUK, MAus, American Alliance of Museums (AAM), and Canadian Museums Association (CMA). All of these organisations have Codes of Ethics which govern member behaviour.

These international codes of ethics share several common points. Codes apply to both individuals and organisations, whether volunteers or professional staff, and they assert that the mission of the museum is to serve the best interests of the public (MAUK 2008, 4-6; CMA 2006, 3.A.1). Although drawing on the experience of other museum communities internationally, it is recognised that ethical codes differ between countries and must be regularly reviewed to reflect the community they serve. The Australian Code (1999) noted that it could not cover every ethical conundrum faced by museums and as such it was intended to be a reference point. Of the Codes examined only those from MAus and MAUK (2006) do not mention human remains. The AAM Code (2000) recognises the 'unique and special nature of human remains and funerary and sacred objects' and takes this as the starting point for ethical treatment of material. The CMA Guidelines $(2006,10)$ state that museums 'should be committed to the return of human remains, directly associated funerary objects and culturally sensitive objects, when requested.' Whether or not the treatment of remains is included in codes of ethics is dependent on when they were written (Marstine et al. 2015, 73). The MAus code is the oldest and does not include 
consideration of human remains, while the North American codes reflect the impact of NAGPRA and recognition of indigenous rights. The MAUK code was written shortly after the implementation of HTAUK and the lack of guidance regarding remains could be attributed to the new legislation and DCMS guidelines (2005). It is only when certain issues are raised in society that their discussion becomes incorporated into professional ethical codes.

MA reviewed and updated its Code of Ethics and Professional Practice in 2013. It affirms the principles which informed the ICOM Code of Ethics, but refines them for use within New Zealand society, especially recognising the Treaty and accepting the principle of tino rangatiratanga as it applies to museum work (MA 2013, 2-3; Harper 2014, 14; National Services \& Legget 1999). Specific mention regarding human remains was given in Appendix B of the Code, referring members to the human remains policies at Te Papa and Canterbury Museum and expecting those institutions which hold human remains to establish appropriate tikanga for their care (MA 2013, app. B). The review of the Code of Ethics in 2011-13 also led to the establishment of the Museums Aotearoa Ethics Committee, with terms of reference listed in Appendix $\mathrm{C}$ of the Code. MA expects all individual and institutional members to promote ethical behaviour and incorporate ethical principles into daily practice.

The human remains policies for both Te Papa and Canterbury Museum largely focus on indigenous remains. Canterbury Museum's policy incorporates an earlier koiwi tangata policy into a wider human remains policy, but Te Papa's policy is specifically limited to unmodified human remains of Māori or Moriori origin (Te Papa 2010; Canterbury Museum 1998). By focusing exclusively on indigenous remains Te Papa's policy limits its applicability and its use as an example for other museums in the treatment of both modified and unmodified remains. Canterbury Museum's policy has wider inclusion of human remains within its policy, and the acknowledgement of the necessity for Police to use remains within the collection for forensic inquiry. Broadening policy examples to include non-indigenous remains allows human remains policies to be applicable to a greater number of existing and emerging contexts, and acknowledges the sacred status of all human remains within museums, rather than just indigenous remains. 
By including exemplars of specific institutional policies the MA Code of Ethics provides the clearest guidelines from professional museum organisations on the treatment of human remains. This can be attributed to the importance of Māori culture within the New Zealand museum sector and wider community. The Code also specifically references the UNESCO (1970) and UNIDROIT (1995) Conventions, and cites a number of other Conventions and treaties relevant to New Zealand museum practice. While these codes focus on how human remains will be treated within a museum setting, the codes of ethics for medical personnel and academics take an entirely different focus.

\section{Medical/Bioscientific professional organisations}

Contemporary medical and bioscientific professional codes of ethics include the Geneva Convention, adopted by WMA in 1949, and the Declaration of Helsinki, adopted in 1964 and most recently updated in October 2013. The Declaration of Helsinki is directed at physicians but encourages other researchers working with human subjects to adopt its principles (WMA 2013). Citing the Declaration of Geneva and the International Code of Medical Ethics, the Declaration of Helsinki states it is the duty of the physician to "promote and safeguard the health, well-being and rights of patients' including medical test subjects.

The welfare of medical test subjects became increasingly important after World War II. One of the foundational documents for consideration of ethical use of human tissue for research and education is the Nuremberg Code (Trials of War Criminals 1949). Behaviour of Nazi doctors and scientists prior to and during World War II led to the acknowledgement that further clarification was required on ethical behaviour. Strict ethical standards were employed in Nazi Germany and medical students studied ethics as a core curriculum requirement (Hildebrandt 2009c). The focus of Nazi ethics was the well-being of the German people as a whole, rather than individuals. Within this climate, sterilization, euthanasia and the systematic execution of whole groups of people were acceptable.

Traditional medical ethics, in which a doctor's work was focused on the individual patient's benefit, became replaced by a rationality, efficiency, and anti-individualism that ran counter to all previously held values in patient-doctor relationships. Not the individual human being, but the "body of the people" was the object of [National Socialist] medical ethics, and human beings were not seen as individuals, but exclusively in their function as parts of the "body of the people" (Hildebrandt, 908-09). 
After the post-war Doctors' Trial the Nuremberg Code was developed, listing ten basic points for ethical and permissible medical experimentation on humans. The Belmont Report elucidated further on these principles in 1979. The International Federation of Associations of Anatomists (IFAA) produced recommendations for good practice for donation and anatomical study of human remains (2012). These guidelines provide eleven key points which constitute best practice.

Medical practitioners in New Zealand are under the auspices of MCNZ. The purpose of the Council is to 'protect the health and safety of the public' by ensuring that doctors are competent and limit risk of harm to patients (MCNZ 2013; 2004). The Medical Laboratory Science Board, as part of MSCNZ, is responsible to the Minister of Health for the registration of medical laboratory scientists and technicians under the Health Practitioners Competence Assurance Act (2003). Their primary purpose is to 'protect the health and safety of the New Zealand public' by ensuring clinical and ethical competence for practitioners (Medical Laboratory Board, 1). As the size of the New Zealand medical community is small there are a number of Australasian professional organisations. The Royal Australasian College of Physicians $(2013,1)$ requires that members 'observe and maintain the highest possible standards of behaviour or ethics'. New Zealand Pathologists are under the auspices of the Royal College of Pathologists $(2014,1)$, whose code of ethics directs them to practise pathology with 'scientific rigour', and 'honesty, compassion and respect for human dignity’.

\section{Archaeology Organisations}

Racial and evolutionary theory inextricably links archaeology with collections of human remains, whether in health science or ethnographic collections. Professional archaeological organisations' Codes of Ethics and Practice, such as that of the British Association for Biological Anthropology and Osteoarcheology (BABAO) (2010) specifically comment on ethical issues surrounding the treatment of human remains. WAC adopted the Vermillion Accord on Human Remains (1989). This Accord states that respect should be afforded to all mortal remains, the wishes of the deceased and the originating communities where known. Respect is also to be shown to the scientific value of human remains. The Tāmaki Makau-rau Accord on the Display of Human Remains and Sacred Objects was adopted by WAC in January 2006. Acknowledging the Vermillion Accord, it highlighted the sensitive nature of displaying human remains but acknowledged that displaying remains illustrates 
our common humanity. WAC restated its commitment to the scientific principles governing the study of human history, and stated that good science is guided by ethical principles which must be consultative and collaborative with communities.

$\mathrm{BABAO}$ recognises the special status of human remains and that working with human remains is a privilege rather than a right, and is sensitive to issues surrounding their use:

$\mathrm{BABAO}$ is aware of the ongoing debate regarding the ethics of excavating, analysing, curating and displaying human remains. It is a complex and multifaceted debate, influenced by concerns of genealogical descendants and cultures of origins; the multicultural nature of modern society, modern religious and humanist philosophies; medical ethics; museological concerns; and ongoing research initiatives. BABAO wishes to engage fully with this debate and to ensure that it considers the treatment of biological remains in a way that maximises their research and educational use while being sensitive to the issues referred to above and treating them with the utmost respect. (BABAO, 2)

BABOA has developed a Code of Ethics and a Code of Practice as general guidelines for working with human remains. Its position is that remains should be treated ethically but they should be retained in a way that allows for further study rather than reburying them. BABOA acknowledges that remains are considered sacred by many but different viewpoints exist in different communities.

Throughout their working-lives, those studying or interested in the fields of the social and natural sciences are required to make decisions that pose ethical questions. The nature of these questions is not static but influenced by intrinsic and extrinsic events. Therefore, it is essential that decisions must be undertaken in such a way as to ensure individual and collective ethical responsibility. As no single framework will fit all circumstances or eventualities, individuals should understand that this Code has been formulated to provide general guidelines to help BABAO members in their decision making (BABAO, 6).

Differing viewpoints on human remains are also recognised by the Museum Ethnographers' Group (MEG) (1994), who state that not all human remains in museums are problematic.

Although different professional groups have various perspectives regarding human remains there is one key point of similarity: respect. To look at human remains is to consider your shared humanity and mortality and in doing so empathy develops (Brooks \& Rumsey 2007). All the guidelines examined show recognition and respect for the individual that remains have come from. "Respect" differs according to profession, cultural variation and understandings of the body (Campbell 2009). As Campbell points out, modern scientific understandings of the body are often based on the philosophical works of Rene Descartes and Immanuel Kant, emphasising separation of mind and body, and predominance of observable, empirical understandings of the body. Within this context, respect is expressed 
as adherence to the wishes of the individual expressed prior to death. Where individuals state a desire for their organs, tissue or bodies to be used their autonomy over their physical remains is to be accepted.

Museum professionals take another perspective on human remains, reflected in their expression of respect. Museum sector Codes of Ethics specifically comment on adhering to culturally appropriate treatment of remains in order to show respect (CMA 2006; AAM 2000; MA 2013). For biomedical scientists and clinicians, treatment of remains refers to a recently deceased, donated body of an identifiable individual, with documented desires for their post-mortem treatment. However, human remains that museum professionals work with are often historic remains and cannot be identified further than to a specific phenotype. Because the specific desires of the individual cannot be known museum professionals must base their expression of respect on what is known about the community from which the individual is thought to come, integrated with their own cultural interpretation of respect and ethical behaviour. This may include the possibility of repatriation.

There are other significant differences between approaches. Health care guidelines focus on living individuals and health impacts on wider society. Their focus is on maintaining or improving quality of life. Where the wishes of the living patient can be known these and those of their family can be taken into account. After the patient's death the guidelines focus on ways to implement these wishes within the framework of the law (HTANZ 2008). The Otago Anatomy Department (2012) will not accept body donations without prior contact from the deceased and written documentation of their agreement to bequeath their body, countersigned by a family representative. The Department is not compelled to accept every body that is donated, even with the necessary documentation.

It is possible to associate particular remains with specific cultural groups but the focus within health disciplines utilising human remains is on their ability to represent all of humanity rather than as exemplars of specific racial/cultural groups. For museum professionals, however, the focus is quite different. It is occasionally possible to specifically name an individual whose remains are in a museum but it is far more common for remains to be identified only by their ethnic group, and to then be treated as the archetype of that group. As noted earlier, much of the debate around human remains in museums has focused on the remains of indigenous peoples, their method of acquisition by museums, and repatriation. MA and HNZ focus predominantly on Māori remains, and it is 
within this context that museum considerations of human remains in New Zealand are largely set. The case study museums, however, must incorporate elements from museum, archaeology and bioscientific perspectives.

\section{Institutional documents}

The case study museums are attached to two academic departments at Otago University and must be considered within this wider institutional context. There is significant overlap between student groups studying in the two departments and a number of departmentalspecific documents will be applicable to behaviour in both case study museums.

A significant proportion of the information for this thesis regarding interaction with human remains in the health science context is drawn from staff and student experiences in the Dissecting Room. The Dissecting Room shares many features with health science museums but does not completely fall within the parameters given for "museum" under the most commonly utilised definition of "museum" provided by ICOM. This definition states that a museum is:

A non-profit, permanent institution in the service of society and its development, open to the public, which acquires, conserves, researches, communicates and exhibits the tangible and intangible heritage of humanity and its environment for the purposes of education, study and enjoyment. (ICOM website)

Both the Dissecting Room and the Trotter Museum are permanent parts of the Anatomy programme at Otago University. Access to both is restricted, although this is a qualified restriction. Tertiary education in New Zealand is public, therefore admission to the restricted programmes that provide access to the Dissecting Room and Trotter Museum is technically public. The Dissecting Room and Trotter Museum are both used for education, study and enjoyment in order to communicate humanity's shared heritage. However the Dissecting Room is not an exhibition space and cadavers are not kept for display. Much of the research into the treatment of human remains within health science education has focused on dissection, its place in the curriculum, and its emotional effect on students, particularly the development of clinical detachment. While the Dissecting Room cannot be defined as a museum it shares enough attributes with museums as defined by ICOM that conclusions can be extrapolated and applied to health science museums. Dissecting Rooms are also the primary means through which contemporary acquisitions of health science 
museums are obtained (Curtis-Richardson 1997, 364; Corradini \& Bukowski 2012, 121; McClea 2008a).

Students working in the Anatomy Department are required to sign a Code of Conduct (Anatomy 2015) before working with human remains. This Code reminds students that all remains in the Department come from bequests and that working with this material is an 'immense privilege'. The Code explains the Department's legal position, stating they are under the jurisdiction of the Inspector of Anatomy, and that the Inspector is a member of the police, not an institutional position. Expectations of students to act in an ethical and moral manner are also documented. The Department takes these guidelines extremely seriously, and any breach is a 'potential disciplinary matter,' which could result in exclusion from practical classes, irrespective of the consequences for their academic performance. Students are also required to sign the Anatomy Teaching Lab Rules (Anatomy n.d.). The Rules state their purpose as showing respect and keeping students safe, and that they apply to all students in all classes without exception. The Lab Rules do not comment on the penalties for breaking the rules. The clauses of the Code of Conduct and the Lab Rules are very similar, emphasising the importance and consistency of these provisions within the Department. These documents state that they apply to the Museum as well as other teaching spaces.

Medical students are required to sign a Code of Professional Conduct (Anderson 2015). This Code explains the trust afforded to doctors, and by extension medical students. The Code also explicitly directs students to the Anatomy Department Code of Conduct when discussing professional standards and working with human remains, linking the ethical expectations in the Anatomy Museum to the Pathology Museum.

The information in the Code of Conduct and Lab Rules is also included in many of the course materials provided to students in the Anatomy Department. For the purposes of this present research, course materials for undergraduate papers taught in the period 2015-2016 were examined. $^{2}$ Otago University teaches a common first year foundation programme for Dentistry, Medical Laboratory Science, Medicine, Pharmacy and Physiotherapy. Students enter the professional programmes in their second year of study. Undergraduate papers in

\footnotetext{
${ }^{2}$ Undergraduate courses are considered to be those taught at first, second and third year. See Bibliography for a full list of course outlines accessed.
} 
these specific professional disciplines are only offered from second year. The Anatomy Department contributes to teaching in Human Body Systems papers (HUBS191 \& HUBS192) at first year level as part of the foundational Health Sciences First Year Programme, as well as a single second year paper for Dentistry and Physiotherapy. The Medicine programme consists of one paper each year until the sixth year of study. A single Biological Anthropology paper is taught at each level from first to fourth year and can be included in either a Bachelor of Science or Bachelor of Arts programme. The Pathology Department teaches three papers at second and third year level but contributes to the teaching of six other undergraduate papers, plus the medicine papers (Pathology website).

Students taking papers in the Pathology Department are not given any written documentation in their course materials regarding working with human material in class, or about use of the Museum. However, the documents signed for the Anatomy Department are considered as applicable to the Pathology Department and there is significant student crossover (Anderson). Students in the Anatomy Department are given a range of documentation guiding their interactions with human remains. Course outlines repeat material from the Code of Conduct and Lab Rules and there is also standard information regarding the Trotter in course materials of many subjects. This standard museum information emphasises its use as an extra resource for independent research. Students taking HUBS191 and HUBS192 are invited to use the Trotter, and are 'given the privilege of studying human cadaveric material.' This pertains to the display and/or use of this material in classes. Physiotherapy students in particular are reminded of the Department's 'reputation for excellence' and that Otago is one of the few universities internationally where they have the "privilege to learn anatomy from donated cadaver material, and an extensive anatomy museum'. The standard information about the Trotter includes its location, opening hours, after-hours access, the museum's general layout, and the collection's purpose. It outlines that the Trotter is 'one of the most important teaching collections of its kind in the Southern Hemisphere, with several areas of the collection of international significance' (BIOA101). It emphasises the importance of the Museum as a learning resource, but that models, specimens and radiographs are only available in the Museum. It states that replacement and repair of objects, whether models or human remains, is expensive and time-consuming, and in some cases the material has "significant historic importance" and may be irreplaceable. While this encourages students to be 
careful in how they treat objects it also states that 'common sense and general care is all that is required' to ensure the appropriate handing of this material . Students are expected to conduct themselves in a 'dignified and respectful manner at all times' with Museum information repeating that the Code of Conduct applies to the Museum as well as other teaching spaces .

Documents provided by the Departments fit into wider institutional policies, such as the Disciplinary Statute (2011), Māori Strategic Framework (2006) Pacific Strategic Framework (2012), Ethical Behaviour Policy (2010), Human Ethics Committee guidelines, and Teaching and Learning Plan (2013). The work of the Departments must also integrate with the work of other areas of the University of Otago, such as the Disability Information and Support Office, Māori Centre, Pacific Islands Centre, and with other internal groups such as the Otago Medical Students Association and the Otago University Students Association.

The Anatomy Department also produce an information pamphlet (2012) for individuals considering donating their body to the Department. This pamphlet fulfils many of the IFAA best practice criteria for body donation programmes. It clearly states the legislation governing the body donation programme, and terms of acceptance. The pamphlet explains restrictions to donation, such as place of death and specific medical conditions, as well as details relating to transport, costs, and length of time the remains will be kept, including the possibility of long term retention. It also gives information about the Departmental Whakawātea (Clearing of the Way), Poroporoaki (farewell) and thanksgiving service. The anonymity of the bequests is restated and respect for donors is reiterated.

\section{Penalties}

Different guidelines each carry different penalties for breaches. Legislation has the strongest penalties for infringement. Under HTANZ people in breach of the law face a fine of up to $\$ 50,000$ or one year in prison. At Otago University, breaches of the Code of Conduct or Laboratory Rules can have significant consequences involving fines of up to $\$ 1000$, sixty hours of community service, loss of the right to graduate in person, or even exclusion from the University. Students are also told that a breach may lead to their exclusion from practical classes. 
Among professional organisations, penalties for breaching Codes of Ethics and Conduct vary. In some professions, especially in health services, membership of the professional organisation is necessary to be recognised as a qualified and licensed practitioner. Penalties for breaches of these codes may result in deregistration. However, not all professions require registration in order for people to be considered "professionals". The museum sector is still in the process of establishing itself as a professional community and consequently there is no accompanying penalty for not belonging to professional organisations. Some museum organisations run accreditation schemes but this is neither widespread nor compulsory. Where these schemes do operate, accreditation can be lost if members do not adhere to organisational ethical and professional practice guidelines. MA is currently considering the introduction of a professional accreditation scheme, and urges members to be 'champions of ethical behaviour', incorporating ethical principles into dayto-day work.

In some organisations codes of ethics are treated as minimum sets of standards for professional behaviour, while in others they are a discussion document to sustain ethical standards. In these instances Codes of Ethics and Standards and accreditation schemes developed by industry organisations are important for establishing the profession but do not necessarily carry punitive measures.

\section{Exhibition analysis}

The two case study museums of this thesis, the W.D. Trotter Anatomy Museum and the Drennan Pathology Museum, are both attached to academic departments at Otago University and were both established as resources for teaching medical students. Their integration within teaching has changed over time as the University and medical education have developed. Analysis of the two museums took place over a series of days during semester 1, 2017. Data were collected on the following:

- the layout of the museum;

- stock-take of the types of objects in the museum;

- information accompanying objects;

- labelling;

- bookings and use;

- restriction of access. 
It was decided to limit data collection to what could be collected with minimal disruption to the activities of the museums. Locked cabinets and drawers were not opened, and objects on high shelves not visible without the aid of a ladder or step-stool were not included.

\section{The Drennan Pathology Museum}

The Drennan is on the first floor of the Hunter Centre, which is a 2008 adaptation of two older buildings. The Hunter Centre functions as a hub for students on South Campus, largely health science students, and contains lecture and tutorial spaces as well as common areas for dining and meeting. It is well used and students are in the vicinity of the Museum at regular times during its opening hours, from 9 a.m. to 4 p.m. One part-time staff member is employed to look after the specimens, and overall responsibility for the museum lies with another professional practice fellow whose office is located in the Pathology Department in the Hercus Building, a block from the Hunter Centre.

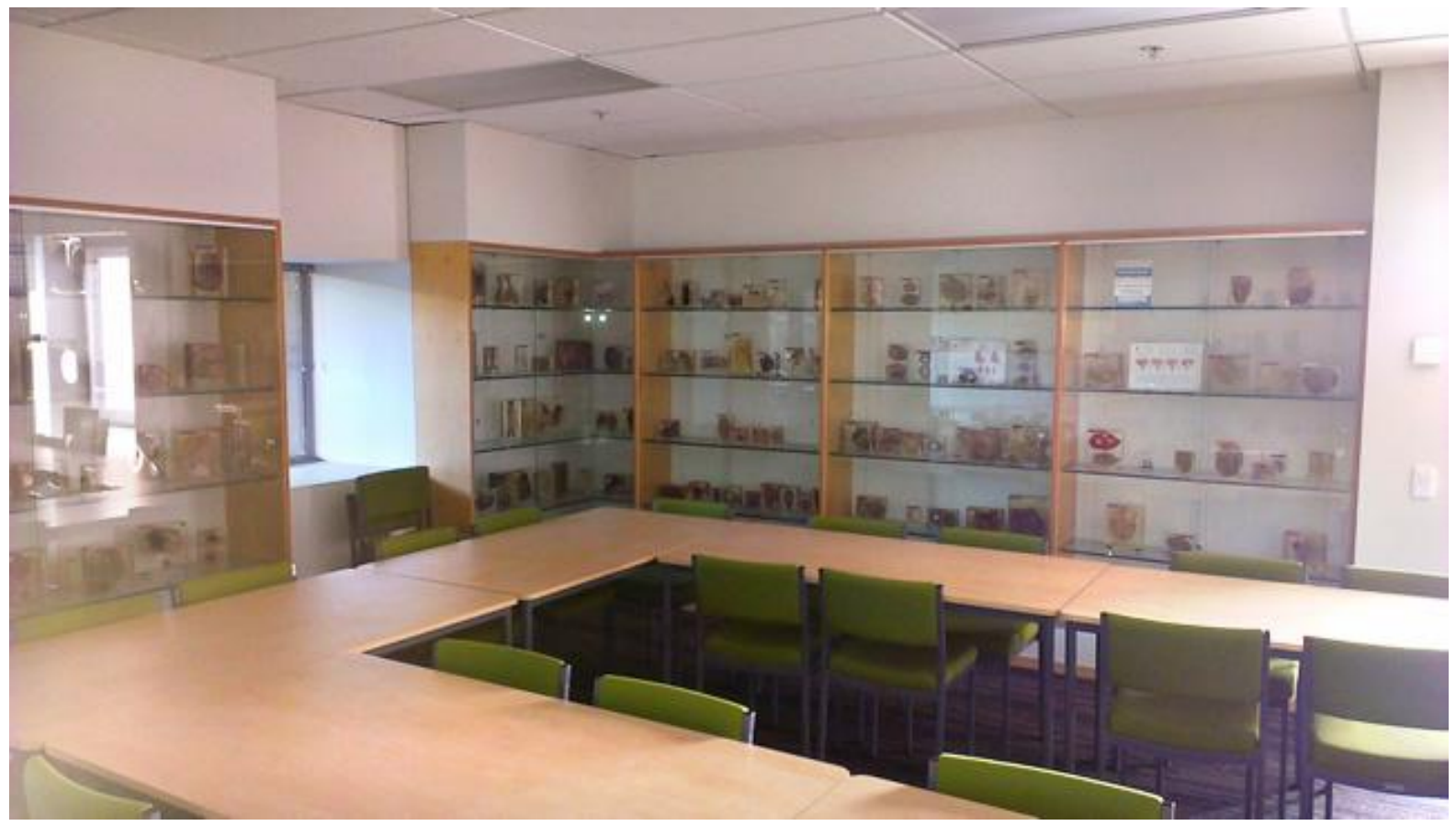

Figure 1: Contemporary view of the Drennan Museum (source: Drennan website)

Analysis of the Drennan took place over two midday sessions on consecutive days in March 2017. During this period the Museum was empty of students and staff. The Museum consists of one classroom-sized room, with access to a single storage room. Small bay windows face into the communal space of the Hunter Centre, and a larger window faces outside. There are large windows in the storage room facing the street. All three 
large windows were covered to some extent. The shelf space in the museum is made from glass and steel wire in custom-made shelving units. The walls beside the entrance are comprised of frosted glass which forms the back of the shelving units in that part of the Museum. The shelving units were locked. Glass shelves allow for viewing of specimens in situ. There were a number of specimens on display but there was a significant amount of empty shelf space. The overall effect of the metal and glass shelving, along with a glass frosted internal wall forming the back of some of the shelving units, is a clinical and modern environment.

The objects were predominantly human remains. The Museum displayed some dried specimens but the majority of the remains were wet specimens created from either surgical resections or post-mortems, stored in clear boxes or cylinders, preserved in Wentworth 111 solution. Signage on the Museum door detailed the indications of formaldehyde sensitivity, stating that Wentworth 111 solution contains a small percentage of formaldehyde. The amount of formaldehyde in Wentworth 111 is considered non-hazardous but first aid measures are described for those individuals hypersensitive to it. More signage stated that food and drink (including water) were not allowed in the Museum. A number of signs were prominently placed around the room reminding students that 'items in this room are electronically protected' by Sensormatic. There was also signage which concerned the intellectual/pedagogical use of the room, indicating that specimens were there to 'reinforce teaching and for tutorials', and that an informational card was allocated to each specimen. In fact most objects did not have such cards.

The proforma information on the cards includes being identified as an Otago University Museum specimen from the Pathology Department, some patient information such as sex, age, and World Health Organisation (WHO) number, a description of the specimen, and case notes. Utilising a standard format for information about specimens aids interpretation and understanding for students. All specimens included labelling. For the wet specimens the majority of the labels were either white codes written on red ribbon labels, or black codes on white ribbon labels. Apart from the specimen cards there was little associated information with specimens. Code numbers may have provided information regarding the type of specimen but there was no legend available. Although cards are not on the shelves with each specimen, books of cards are held in the storage room of the Museum. The amount of information and interpretation provided for museum objects is pedagogically 
important for students to acquire set knowledge and understanding within a teaching museum.

The unlocked storage room off the Museum contains hundreds more specimens and spiral bound booklets of specimen cards. Shortly before the exhibition analysis by this author there had been a problem with the shelving units in the storage room, and the room was in obvious disarray as they awaited replacement shelving. Due to the disruption to collection storage at this time it was decided not to include the contents of the storage room in the exhibition analysis. The Museum and storage room are not large enough to house the entire collection, and it is split between the Museum and the Pathology Department.

\section{The W.D. Trotter Anatomy Museum}

The Trotter is housed within the Anatomy Department on the second storey of the Lindo Ferguson Building, a grade one heritage listed building. It retains an old world atmosphere and decor consistent with this rating. The main access to the Museum is directly opposite the main administrative offices of the department. The prominent position of the Museum reflects its place in teaching, both historically and currently.

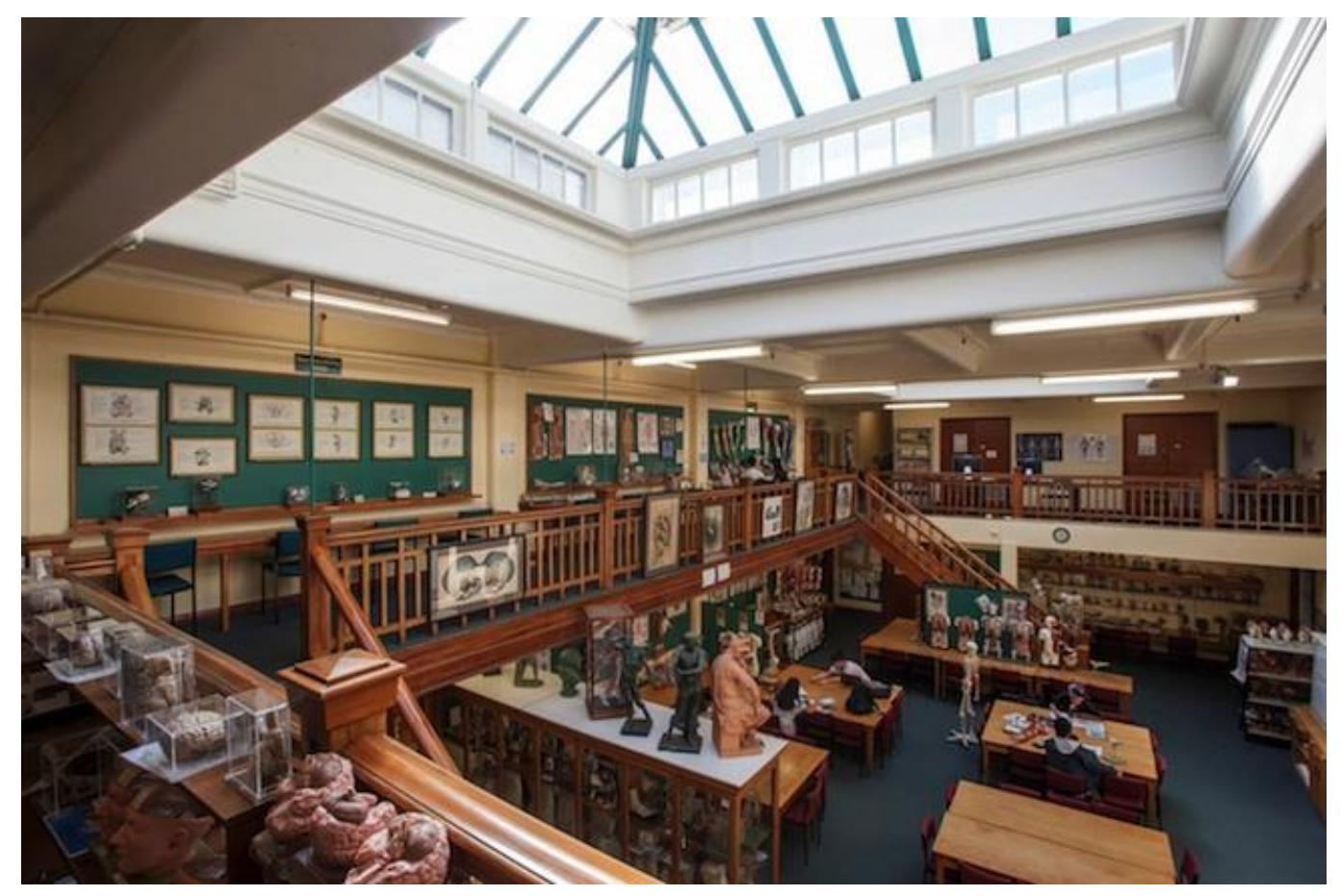

Figure 2: Contemporary view of the Trotter Museum (source: Trotter website) 
The Museum has regular open hours, 8.30 to 5, but after-hours access is available for students and staff with authorised university identification. Two full-time dedicated museum staff care for the collection. Their office is accessible from the Museum.

Analysis of the Trotter was undertaken over three non-consecutive days in March-April 2017. It took two full days and an evening. The Museum has a large open space with tables for tutorials, two internal staircases to a mezzanine floor, a large skylight, and seven small rooms off the main space. There is a second entrance at the opposite end of the main room, and a ramp off the mezzanine floor leads to teaching space and doubles as wheelchair access to the mezzanine floor. The room has large windows facing the street. There are a number of open and closed shelves containing models and specimens. Small replica statues of classical works are on top of one display cabinet. During all three periods of analysis the Museum was in constant use for tutorials, exams and independent study.

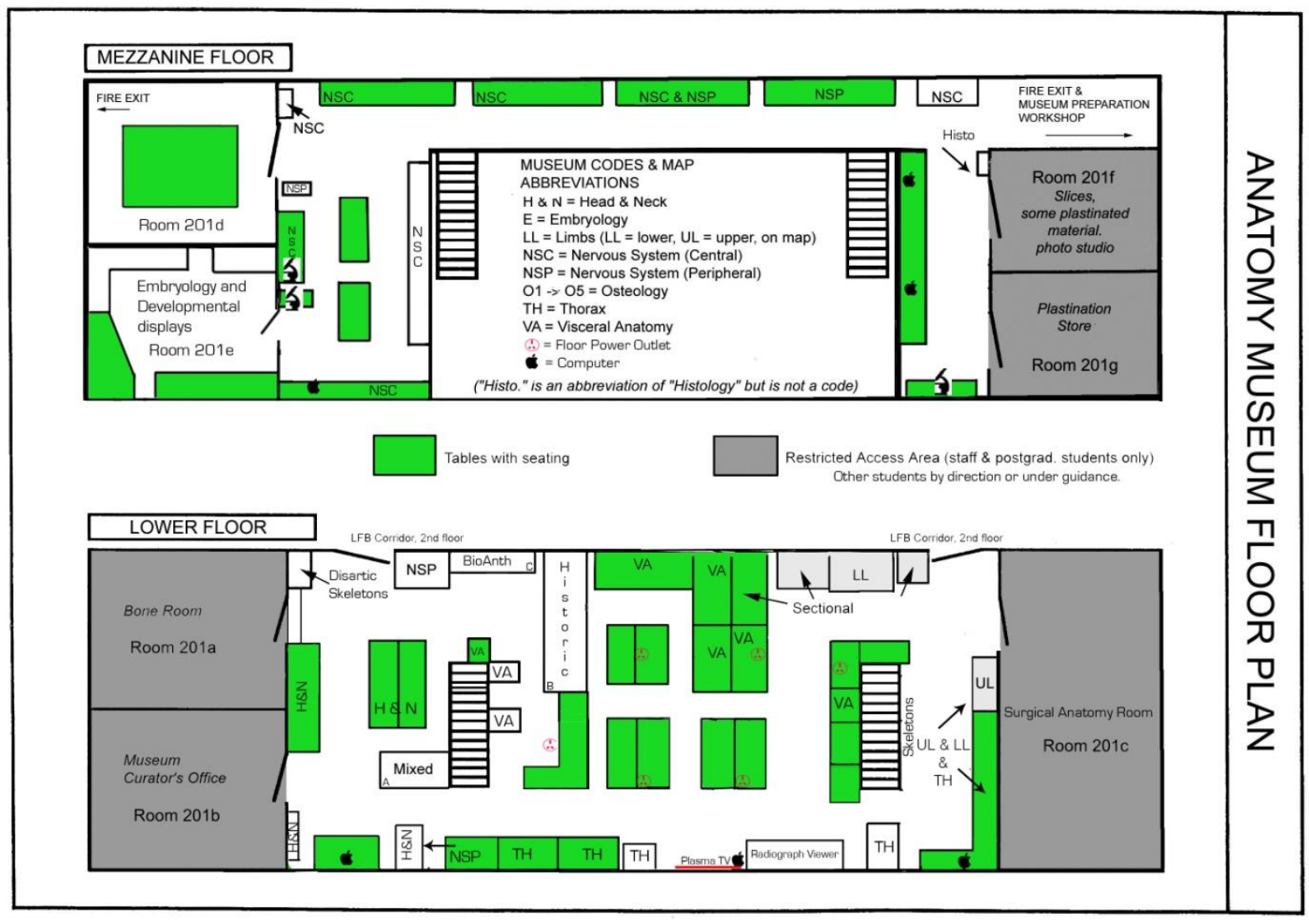

Figure 3: Layout of the Trotter Museum (courtesy Trotter curator)

The main museum space integrates large numbers of models and specimens in its displays. The human remains in the main space are either housed in locked display cabinets or 
drawers or are large, heavy fragile preparations which can be examined in situ. The locked cabinets and drawers can be accessed with permission from the curator. These cabinets are mainly constructed from glass and wood, with glass shelves. During the exhibition analysis museum staff were available to provide access. The Museum is laid out in sections of human anatomy. Displays include both human remains and models with large amounts of associated information.

Access to the small rooms off the main museum space is limited to certain groups. Access to room 201a, the Bone Room, is through Room 201b, the Museum Curator's office. There is a door directly from room 201a into the main museum space but this has been blocked by displays. Room 201c is the Surgical Anatomy Room. Due to being locked it was not included in the museum analysis. Room $201 \mathrm{~d}$ is a small study space which contains large numbers of documentary archival materials for the Museum and Department. The Embryology Room (201e) contains a large number of human remains and a small number of models. These remains concern sexual reproductive systems, development of embryos, and child development. The door to this room remained closed during the exhibition analysis. Room $201 \mathrm{f}$ contains a photo studio, and plastinated sagittal and transverse slices. Room 201g is the plastination store for gross plastinated anatomical specimens.

Specimens in the Trotter are preserved and displayed in a variety of ways, dependent on the type of tissue, techniques available at the time of preservation, and the use to which they will be put. This includes dried specimens, cleaned bone, corrosion casts, plastination, and wet specimens in clear jars and boxes. Bone specimens were often written on in black ink with code numbers and/or Anatomy ownership marks. Most specimens had code numbers affixed to them, either white text on black ribbon or black text on white ribbon. An occasional specimen included white text on a red ribbon. These particular specimens appeared to be part of the Pathology collection, hence the different markings. The code numbers referred to different parts of the body and there were often accompanying notes nearby. Most specimens were alongside written information pertinent to the body system or particular specimen. Some of the specimens in the embryology room include dates as to when they were collected. Many of the objects were mounted in clear containers on top of a variety of styles of green bases. ${ }^{3}$ Some objects were then given an additional base of

\footnotetext{
${ }^{3}$ In this context 'objects' refers to human material, animal material and models.
} 
wood. Some objects were mounted on small sets of drawers which could be opened for further information. The majority of the wall space in the Museum is covered in peg-board, allowing for easy removal and replacement of objects hung on the wall. Easy access is given to much of the material although some items are too fragile to be moved. These items are clearly labelled and are able to be used in situ. At the time of this author's examination approximately $72 \%$ of the Trotter's displays were human remains, preserved in various ways. Frequent usage during the examination precluded a precise calculation, but the high percentage indicates the importance of the Guidelines.

Signage in the museum prohibits photography, drinking and eating, reinforcing content from Course Outlines, Code of Conduct, and the standard information provided about the Museum. The Trotter is included in the MA New Zealand Museum and Galleries guide (2017). The Guide notes that it is not open to the public, but conducts tours. It is also listed in the UMAC Database. The Drennan is not listed in either catalogue.

An analysis of the room booking system for the two museums revealed that in the period 2015-6 the Trotter was booked regularly for outreach and promotional activities for the Department and the wider University. These bookings were made around the use of the space for teaching, exams and independent study. There was no evidence of correlating use of the Drennan.

\section{Interviews}

Interviews published as a series of DVDs by Paul Trotman (2009), all of which were undertaken as part of the Donated to Science and Practising Medicine projects, were analysed for this research. These interviews were undertaken with body donors, staff and students at Otago Medical School. Body donors gave specific permission to be identified and for their bodies to be followed through the dissection process. Students discussed their experiences with human remains, specifically their dissection cadaver, their personal exploration of mortality, their gratitude to the body donors, and their emotional journey through their medical programme. Structured interviews and reflective video diaries were included in the final documentary and DVD extras as students moved into their clinical years. Recordings of the Whakawātea (2009g), the Bequest Lecture (2009c), the Thanksgiving Service (2009e), interviews with body donors (2009a; 2009b; 2009d) and a donor's visit to the Trotter (2009f) provide an evolving context in which the participants 
interacted with human remains in a way that could not be provided by one-off research interviews. Although the focus of the interviews is on medical students' dissection experience, the Museum is still an integral part of the study, and many of the interviews were conducted there. As discussed above the correlation between the Dissecting Room and Museum allows information to be extrapolated about the Museum. Furthermore, although the interviews specifically relate to the students' experiences in the Anatomy Department, documented links between the Pathology and Anatomy Departments ensure that the reflections from the documentaries apply across both departments and museums. The use of donor interviews provides an interesting perspective on the use of human remains. The opinions and attitudes of donors are not usually included in discussions of human remains as they are not available post-mortem, so these pre-mortem interviews convey important points of view for consideration of the topic. The donors were aware that their bodies would be used for dissection and that there was the possibility of long-term retention of parts of their body within the Museum.

Written documentation, exhibition analysis and interview data have been used as the foundation for investigation into the ethical treatment of human remains in museums. By utilising three types of data in a mixed methods approach the inherent weaknesses and biases evident within them can be balanced. This allows the validity of the conclusions drawn to be tested against conclusions from the other data.

All three sources emphasise respect as underpinning treatment of human remains. Guidelines for medical professionals focus on their ethical responsibilities and respect towards the living. For professional groups working with the dead the situation is more complex. For health science academics and students the use of human remains is founded on the principle of future benefit for society in training health professionals or developing new treatments. In this context remains are often portrayed as 'first patient', and their individuality and respect for human life is emphasised (Jones 2016b, 49, 52). The other key point of difference is where human remains are treated as an example of a particular phenotype. The remains cannot be further identified so respect is applied within cultural norms rather than the specific wishes of the individual. Distinctions between these two categories are often unclear and remains in museum collections fall into both. However, all groups have a focus on respect, whatever this means in a given context. 
The following chapters explore the three interconnected aspects of this research based on the information from the sources described above. Taking respect as a foundation, they consider codes of ethics in society and professional practice, the way human remains are conceptualised as objects and how this affects their treatment, and integration of health science museums into the tertiary curriculum. 


\section{Chapter 3: Ethical Guidelines}

Human remains are held in numerous collections throughout the world, in a variety of contexts. For many this has become problematic. Literature on problematic human remains in museums focuses on repatriation claims, historical and archaeological acquisition, or Body Worlds. Donated human remains are largely overlooked, despite being the primary contemporary acquisition method for health science museums. Reviews of bequest programmes largely focus on dissection and research as the only destinations for bequeathed remains, and predominantly ignore health science museums.

The previous chapter explored some existing guidelines and codes of ethics used to govern treatment of human remains in a number of contexts. This chapter considers the implementation of these codes within society's changing relationship with death, and discusses evolving ethical understanding and practice. Societal issues relating to human material are considered in relation to museum positions regarding the acquisition and holding of human remains, including changing ideas of bodily autonomy and body-asobject, with specific reference to New Zealand and the Otago University contexts.

Examination of these areas provides insight into the nature of ethical codes, and explores whether they are the best means of directing treatment of human remains. By understanding this nature within changing ideas surrounding death in modern society justifications for the use of human remains can be understood and tested.

$* * * * *$

\section{Society's changing relationship with death}

Society's relationship with death has changed in the twentieth century. Historically life and death were intimately entwined, with death being an accepted part of life. However, a number of factors have contributed to changing society's understandings of death. World Wars I and II and the Spanish Influenza outbreak led to substantial loss of life. Prior to this, wars had been largely limited to combatants and those unfortunate enough to occupy disputed territory. Strategies in WWI moved towards total warfare, where civilian populations and supply lines were targeted. The Spanish Influenza outbreak became a worldwide epidemic, with troop movements after the war contributing significantly to the international death toll. World War II led to more loss of life. Subsequent medical 
advances led to decreasing mortality. Pharmacological developments made formerly fatal diseases treatable and prolonged life expectancy and quality. Increased life expectancy, coupled with professionalisation of the funeral industry, led to less familiarity within the general population with death. Today many people in the West have never seen a dead body or witnessed an actual death (Foltyn 2008).

Consequently there has been a gradual shift in the public's understanding of death. With rising popularity of medical dramas and murder mysteries in novels, television and movies, death, especially violent death, has became associated with fiction. When people died, it was traumatic, through suicide, accident, or crime, or it was through the failings of medical professionals who had not "saved" a patient. This change in societal attitudes towards death affects how human remains are considered. Dead human bodies became objects of horror and the macabre, rather than the vessel of the individual. Bodies had long been sources of veneration, with changing ideas towards death they became more sacrosanct, and in some ways more objectified. Outside of accepted funeral rites, any treatment of human remains became sacrilege, despite changing societal understandings of the sacred. How remains were treated became incredibly important, and objections to holding and using human remains in museums and in research increased. Conditions surrounding acquisition of remains became increasingly important with concerns over using unclaimed bodies, especially those of the vulnerable such as mental patients and children. There were different concerns raised over collecting human material from living and deceased individuals. In New Zealand the Code of Patients' Rights governed collection of tissue from living patients and the HTANZ governed tissue collection from cadavers.

\section{Ethical guidelines for the treatment of human remains}

It is within this context that the development and implementation of guidelines for the treatment of human remains becomes important. Ethical regulations provide guidance to practitioners, assurance of ethical behaviour to the public, and accountability for breaches. Legislation is implemented to provide baselines for acceptable behaviour and cannot be breached, under threat of incarceration or significant financial penalty. Professional organisations further develop these rules to clarify expectations of their members. Similarly, individual institutions refine professional guidelines to fit their specific circumstances and needs (Brooks \& Rumsey 2007, 267). Legislation includes the ability to 
punish individuals and institutions for breaking standards, but as noted earlier the ability of professional organisations to impose penalties varies. Codes of Ethics and Professional Practice are often used as a means to define a profession and as grounds for inclusion or exclusion. They are developed by communities of peers, providing guidance on practice and as a guarantee of competency and credibility.

\section{Types of Ethical Codes}

Two main forms of ethical codes have developed within museums: codified and consultative ethics. Codified ethics are comprised of written guidelines, which are standardised into a set of regulations (Alfonso \& Powell 2007, 5-6; Edson 1997). Codes of ethics establish professional boundaries and standards, providing adherents with a sense of belonging to the profession and a set of shared values, and the public with a standard against which behaviour of professionals can be monitored. No code can address every ethical conundrum, and so codes are periodically debated and reviewed. Each revision is a product of its historical and cultural context, and as such does not have flexibility to adapt to changing circumstances, and may even be used to avoid engaging with complex ethical issues (Marstine et al. 2015). The process of revision of Codes of Ethics may cause changes but this does not mean that foundations for the Codes have necessarily changed. The prominence of certain issues over others reflects the amount of debate each issue causes. Consequently Codes of Ethics written around the same time indicate which issues caused ethical debate within the wider sector at that time. It is not that previous clauses are ignored, but rather that they have been fully integrated into practice and are no longer considered ethical conundrums. However, the process of revision itself indicates that established practice must be continually reviewed to ensure it still reflects the standards of the professional community amidst changing circumstances (Edson). Codified ethics tend to take a legalistic approach to ethical conundrums, a practice which produces incremental change as a reaction to challenges (Marstine et al.).

New Museum Ethics are a form of consultative ethics, and have developed as a response to codified ethics. Codified ethics are viewed as a constraining force that limits ethical understanding to what easily fits within existing frameworks. New Museum Ethics view ethics as a 'dynamic social practice, it encourages dialogue and critical thinking' (Marstine et al.,74). As demands for museums to engage ethically with the public increase, the failings of codified ethics become apparent: 
[T] he predominant late twentieth-century approach to ethics as professional practice, which relies on ethics codes revised perhaps once a decade and authored by like-minded individuals to produce and implement these codes, has proven to be a constraining factor, rather than an enabling process. In order for museums effectively to negotiate difficult issues as well as ethical opportunities that arise, novel approaches to ethics are required in which the museum sector actively pursues a dynamic ethics-based museum practice.

(Marstine et al., 69)

The proffered solution to the stagnation of codified ethics is to view ethics as discourse, allowing for intellectual discussion within specific contexts to develop new ethical practices, reliant on postmodern critical theory, feminism and neo-Marxism (Marstine et al., 69). Consultative ethics approaches take the stance that professional ethics codes are insufficient to handle the myriad ethical issues that face modern museums and that continuing discussion on the specific ethical issues to hand is required (Harper 2014, 12; Brooks \& Rumsey 2007, 261; Curtis 2003, 27; Bud 2013, 69-70; Bounia 2014, 1, 5). They draw on experiences from a range of disciplines, including medical ethics, to explore issues and welcome previously marginalised views as productive contributions aimed at developing more nuanced understanding of issues. Consultative ethics are 'an opportunity for growth, rather than a burden of compliance' (Marstine et al., 91).

Ethical codes for health professions take a very different perspective from those of museum organisations and are largely codified ethics that focus on how practitioners should treat living patients and how professionals should conduct themselves in order to maintain the respectability of the profession. Their primary focus is the health of living patients, and are largely prescriptive codified guidelines.

\section{Terminology used for discussing human remains}

Terminology used to describe human remains is important as a reflection of professional and personal attitudes to those remains. The expectation at the outset of this present research was that professional documents from the health and museum sectors would differ in terminology used to describe human remains. However this assumption proved largely false. The majority of professional guidelines examined from both museum and health sectors refer to tissue taken from the body as 'human remains'. Other terms used often related to more contextually specific remains, such as 'kōiwi tangata' for Māori remains, 'human osteological material' for bones, 'biological remains' to distinguish between remains and artefacts, and 'human subjects' for research participants. HTANZ and 
HTAUK use very specific terms to describe remains. HTAUK repeatedly refers to remains of an individual as 'deceased person', 'body of a deceased person', 'body of a person', and 'material [that] has come from a living person'. This language may reflect the fact that revision of British legislation was instigated by public outrage over the organ retention scandals. HTANZ defines human tissue as material that:

(a) is, or is derived from, a body, or material collected from a living individual or from a body; and (b) is or includes human cells; and (c) is not excluded, for the purposes of some or all of the provisions of this Act, by subsection (2) or (3). (HTANZ s7)

Subsection (7.2) specifies that a human embryo or human gamete is not human tissue for the purposes of any provision of the Act, and (7.3) states that cell lines derived from human cells are human tissue only for some purposes, specified in later sections of the Act.

An inherent tension exists in health science museums caused by attempting to adhere to two competing sets of ethical guidelines. The main conjunction between museum guidelines and health science guidelines is in showing remains "dignity" and "respect". Discussions of "dignity" and "respect" assume a universal understanding of these concepts but this is erroneous (Gladstone \& Berlo 2011, 361). Even within disciplines there are differences in what constitutes respect, demonstrated by interview participant's comments (Trotman 2009a, 2009b):

We are by law required to follow respect and dignity when dealing with human tissues... They are allowed to enjoy dissection by smiling and laughing and joking etc but [must] be respectful at the same time. Dr Latika Samalia, Anatomy Lecturer

Just looking around the dissecting room people show respect in different ways and obviously everyone has a different point of view on the body and that's fair enough. For me personally I like to think that this is a once in a lifetime opportunity. I should make the most of it. Herv Vidakovic, medical student.

Respect is to acknowledge them as a person and not be bothered by the fact that you can see their face... I think that disrespect is to cover them up and pretend that they're not or they weren't a human being. It's like you don't want to acknowledge that they were a person and they were someone. Whatever your belief in spiritualism, is that they can see you or whatever that shouldn't matter. Heather Mitcheson, medical student

I kind of decided that this man had given up his body so I could learn, so I was going to learn all I could from him so it wasn't for nothing, and if it was really difficult for me I still had to really focus on what I was doing so what he had done was worthwhile. Kathryn Foster, medical student 
I'd like to say well just treat me with a bit of respect and go ahead, and do what you've got to do, and hope you learn something from me. Janet, donor ${ }^{l}$

In legislation "respect" is embodied as informed consent and informed objection (HTANZ 2008). This application of "respect" and the determinative rights of individuals over their bodies is a reflection of body-as-object. The development of perceptions of the body as an object are based on Cartesian dualism, which is the philosophical foundation for many discussions of the treatment of the human body (Campbell 2009, 2; Sharp 2000, 290).

From a scientific perspective the human dead body - or cadaver - is easily viewed in an impersonal way, as a source of knowledge of the causes of death or the effectiveness of therapy through autopsy, or as a source of benefit to others, through the 'harvesting' of organs and tissue. Such an objectified view of the dead body is, however, a universe of meaning removed from the perceptions of the bereaved family of a dead person. For them the body of the deceased represents all that they cared for and all they have lost (Campbell, $1)$.

Different perspectives on an individual's bodily autonomy are reflected in legislation on donation of human tissue. Two forms of system exist for the acquisition of human tissue, 'opt in' and 'opt out'. In opt in systems individuals need to actively decide to donate tissue (informed consent). In opt out systems consent is assumed unless specifically objected to (presumed consent). Both systems are based on tenets surrounding ownership of bodies, but take different perspectives. Opt in systems view bodies as being principally property of individuals, while opt out systems invest authority over bodies to the State. Bodily autonomy can be asserted by individuals (objection) but this must be actively asserted rather than implicitly understood. Opt out systems recognise the need for human tissue in treating others, whereas opt in systems put greater emphasis on bodily autonomy of individuals.

New Zealand operates an opt in system, meaning the decision to donate tissue, organs or full bodies needs explicit consent. The extent to which consent needs to be formalised depends on what tissue will be used for. In the case of general purpose use consent can be given by an individual before their death, or by a nominated individual, immediate family or close available relative (HTANZ). For use of bodies for anatomical examination or public display individuals must give informed consent before their death, countersigned by immediate family or close available relatives. HTANZ defines informed consent and informed objection as that given or raised 'freely, and in the light of all information that a

\footnotetext{
${ }^{1}$ Donors were identified on film only by their first name.
} 
reasonable person, in that person's circumstances, needed in order' to give that consent or objection. HTANZ makes informed consent necessary, but there is no obligation to accept donated tissue. All tissue used by the Anatomy and Pathology Departments at Otago University is derived from donations. Discussions regarding the use of human tissue is couched in terms of 'respect' and 'privilege' but this does not change the foundational understanding of body-as-object where human tissue is designated as 'gift' and 'donation' (Campbell 2009, 2-3; Sharp 2000, 292). Understandings of body-as-object do not negate concepts of "respect" but it must be acknowledged that discussions of respect operate within these boundaries.

Respect is extended further to particularly sensitive remains, especially reproductive organs and children. Under HTANZ people are thought to have the appropriate maturity to make adult decisions at age 16, and the Act is specifically limited to not apply to foetal tissue. Arguments against the use of human remains for display have often included concerns over titillation, particularly in reference to sexual organs, and remains of children, foetuses and other vulnerable bodies can be particularly disturbing (Durbach 2014, 40-41; Alberti 2011, 133-6). HTANZ explicitly makes it an offence to publicly display individuals under age 16. The Trotter displays historic human remains related to reproduction and embryonic development in a separate room off the main museum space, and does not accept body bequests from minors.

Donors need to register for the Otago Anatomy Department to be able to accept their whole body donation. Registration requires dual signatures from individuals and a family member. Where there is no living immediate family member to co-sign the consent form the bequest will not be accepted (Anatomy 2012). The Department is not obliged to accept bequeathed bodies and strict guidelines and policies exist to determine which bodies can be accepted. Donated bodies need to be specially embalmed within 24 hours of death to be suitable for use. Because of this, bodies can only be accepted from Dunedin, Invercargill, Christchurch, and Nelson/Marlborough. If donors move or die outside of these areas they cannot be accepted. They can also not be accepted if they have been used for organ donation, or if they have certain physical conditions, including a Body Mass Index over 30, rapid onset dementia, have undergone a post-mortem, have infectious diseases like Hepatitis B or C, Creutzfeldt-Jakob disease, tuberculosis, or HIV, or lived in the UK, France or Ireland for more than six months between 1980 and 1996. 
When the Department decides not to accept bodies the decision is founded on legislation. HTANZ (s16) states that ' $[\mathrm{N}]$ othing in this Act requires any person to collect or use human tissue.' Acceptable reasons for not accepting tissue are not clarified.

HTANZ's references to 'cultural and spiritual needs, values and beliefs of the immediate family' and 'cultural, ethical, and spiritual implications of the collection or use of human tissue' provide plenty of ambiguity and scope for grounds for refusal (s3). Conversely, it is 'an offence to collect or use tissue if the informed consent required has not been given' (s4) The provisions of HTANZ apply largely to acquisition of new tissue and do not specifically comment on existing human remains in collections.

Within New Zealand's bicultural society the most immediate 'cultural and spiritual needs, values and beliefs' to be considered are those of tangata whenua. There have been historical and contemporary concerns over Māori remains within the medical school collections. The Office of Māori Development at Otago University is currently developing an institution-wide human remains policy to establish best practice for Otago University. For this reason it is untimely to specifically address Māori remains within this thesis. The need for cultural safety when working with human remains is recognised by the Anatomy Department and a Whakawātea (Clearing of the Way) is conducted at the beginning of each year to lift tapu.

The importance of the bequest programme to the Anatomy Department is evident in the course materials and layout of the Department and Museum. Posters line the walls near the dissecting room and Museum discussing the bequest programme, relationships with nextof-kin, and reflections from students (McClea, 2008a, 2008b). The gift nature of the remains in the Anatomy Department is highlighted in a number of ways, through the Code of Conduct, posters in the department, course outlines and the annual thanksgiving service. The Code of Conduct (2015) states:

All cadaveric human material in the Department has been obtained as a result of people generously bequeathing their bodies for teaching and research.

The Lab Rules instruct students to '[s]how respect for the people who donated their tissues.' Posters about the bequest programme highlight the process of bequests and student reflection on it. These comments come from the Second Year dental class (2007): 
I am very thankful and grateful of your generous decision to donate your body for the benefits of study. I would also like to thank your families and friends who allowed your wish to donate your body to be followed through.

To enhance our learning, you gave us your physical identity, your temple, your body. To enhance our learning your families gave us their loved one and their chance at a last goodbye. To enhance OUR learning, you all gave us your trust. And for all of this we give you our deepest thanks and respect. Thank you.

Thank you for giving us the greatest gift, for our learning of the human body.

We are so privileged to be given such a gift. Thank you.

The Thanksgiving service echoes this language (Trotman, 2009e):

An opportunity for the family to remember them. Also, an opportunity for our students and staff to say thank you. To say thank you to your loved ones for the huge gift that they have given us and without that gift it would be very difficult for us to teach the students the way we do and to undertake some of the research that goes on within the department. Professor Helen Nicholson, Dean of Medical Sciences.

\section{New Zealand museum codes of ethics and human remains}

The MA Code of Ethics (2013) does not specifically comment on human remains in museums. Appendix B of the Code refers readers to Te Papa and Canterbury Museum for examples to illustrate current ethical debate. The Code does comment on relationships between the museum sector and iwi, and efforts to incorporate values of all New Zealanders into museum practice for stewardship of collections (MA, 2-3). Canterbury Museum's kōiwi tangata policy refers to care of human remains as 'matters of the greatest sensitivity' and states that the Museum 'will seek the advice of the relevant iwi and/or cultural group in any matter regarding the care and management of kōiwi tangata/human remains' (Canterbury 1998). The development of a 'restricted and spiritually dignified' repository for remains on site reflects the respect shown to remains by Canterbury Museum. The kōiwi tangata policy is codified but refers to action taken only in consultation with local iwi, and as such is a form of consultative ethics. Appendix $\mathrm{C}$ of the MA Code of Ethics sets out the draft terms of reference for development of the Museums Aotearoa Ethics Committee. The Committee is to be a small representative panel to mediate on ethical dilemmas when required. They are to advise on training, specific ethical issues, and to consider the advice of Kaitiaki Māori. The development of an Ethics Committee provides an avenue for consideration of particular ethical issues within context and their applicability 
to the wider sector. It allows for the codified ethics to be expanded and finessed, and an avenue for codified ethics to be consultative.

\section{Tensions between different types of ethics in health science museums}

How problematic the inherent tension between medical and museum perspectives actually is depends on the importance placed on each respective code of ethics and practice. If either set of guidelines is considered more important, the tension will decrease as observance of one set of guidelines becomes less important. Where both sets of guidelines are considered of equal importance, compromise and accommodation must be found and this is where tension lies.

Appendix B of the MA Code of Ethics is the main museum professional guidance for treatment of human remains in New Zealand (MA 2013). However, the focus on Māori remains is not particularly pertinent to the Trotter and Drennan. The Trotter is used to teach biological anthropology but the majority of relevant items on display during exhibition analysis appeared to be casts and models of skulls for teaching evolutionary biology rather than Homo sapiens remains. The Trotter previously held large numbers of indigenous remains, largely due to Professor John Halliday Scott's research interests (Neuman 1993). ${ }^{2}$ However, these are no longer on display or available for teaching. Otago University is working towards biculturalism and fulfilling its Treaty obligations and has several initiatives in place to achieve this, including the Māori Strategic Framework (Otago 2006) and an Office of Māori Development. These provide more specific and focused guidance on Māori issues in the University. This can be viewed as a form of consultative ethics within the wider institution as the Trotter and Drennan need to consult with the Office of Māori Development over any concerns regarding Māori remains or protocol. The establishment of this office demonstrates the University's willingness to create substantial and enduring links with Māori and provide an avenue within the institution for consultation.

\section{Guidelines for working with human remains at Otago University}

The rules governing the case study museums are a mix of codified and consultative ethics. At first the rules seem purely codified and static, but under closer examination their

\footnotetext{
${ }^{2}$ Scott was Professor of Anatomy and Physiology from 1877 and first Dean of the Medical School from 1891.
} 
consultative nature becomes apparent. Students are provided with strict rules to learn accepted ethical boundaries of their intended professions. This is in keeping with the sensitivity of the material they are working with and their status as undergraduate students.

The consultative aspect comes into focus when the wider institutional context is taken into account. Otago has an established reputation for the strength of its health science programmes (QS website). Academic staff provide expert guidance to national and international legislative and professional bodies which develop codes of ethics and practice. The current Education Act (1989, 14.162.4.a.ii) states that research and teaching should be 'closely interdependent', ensuring that developing ideas about the nature and applicability of ethics are applied within teaching programmes. This close association between research and teaching ensures that developing ideas regarding ethical treatment of remains are incorporated into teaching practice. The Act also states (14.161.3.a) that universities should be held to the 'highest ethical standards' and 'permit public scrutiny to ensure the maintenance of those standards.' Institutional codes of ethics and practice are easily modified by staff between teaching semesters.

The Medical Humanities programme at Otago offers health science students an avenue to 'foster critical thinking and analysis' (Humanities website). This willingness to integrate health science and humanities subjects demonstrates understanding of the importance of incorporating health science education into wider societal contexts and ethical discussions. The University also offers highly regarded bioethics and law degrees. This provides capacity within the institution to explore any possible changes to practice with colleagues to ensure their legality and ethical position.

$* * * * *$

This chapter has focused on the nature and implementation of codes of ethics relating to human remains. The codes considered have demonstrated ongoing discussion about the ethical treatment of remains. These considerations are underpinned by philosophical foundations on the nature of the body and ownership rights. Divergent perspectives of the body cause conflict between understandings of body-as-object and body-as-individual. However, treatment of human remains by professional organisations falls within the parameters of body-as-object. Despite this conception of the human body, acceptable treatment of remains is defined within strict ethical boundaries by the various professions 
involved. These boundaries provide the ethical foundations for acquisition and display of human remains in museums.

The focus of professional museum codes of ethics on indigenous remains results in documents particularly slanted towards their treatment rather than more general approaches applicable to wider circumstances. In New Zealand the majority of remains in museums are likely to be of Māori or Moriori origin, but this does not preclude museums from holding other human remains. By limiting ethical guidelines to specific groups, codes discount other contexts, restricting their usefulness. This leads to greater reliance on other ethical codes for guidance, creating distance between members of the profession as they follow divergent ethics. If shared ethical codes help define a profession then adhering to multiple ethical codes undermines this.

Debate regarding ethical codes must consider whether codified of consultant codes are more appropriate. However, codified ethics within tertiary environments may be a misnomer. The development of written codes of ethics necessitates expert input. By definition the academy is a community of experts, and within this context codified ethics can be continually subjected to review and revision.

Chapter 4 considers why human remains are used. The justifications for their use are usually based on the importance given to real objects over simulations and models. The place of real objects in museum development, their ongoing importance, and how human remains are conceptualised as objects, are also considered, and the place of consent and the legalities of ownership of remains are discussed. 


\section{Chapter 4: Justifications}

The previous chapters have explored codes guiding treatment of human remains, and have discussed the nature of different types of codes. They demonstrate a desire to ethically treat remains in their care. However, they fail to address fundamental assumptions regarding the necessity of using human remains, an issue that is not addressed in codes or literature. This chapter considers how using human remains in museums has been, and is, justified, and the wider ramifications of using remains by placing their use in a wider context.

Justification for using human remains cannot be separated out from the objectification of remains in general, and indeed, objectification of living persons. To consider these wider issues this research examines the historical and theoretical context in which human remains exist. This includes the objectification of remains and its justifications, the concept of moral complicity, and the impact of consent on use. This chapter will also consider the legalities involved in ownership of remains, and commercialisation of bodies. In examining these matters it will consider whether existing codes of ethics adequately govern the use of remains and if their continued use in museums can be warranted. The special status afforded human remains means that any treatment other than accepted funerary practices must be robustly defended and justified. If the necessity of their use cannot be fully demonstrated it must cease.

The historical use of human remains for dissection and in museums is well documented. The Anatomy Act (1832) ensured legal supply of bodies, supposedly ending the need for a black market in cadavers in the UK. This Act removed the penalty of dissection from murder sentences and allowed unclaimed bodies to be used for anatomical dissection. This law changed the legal basis for dissection from criminal behaviour to poverty (Richardson 1988). Legalising dissection in the USA had a protracted history. Massachusetts was the first state to pass an Anatomy Act allowing dissection in a medical school in 1834, followed by New York in 1854, but no further states legalised dissection until the mid1870s. Otago University Medical School was established in 1875. From the outset staff were well aware of international debates surrounding using cadavers for dissection and the need for an Anatomy Act in New Zealand (Page 2008, 18-21). Close links between the Universities of Otago and Edinburgh ensured Otago staff were familiar with the controversies surrounding Edinburgh's supply of cadavers highlighted by the Burke and 
Hare murder trial. The first New Zealand Anatomy Act was passed in 1875, at the instigation of the Medical School, providing a legal source of cadavers. Shortly after the establishment of the Medical School the Otago Anatomy Museum was created as a crucial teaching resource. ${ }^{1}$ Museums were seen as vital teaching tools within medical education and dissection provided the route through which human remains entered the museum collection (Page 2008, 31; Curtis-Richardson 1997, 364; Corradini \& Bukowski 2012, 121). As medical education develops, the fundamental assumption that human remains are essential resources needs continual review.

$$
* * * * *
$$

\section{Early museum development}

Museums in medical schools were not the only or first institutions collecting human remains. Cabinets of curiosity gradually evolved into carefully ordered taxonomic collections. These early collections drew little distinction between human remains and other natural specimens as they attempted to catalogue God's creation. Theological foundations for collections changed but the desire to collect and catalogue the natural world remained. The French Revolution led to development of a more rigid museum structure at the Louvre which became widely applied elsewhere. It altered not only the practical elements of museum storage and display, but also philosophical underpinnings of what and who museums were for. Museums became a vehicle of State control through education of the masses (Hooper-Greenhill 1992). The increase in uneducated visitors led to increases in security, and development of sight as the primary means of interacting with objects. Belief that the entirety of all knowledge could be delineated and understood led to exponential collection growth (Hooper-Greenhill). This eventually led to storage issues, fragmenting collections along developing disciplinary boundaries (Arnold 2006, 288-244; Larson 2009, 3, 64-65). As noted in previous chapters, theories of humanity, evolution, and hierarchies of race influenced anthropological and archaeological collections, and human remains were collected in a variety of historically ethical and unethical ways. These theories and the

\footnotetext{
${ }^{1}$ Sources disagree on the establishment date of the Anatomy Museum at Otago. The Departmental website lists its establishment at 1874 and the official history of the Medical School lists it as being established in 1881.
} 
actions they justified had a significant impact on how various cultural groups have been treated, both historically and currently.

Prior to World War II, racial theory and eugenics were openly discussed in scientific circles worldwide. In Nazi Germany these ideas were taken to the extreme with state execution of significant proportions of the population thought to be damaging elements in society. While some individuals were summarily killed, other groups were used for biomedical scientific experiments. There has been a popular tendency to dismiss all Nazi scientific experimentation, but the value of the experiments was highly variable (Jones \& Whitaker 2009, 79; Evans 2005, 319-20; Shirer 1998, 979). There is also misunderstanding between bad science and unethical science (Jones \& Whitaker). Bad science is undertaken with poor foundation in scientific theory and methodology yielding scientifically invalid results. Unethical science is where research is undertaken without consideration of ethical implications, although results may be scientifically reliable. There have been calls for all results from Nazi experimentation to be dismissed, irrespective of their scientific validity. It is argued that to use any data from experiments undertaken by Nazis is to be morally complicit in their activities, and that by using their results researchers validate Nazi experiments and actions (Jones \& Whitaker). The counter argument is that subjects died in experiments that, although undertaken in an unethical way, have provided useful data. The development of modern ethical guidelines is largely due to how these experiments were conducted and the impact on the people involved. The principles laid out in the Nuremberg Code and the Belmont Report implicitly acknowledge the value of research on human participants, and aim to ensure that there is no detriment to either individuals or society by ensuring that necessary experiments are undertaken in an ethical manner (Trials of War Criminals 1949; Belmont 1979).

\section{The objectification of human remains within museums}

All objects in museums are decontextualised from their original meanings and significance (Marshall 2005, 172-3; Bennett 1995, 33; Keene 2005, 15, 22; Knell 2003). However, acquisition recontextualises them within the rest of the collection as a member of a selected group and how it is displayed and interpreted provides more layers of meaning (D.

Cameron 1971, 11-24, 16; Hooper-Greenhill 1991, 50). The semiotic and symbolic meaning of each object can be viewed in a variety of ways (Hooper-Greenhill, 49; Peräkylä 2005, 870; Bourdieu \& Darbel 1991, 39, 45; Duhs 2010, 184; Arnold, 2006, 167). As each 
visitor brings their own perspective to bear on exhibitions this provides yet another layer of interpretation and meaning (D. Cameron 1968, 35; 1971, 16; Hooper-Greenhill, 59; Bourdieu \& Darbel, 37). Exhibitions of discrete body parts alongside other remains of the same type contextualise them as examples of a type of body part or system rather than as part of a holistic body. Exhibits are housed in display cabinets or in roped off areas, creating distance between visitors and objects. Objects are positioned in ways that provide visitors the best angles for observation. These exhibition techniques privilege the sense of sight over other senses, limiting ways that objects can be explored and understood (Candlin 2003, 101; 2006, 137).

The Trotter exhibits are laid out in body sections, compartmentalising discrete body parts. By fragmenting the body into distinct parts the Museum reflects the 'hidden curriculum' (Hooper-Greenhill, 51). The hidden curriculum refers to the largely unconscious and widely accepted symbolic elements within pedagogical frameworks. Over time depictions of the human body within medical education has changed. Historically illustrations of human remains had depicted them as whole bodies within an idealised setting, such as a landscape, but contemporary representations of human remains are devoid of context, often fragmented pieces photographed on plain backgrounds.

One purpose of museum objects is to provide tangible expressions of theoretical knowledge, but without accompanying interpretive material, objects are open to multiple interpretations and misrepresentation (Dean 1994, 1; Brooks \& Rumsey 2007, 281; Knell 2003, 138; Witcomb 2003, 146). Accompanying documentation is important for understanding objects and provides a starting point for further discussion (Case 1998, 14; Knell, 161; K.S. Thomson 2002, 3; Bourdieau \& Darbel, 36, 55). Although further discussion is important for understanding it must be tempered by expert knowledge. In general museums multiple interpretations, community development and expansion of information about objects is encouraged; however, in disciplinary museums this is not the case. The main purpose of disciplinary specific museum within tertiary education is to teach students set information and to provide physical objects to embody theoretical concepts. The multiple interpretations encouraged elsewhere are discouraged in this setting, as there are clear ways for objects to be understood, defined by the information required to pass exams and advance through the programme. 
The means of preservation and display of human remains in the Trotter and Drennan distance viewers from remains by placing them in boxes or cylinders, and for some specimens another layer of distance is applied by housing them in locked cabinets, which is inconsistent with claims that specimens are available for student use. Considerably more interpretation is provided for material in the Trotter than for those in the Drennan. The majority of specimens have code but unless individuals are familiar with these codes they provide no information. Remains in the Drennan are meant to have standardised information cards with items but this proved not to be the case during exhibition analysis. There is no other information to contextualise specimens as being from humans, or reference to specific bodily systems. Considerably more interpretation is provided for objects in the Trotter. Cards including code numbers and further information are housed alongside remains, and for a small number of objects audio material is available on request. Additional interpretation provides students with various learning opportunities.

Both the Drennan and Trotter display human remains and other objects in ways that distance viewers from objects, both intellectually and physically. This distance in relation to human remains reinforces conceptions of body-as-object, prioritising empirical knowledge about disease rather than the patient's experience of health and disease. Most students using the Museums will also be involved in conducting a full cadaver dissection. This will help them to recontextualise discrete body parts used in classes and displayed in the Museums within the whole body. There is a disconnect between the body-as-object as contextualised in the Dissecting Room and Museums and body-as-individual.

Student comments about their dissection experience demonstrate their awareness of this (Trotman 2009a; 2009b):

There was one time when I looked because they had all the photos up and there was a picture of an old guy who was just smiling and when I saw it I just almost couldn't look at it because it was then you realise that he was a real person and his family probably had that picture at home and all these people knew him and I think it was stuff that I almost hadn't thought about before. Andrew Gemmell, medical student

I'd like to say that my attitude to the body would be quite dispassionate that I would feel nothing just looking at them because they were just a body but it's hard to see a body and not think of a life so I shall see. It was something like I've never experienced before. It was kind of stressful. I found it really, really, difficult. Kathryn Foster, medical student

Initially it was quite hard to detach myself but after a while you just kind of get used to it. Stephanie Savage, medical student 


\section{Primacy of the object}

The value of using experiential forms of learning is well established, although underexplored at tertiary level (Hannan et al. 2013, 160; Chatterjee 2010, 179; Verschelde 2013, 71). Reference to original objects can validate or disprove theories, provide further avenues for exploration of curriculum content, and produce emotional experiences (Knell, 2003, 139-40; Arnold 2004,157; 2006, 167; Bud 2004, xv; Suarez \& Tsutsui 2004; Froelich 2003, 328). For students the benefit of working with genuine human remains in the dissecting room and museums is the opportunity to explore variety within normal limits of the human body and bodily structures in three dimensions. There has been a highly controversial move away from using remains in health science education (King, Whitaker \& Jones 2014). An array of alternative learning methods has been introduced internationally, including the use of prosections, medical imaging technologies, live anatomy, animal dissection, computer simulation, models, and body simulators (McLachlan \& Patten 2006, 252-53). The efficacy of traditional and developing techniques has been questioned but issues exist in assessing worth (Winkelmann 2007, 15-22; Warnick 2004; McLachlan et al. 2004, 41824; Qamar et al. 2014, 219-24).

One of the key issues in assessment of these methods is the nature of the students working with this material. Health science students are often amongst the most motivated and highly performing. If teaching methods do not fulfil their perceived learning needs they are likely to explore alternative learning methods which may skew results of research on teaching methods efficiency. Much of the research undertaken on efficacy consists of case studies in specific medical schools. As such, evaluations cannot easily be undertaken as there are few points of similarity for direct comparison. Different teaching methods do not need to be mutually exclusive and the use of a range of complementary methods will achieve the most benefits for the largest number of students. Direct access to human remains, whether through cadaveric dissection, prosections or demonstrations, is still preferred by many students (Kerby et al. 2011, 494; Biasutto et al. 2006, 187; Boys et al. 2013, 180; McClea 2008b).

Otago students and staff realise the limitations of models and textbooks in comparison to cadaveric dissection and authentic human remains in the museums. Trotman's films provide many examples of awareness of this (2009a; 2009b; 2009e): 
You cannot learn anatomy by just reading a text book, that's why we have labs, to come and do dissections. Dr Latika Samalia, Anatomy lecturer

I love anatomy. I like to know all the different body parts and what they're for and what they do. To me it would have to be really, really hands on. It's definitely a hands on subject. You can't learn it just looking at it on a piece of paper because the human body is 3D and you need to see it in 3D. Victoria Blanks, medical student

It's a lot more complex than it looks like in the textbooks. There's just things everywhere, things in three dimensions. James Slater, medical student

It seems stupid looking back but in books they have the heart and they say in those schematic diagrams the blood goes up to the lungs. Because of those diagrams I had an idea that the heart was down here and the lungs were up (demonstrating) and there it is, the heart's in the middle of the lungs. Andrew Gemmell, medical student

Books and pictures don't quite convey how much is interlinked. For example the aorta and the pulmonary trunk, pulmonary vessels, and the bronchi. They're almost like they're tangled up in the thorax. Marcus Lee, medical student

These resources have been valuable for my learning as textbooks can be limiting in comparison to seeing the real thing. Sharon Chau, physiotherapy student

Despite all the advanced technology available in this $21^{\text {st }}$ century in medicine it remains impossible for us to accurately and fully visualise the physical attributes of any body system There are a myriad of important internal structures that simply cannot be observed with the clarity needed by a student of anatomy such as me without access to the bequest resource. One of the more astounding pieces of learning for me personally has been the simple realisation that we are all as physically unique internally as we appear on the surface. Luke, physiotherapy student

Working with human remains is framed as a privilege in course materials. Student comments reflect awareness of the great privilege that was afforded to them in working with donated cadavers, one that is not universally given through health science programmes elsewhere (Trotman 2009a; Dental class 2007):

It has been amazing to work with real bodies. I know we're one of the few medical schools that still do this, and I think it's a really valuable way to learn. Cindy Grobler, medical student

Thank you. It is a privilege for us the dental students to be able to examine the human body in this way and from what I understand not available to many other students around the world. Dental Student

\section{How have these justifications changed over time?}

Justifications for using human remains have changed over time. The axiom was that if it was legal it must be ethical. This highlighted paternalistic and often Eurocentric views of medical and scientific professions. International organ retention scandals constituted a significant challenge to this attitude (Jones \& Whitaker, 2009, 50-51; Alberti 2011, 205-06; 
Jones 2011, 20; Fforde 2004, 1; Jenkins 2011, 25; Redfern et al. 2001; Palmer 2003, 81). Medical staff in these instances felt they had a right to take tissue for education and research purposes and therefore felt no need to justify their actions. Under HTAUK and HTANZ this supposed right no longer exists and informed consent is required for retention of human tissue. HTANZ stipulates that the purpose of the Act is to ensure collection or use of human tissue occurs only with

... proper recognition of, and respect for... the public good associated with collection or use of human tissue (whether for health practitioner education, the investigation of offenses, research, transplantation or other therapeutic purposes, or for other lawful purposes)

(HTANZ s3.a.iv).

This clause accomplishes two things. It acknowledges that collection and use of human tissue needs to be properly explained and conducted with respect. It also takes for granted that a valid reason for collecting and using human tissue for 'the public good' exists (s9). The assumption that collection and use of human tissue is necessary is not questioned.

\section{Consent}

Informed consent has been incorporated into a large number of the documents regulating the use of human tissue. Informed consent allows individuals to establish and maintain authority over collection and subsequent use of their tissue. HTANZ clearly states what constitutes informed consent or objection (s9). While informed consent does not obligate others to collect or use that tissue, informed objection is binding (s16-18). Informed consent is required for most tissue collection but there are some circumstances where it is not required, including 'prevention, detection, investigation, prosecution, or punishment of offences', 'protection of the health or safety of members of the public', auditing or improvement of services, or where a post-mortem is required by the coroner, High Court, or Director-General of Health (s20). Other collection or use of tissue without informed consent constitutes an offence (s22-24). Limitations exist on what can be consented to ( $\mathrm{p} 2$ s16).

Informed consent provides legal and ethical authority for students and researchers to use tissue for permitted research and education purposes. Bequests are currently the sole source for human material in New Zealand medical schools but this has not always been the case. Both here and elsewhere unclaimed bodies have been widely used for research and teaching (Blakely \& Harrington 1997, 168; Jones 2016a, 2; 2016b, 48; 2011, 18; Jones \& 
Whitaker, 2009, 23; Riederer 2016, 11-12; Hildebrandt 2016, 38; Wilkinson 2014, 286; 2006, 235; Quigley 2001, 4; Alberti, 2011, 101). The Anatomy Department at Otago University accepted its first bequest in 1943, having previously used unclaimed bodies. They receive hundreds of enquiries annually regarding body donation, and of these enquiries approximately $75 \%$ complete bequest documentation. In the period 1876-2008 over 2700 cadavers had been received by the Department, and at the end of that period there were over 1800 donors who had registered their bequest. The Department accepts approximately 40 cadavers annually, using $90 \%$ for teaching and $10 \%$ for staff and postgraduate research (McClea 2008b, 72-75). Occasionally the Department cannot accept bequests because they have reached their annual capacity. After the dissected bodies are cremated their ashes are scattered in publicly accessible gardens in Dunedin and Christchurch.

Human remains in collections are often anonymised, whether unintentionally or deliberately (Jones \& Galvin 2002; Jones, Gear \& Galvin 2003, 344). The Drennan's proforma sheet of standardised information removes patients' names although the WHO number is retained. The remains in the Trotter have accompanying information about structure and form but no identifying information about the source individual except in exceptional circumstances, such as those of Ah Lee, a convicted murderer. Students at Otago expressed the desire to have further personal information about their cadaver in order to humanise them (Trotman 2009a):

I'd like to know a bit about their history and what they'd done with their life. Whether they had a family, things like that. Edward Stace, medical student

I'd be interested to know what kind of life they had beforehand cause I don't know if they had kids or family, things like that. That would be the most interesting part. I'd be thinking about what their life was like. Andrew Gemmell, medical student

Anonymising human remains complies with the IFAA Recommendations (2012). However, the advisability of anonymisation, human remains as objects, and the impact and importance of clinical detachment are all becoming issues for debate (Jones, 2016a, 49; Hildebrandt, 2016, 41; Hildebrandt 2014; Jones, 2011, 19). The specimens in the Drennan can technically be identified through their WHO number, but anonymity for dissection cadavers, and any body part preserved in the Trotter, has traditionally been maintained. Donated to Science received specific permission from donors to follow their bodies from before their death through to the conclusion of their dissection (Trotman 2009b). At the 
completion of the dissection process students were shown interviews with the donor of their cadaver. This removal of anonymity is in keeping with the IFAA guidelines which state that any exceptions to anonymity 'should be formally agreed to beforehand by the bequestee and, if appropriate, the family' (IFAA, 2012, clause 5). The students' comments are revealing about the emotional impact of depersonalisation for dissection (Trotman 2009d):

It feels good that there is a name and there is a face. It feels like combining these two years working on the body, and now I combine the human side of the person I was working on. So now I can say I feel I truly got to know this person. Now it's so good to have a name so that now I can remember George, this person that I had been dissecting on. I can remember him in my prayers. To what he said in the interview about what he hopes to achieve by donating his body so that we'll benefit and learn, so that in the future when we are out there to see other patients, then we'll benefit them. I really want to tell him that this purpose, what he wants to do, will be achieved. Alfred Kwan, medical student

I thought I was going to be just an emotional wreck but it turned out to be completely different. He was just such a sweetheart. He was just such an honest down to earth guy, and it was so far removed from the body in the dissection room that it was not... they weren't even connected. There was this surreal disconnection. It was that guy, the person, and the body, and they were completely distinct... I've done the dissection, and all the way through the dissection I've felt uncomfortable, until now. Until I've watched this man who's given his body to us, and if I'd have seen it at the start it would have been completely different. I wouldn't have been afraid. I wouldn't have felt like I was desecrating the man, because it's what the man wanted. And I heard him say that, and I heard what sort of a man he was. Gareth Keat, medical student

Other considerations exist with anonymised remains. There are arguments that all identifiable remains should be returned. This specifically relates to indigenous remains. These arguments do not take into account donated remains which are identifiable but willingly given. There have been arguments that anonymous tissue can be ethically used for research (Jones \& Galvin 2002, 3). However, it is also argued that all remains without consent should be disposed of. As it would not be possible to ascertain whether anonymised remains had given consent they would need to be disposed of. This would lead to a significant loss of resources and information and highlights significant ethical questions. If the remains cannot be identified, who is being harmed by their continued use, or by their disposal and/or destruction? Is it ethically responsible to use remains that were obtained without consent? If the argument that consent must be obtained is to protect the interests of family, is it ethically responsible for departments to dispose of remains where no harm is being done to descendants, as there are no known descendants who can be 
harmed? The position taken by institutions will be unique to their individual circumstances and environment.

\section{What is the legal position regarding ownership of human remains?}

In New Zealand the 'no property' rule applies and hence human remains cannot be owned. However, exceptions to this rule place human remains in an ambiguous position as quasiproperty where they are viewed as both property and non-property. There is debate over whether full property or quasi-property status is appropriate for the human body (Andrews 1986, 36; Mason \& Laurie 2001, 723; Palmer 2003, 241; Sharp 2000, 292, 298). There are arguments that commodification and commercialization would provide individual and societal benefits. Allowing individuals the ability to sell renewable parts of their body, such as blood or bone marrow, would provide income for donors, while providing a stable market for organ transplants. The danger with this is exploitation, whether as sources of raw materials, or transfer of property rights resulting in slavery. These dangers may be mitigated if contemporary property rights are extended to human bodies, specifically the inalienable aspect of some forms of property. Another argument against body commodification is the nature of altruism and its impact on society (Cambell 2009, 20-23). Commercialisation of blood, tissue, organs and bodies is thought to undermine altruistic giving of this material to non-related recipients. This affects wider issues of generosity and care for other community members, as well as increasing the dominance of the market paradigm within society.

Despite arguments claiming protection for individuals, historical examples of markets for human tissue have demonstrated how easily any system can be abused. Slavery and graverobbing were lucrative business ventures providing human material. Human remains were openly sold from India until 1985, when it became illegal. The United Nations is actively working to end trafficking of persons and any changes to the legal status of human tissue as a commodity for exchange would complicate this (UN 2010). HTANZ makes it an offence to trade in human tissue, although there are certain exemptions to this which cover tissue for certain research, hair taken to make wigs from living individuals, and tissue that is part of a controlled drug or medicine (s56).

The property status of human remains affects museum collections and repatriation. If museums accept that they cannot own remains, instead holding them as guardians, then 
claims for repatriation from more suitable guardians must be considered differently than if museums owned the remains. In the UK prior to the implementation of HTAUK, objections to repatriation were often based on legislation prohibiting deaccession (Jenkins 2011, 9-10). If human remains could not be owned, they could not be accessioned, and hence these objections to deaccession would not apply.

\section{Definitions of normality and pathology}

It is important to consider what types of remains are collected and why. Historically human remains in the Otago University collections were obtained for a single collection. With the establishment of the Pathology Department remains in the collection were divided between the Anatomy and Pathology Museums (Neuman 1993, 18). The Trotter largely contains specimens of normal human anatomy, and variations within this. The Drennan contains specimens of pathological tissue. In general, more pathological than normal specimens are collected for health science collections. This is because there is a range of pathological conditions and for each condition there is as much variation as there is for healthy anatomical specimens. This variety in pathological specimens is important for medical personnel to see. As Hallam \& Alberti $(2013,6)$ have reported:

What were identified as pathological specimens were used to show students and clinicians rare diseases that they would not otherwise encounter in living patients or dissections. This use of medical collections - for vivid and tangible demonstration of what could go wrong with the body, as well as what a healthy body should look like - was a key function.

Definitions of what constitutes normality and pathology affect what specimens are collected, although understandings of "normality" and "pathology" have changed over time and different theories have taken prominence in different periods. Definitions have ramifications for the treatment of individuals and their livelihoods as sickness and disability benefits are based on medicalised definitions of impairment (Beatson 2000, 49-50). Utilising the male body as the standard has had implications for conceptions of the female body. In some contexts all female anatomy has been considered pathological. This has significant implications for medical treatment of women, reproductive health, and embryology (Hallam \& Alberti 2013, 7; Alberti 2011, 133-36; Jenkins 2011, 116; Bennett 1995, 46; Blakely \& Harrington 1997, 178). The practice of medicine and medical education do not exist in a vacuum but is entangled in social practices of gender, race and ableism, and changing ideas must be reflected in the classroom and museum (Hallam \& 
Alberti, 7; Jenkins, 116). An understanding that 'normality' and 'pathology' are abstract concepts challenges static interpretations of data. This leads to greater questioning of the foundations underpinning health, disease and treatment of the community.

\section{Gratitude of those involved with human remains}

Opposition to objectification of human remains in museums is countered by the use of remains acquired through informed consent. Where informed consent can be demonstrated, the objectification of human remains is mitigated and the rights of individuals respected. If informed consent is the legal expression of respect and bodily autonomy, then how people treat remains is the personal expression of respect.

HTANZ states that anatomical examinations of human remains must be performed in association with a School of Anatomy in 'an orderly, quiet, and decent manner', avoiding 'unnecessary mutilation' (s52-53). The guidelines for working with human material provided by the Otago Anatomy Department, discussed above (Chapters 2 \& 3) reinforce this. While these guidelines and rules could be interpreted as being imposed on students in order for them to develop accepted professional standards and not a true reflection of students' thoughts and behaviour, comments made by students contradict this view (Trotman 2009a; 2009e; Dental class). The Thanksgiving Services are organised by the Anatomy Department with student involvement, including musical performances, readings, and meeting with families of donors. Students are aware of the privilege of working with cadaveric material, as noted above, and are thankful to donors for bequesting their body (Trotman 2009a).

Someone when they were alive thought about being dissected and let students cut them up, and still decided to do it, must make you see a bigger picture, something deeper in it. I think it's pretty special to donate your body to science. Cindy Grobler, medical student

To the donor I just say a huge thank you. Edward Stace, medical student

Through the Thanksgiving Service, which involves interaction with friends and family of donors, the Anatomy Department actively recontextualises human remains as individuals for their students. The ethical dimensions of the policy of anonymity for human remains is being questioned, and there is growing awareness that the emotional impact of working with cadavers needs to be addressed (Jones 2016a, 49). 
The use of human remains has been rationalised and defended, but there has been little exploration of why remains are needed. Within the early development of museums the importance of real objects was emphasised and the importance of authenticity has continued. It is within this context that human remains have been contextualised as objects. Justifications for framing remains this way have changed over time but little examination has been undertaken regarding the foundations of these perspectives within museums, with the exception of how indigenous remains were framed as 'Other'.

Research into the efficacy of human remains in health science education is inconclusive and further consideration of effective teaching methods is required. The use of remains is sustained as it is the traditional, proven method and is shown to be more effective and preferred by students in some studies. Fundamental assumptions about the necessity of human remains, and assessment of teaching methods need more exploration and research to ensure their rationalisations are justified.

The next chapter will consider how Otago University uses and justifies use of human remains in their Anatomy and Pathology Collections and if any wider conclusions can be drawn about whether or not there are justifiable reasons for museums to acquire and hold collections of human remains. 


\section{Chapter 5: Tertiary Museums and Health Science Education}

Codes of ethics and practice have been developed and implemented by many professional and institutional bodies. The way codes address concerns surrounding human remains is dependent on the focus of the organisation they were written to serve. Where two or more professional guidelines exist within the same context the possibility exists for conflict over which perspective is dominant, so it is important to view these guidelines in context.

Tertiary health science museums are an example of this type of conflicting situation as they must adhere to the professional norms of bioscientific professions and those of the museum community. For the scientific community the focus is mainly on advancement of knowledge and therapies through the use of existing collections of human remains, and those acquired through bequest programmes. Meanwhile the museum sector focuses largely on indigenous remains and repatriation. For staff working in health science museums this causes tension between scientific advancement and museum ethical codes which may not be pertinent to the material in their collections. Without clear guidance on how to treat these kinds of remains museum ethical codes are of little relevance to the daily practice of these museums.

A discussion of human remains in tertiary health science collections cannot be separated from wider consideration of tertiary museums within their institution, and broader tertiary education trends. If tertiary museums are not judged to be valuable for teaching or research, then holding collections is not warranted. Where these collections contain human remains then their continued presence in collections cannot be justified. However, if museum collections are accepted as significant resources there may be acceptable reasons for holding remains.

This chapter will explore the issues raised in this thesis with specific reference to the Drennan Pathology Museum and the W.D. Trotter Anatomy Museum, Otago University. The Drennan and Trotter provide specific case studies for testing the conclusions drawn in this thesis and allow examination of how matters play out in practice. Only by understanding the wider contexts and exploring issues within more specific circumstances is it possible to address the thesis question of whether using human remains in tertiary health science museums can be justified. To do so it will consider the differences between tertiary museums and the wider museum sector and how object primacy fits into 
pedagogical frameworks within tertiary education. It will explore the history of museums in higher education, Otago University and the tertiary sector in New Zealand, and will analyse how Otago's use of human remains fits into established codes.

$* * * * *$

\section{History of museums in higher education}

The role of museums in higher education has evolved as attitudes and theories about knowledge have changed. The close alignment between research and teaching means that contemporary universities are the location for knowledge creation, discovery and dissemination, but this has not always been the case (Conn 1998, 15-18; Arnold 2006, 177). During the Victorian period museums were the primary sites of original research through their use and interpretation of objects, which was then disseminated through exhibits and highly popular public lectures. Universities were largely viewed as places for teaching rather than research. Museum collections grew exponentially during this period, eventually requiring fragmentation for storage and intellectual and physical accessibility. Academic disciplinary boundaries were delineated by the specialisation created by this fragmentation (Arnold, 238-9). Although research continued in museums, their former prominence decreased as the emphasis on object-led research diminished. This rise of universities in intellectual leadership led to a change not only in the kind of research undertaken, but also in who could access it as knowledge was limited to those who could attend university, rather than the general public (Conn, 17-18).

Museum objects were critical to the study of medicine (Alberti 2011, 65). Historically specimens entered museum collections through on-site dissection or complicated networks of gift exchange and purchase. As medical education became more regulated, private medical schools closed and their collections became amalgamated into a smaller number of larger collections. Prominent collectors gifted or sold their collections to larger medical schools. The proliferation of private medical schools in the UK was not paralleled in New Zealand.

Otago University's health science museum collection was founded shortly after the establishment of the Medical School by Professor John Halliday Scott. Initially the collection incorporated healthy and morbid specimens but these were eventually separated 
into two collections of anatomy and pathology which became the Trotter and Drennan. The history of the two museums is intimately linked to the early professors of anatomy at the University, who had close ties with Otago Museum (Hudson \& Legget 2000, 23; K.W. Thomson 1981, 82; F. Cameron 2014, 211-12). Early professors and technicians dissected and preserved large numbers of specimens for inclusion in the collections. Although working with the collection, these staff were not employed primarily to deal with the Museum. Alfred Jefferson was employed as the dissecting room porter and he worked closely with Scott to prepare specimens, plaster casts and models for the Museum (Neuman 1993, 18). During the 1930s and 1940s Professor William Gowland employed medical graduates to assist with research and as demonstrators in classes. Their work often resulted in the creation of wet specimens and models for the Museum. Rising student numbers after World War I led to the construction of the Lindo Ferguson Building, which included a purpose-built Anatomy Museum. Displays were housed in large glass cabinets and the mezzanine floor was closed to students. Specimens were often used in classes but the Museum itself was not used for teaching.

It was a Museum in the old-fashioned sense of the word - quiet, still and impressive - and stayed that way right up to the 1970s (Neuman, 20).

During Gowland's tenure as Professor of Anatomy, classes were widened to include physical education and dental students. In 1969 William Trotter became Professor of Anatomy. Trotter made major changes to the way in which the Anatomy Museum was configured and used. He instigated the use of the Museum as a teaching space, incorporating a number of tutorial rooms into the Museum. He also removed the majority of the locked exhibition cases, allowing student access to objects. Professor Gareth Jones became Head of the Department of Anatomy in 1983 and actively encouraged the use of the Museum as 'a classroom and resource centre' (Neuman, 20). In 1986 Fieke Neuman was employed to care for the physical state of the Anatomy collection. This role quickly expanded and Neuman became the Museum's first curator. Neuman held a BSc (Anatomy) and was working towards a Diploma in Museum Studies, highlighting the importance of both disciplinary and museum specific knowledge. Since that time the Trotter has continued to be used by students. The Museum is included in the MA Museums and Galleries guide, and the current curator, Chris Smith, continues to have ongoing connections with New Zealand's professional museum organisation. 
Many Medical Schools in Australia and England lost their old-style Museums when they restructured but are now, several years later, regretting the resources that they lost. This Anatomy Museum is still in existence because it did not remain a static display of curiosities and instead adapted to the changing needs of students. Some of the changes yet to come may seem difficult but looking back over the past, will probably be no worse than those that led to the development of the Museum in the first place (Neuman, 22).

\section{Differences between tertiary museums and the wider museum sector}

Museums in tertiary education institutions often reflect older, historical forms when compared to museums in the wider sector. This is due to a number of factors primarily revolving around audience, funding and mission. Museums in the wider sector have evolved in response to calls for greater audience and community engagement, pressure to entertain as well as educate, and to provide a civic space for the community. Civil rights and social justice movements have affected how museums have engaged with the community, resulting in reassessment of the purpose and mission of museums in society. Funding pressures have caused further reassessment of museums' role. The necessity of attracting audiences and sponsors has affected museum business development and management. Museums in tertiary education institutions have faced some of these issues but they have been mitigated by inclusion in a larger institution. Due to the pedagogical nature of tertiary museums they have a clearly defined audience of staff and students who are already engaged with the subject matter. This allows them to provide more sophisticated disciplinary-specific interpretation for exhibits as opposed to museums in the wider sector which must aim interpretation at a level that can be understood and entertain large numbers of people from a range of educational backgrounds and levels. Tertiary museums provide scope for greater educational engagement and achievement through embedding exhibitions within course related goals and interpretation integrated with high levels of scholarship from researchers in the field. Audience development is linked explicitly to increased student numbers of involved academic departments. This is a matter of recruitment for the department and wider institution rather than the museum. Museums may be used for institutional promotion, enticing students with privileged access to collections. Funding pressures for tertiary museums are different from those in the wider sector. Tertiary museums are not subject to the vagaries of sponsorship or attracting wider audiences, but there is greater pressure to demonstrate their educational worth within the established curriculum and research potential to ensure ongoing institutional funding. 
Despite the divergence of forms between tertiary museums and the wider sector, tertiary museums are still easily recognisable as museums. Debates exist regarding the necessity for museums to hold collections but they are still one of the key aspects within the ICOM definition of "museum" and widely recognised as significant (ICOM 1996). If the collections maintain their status as core elements within museums and important primary source material, then changing methods of interpretation and display are irrelevant to the definition of an institution as a "museum." The Trotter and Drennan have both been updated and changed form over their lifespan, and irrespective of their current state or rate of use they can both still be understood as museums. These types of tertiary museums may appear anachronistic and out of synch with developments in the wider sector, but their continued use, and the resurgence of interest in the educational value of tertiary museums provides evidence of their persisting relevance within developing educational pedagogies.

Museum collections of human remains were shaped by the development of specialisations within medicine. Pathology emerged as a discipline well after Anatomy although pathological specimens had long been included in anatomical collections. Scott recognised the importance of Pathology, including it in the list of required subjects for the expansion of the Medical School in 1881, and Dr William Roberts was appointed as lecturer of Pathology at Otago in 1885 (Stewart 1994, 1-2; Page 2008, 31). ${ }^{1}$ By 1899 Pathology was so entrenched within the medical programme that Scott, now Dean of the Medical School, claimed that 'Pathology is the foundation of medicine' (Stewart, 4) This reflects the position that what is normal can only be understood in comparison to the abnormal. Specimens for the Pathology Museum were collected from 1886 to the 1980s, when acquisition was suspended due to ethical concerns. The Drennan resumed collecting in 2013.

\section{Object primacy in tertiary education}

How does object primacy fit into the pedagogical frameworks of universities, in both teaching and research? Many universities have museums and hold collections. However, the importance of collections to teaching, research and the larger institution are variable

\footnotetext{
${ }^{1}$ The subjects required for the development of a full medical course at Otago included three already taught: anatomy and physiology; chemistry; and surgery. The four new subjects were the practice of medicine, including insanity; midwifery and the diseases of women and children; medical jurisprudence and public health; and materia medica and dispensing.
} 
(OECD 2001, 2, 7; Stanbury 2000, 4-9; Committee of Ministers 2005). The shift towards universities as the seat of scholarship caused a crisis for museums, resulting in a significant shift in focus (Harrison 2005, 39; Keene 2005, 5; Conn 1998, 17-19; Stanbury, 5). Informal learning was prioritised, with formal learning opportunities largely limited to primary and secondary school sessions (Moreland et al. 2006; Deaker 2006; Anderson et al. 2006; Falk \& Dierking 1997; Falk 1999, 259; Winstanley 2013, 126; Newman 2005; Hannan et al. 2013, 166).

Changes in the curriculum and school management forced museums to provide specific curriculum-focused content rather than concentrating on collection strengths (Moreland et al.; Deaker). In the wider museum sector community engagement became a greater focus than collection-based research as museums fought to justify funding. Museums began to be treated as civic spaces for community use rather than places of scholarship for the elite (Matthews 1991, 5; Hatton 2012, 135; O'Neill 1999, 22-23). Although the educational and research nature of the wider institution buffered tertiary museums from these pressures, other issues unique to tertiary museums arose.

Most, but not all, tertiary museums have been developed for use in teaching and research. The range of collections includes those created from objects involved in significant research, remnants of academic careers, and accumulation of objects that departments are reluctant to discard despite having no use for them (Were 210, 296-7). Some of these collections are under-utilised and unknown outside their host department, resulting in little or no access (Kelly 2001, 11; Hudson \& Legget 2000, 22). Changing research and teaching interests have also affected collections' relevance within their host department (Kelly, $7 \&$ 11; Mack 2001, 30; Stanbury 2001, 70). Tertiary museums need to embed themselves within the teaching and research programmes of a number of departments for their importance to be widely recognised. Fostering interdisciplinary and cross-departmental research and teaching based on collections balances out reliance on individual departments, and cements the museum within the institution's core business (Baines 2015, 7; Soubiran 2010, 1; Yerbury 2001, 66; Weeks 2000, 12; Willumson 2000, 18; de Clercq 2001, 89; Cassman et al. 2007, 22). Some researchers are aware of the importance of the collections they develop through research and are exploring museum studies literature for guidance on best practice (Turner 2014). Collections have a symbiotic relationship with researchers. They provide avenues for new areas of research and the means to explore new ideas, which 
in turn provides new objects for collections (Soubiran 2010, 25). OBL pedagogies provide an avenue for the continued use of tertiary museum collections. OBL is closely linked to experiential and active learning, which have proven their efficacy in other educational contexts, but it is still viewed as niche activity at tertiary level (Hannan et al. 2013; Hudson \& Legget, 25). OBL provides students with different ways to engage with course content and explore theoretical concepts, building on their previous experience (Duhs 2010, 184; Manfredi \& Reynolds 2013, 139; Hannan et al. 161).

One of the most significant challenges tertiary museums face, alongside continued recognition, relates to staffing. Isolation is a well recognised issue for museum staff working with tertiary collections. Staff exist in limbo between academia and the museum sector, not quite belonging to either group (Stanbury 2000, 6-7; 2001, $70 \&$ 73; Weeks 2000, 10; Kelly 2001, 13; Mack 2001, 33-34; Yerbury 2001, 58; Willumson 2000, 15-16; Hudson \& Legget 2000, 21). Professional training is often overlooked by employers, leading to a disconnect between professional standards in tertiary museums and those of the wider museum sector, and cooperation between tertiary museum curators, within and between institutions is stifled by interdepartmental barriers caused by institutional politics (de Clercq 2001, 93; Weeks, 10). Few tertiary museums employ professional museum staff and responsibility for collections often falls to academic staff. These staff must incorporate it within their wider responsibilities, and its value can be overlooked when they apply for promotion. In institutions where knowledge is a consumable product power is held by those who control access to knowledge (Speight et al. 16; Were 2010, 292). There is the possibility of conflict between academics and museum professionals over who has the right to decide what information can be disseminated and the best way for it to be displayed and explained.

The Trotter and Drennan take different approaches to exhibiting their collections. This is largely tied to their use for teaching purposes. The Drennan is much smaller than the Trotter and it is difficult for many students to use the space at one time. The Trotter is much larger, and during the exhibition analysis period was in constant use. Students were easily able to access collection objects for independent study. The Drennan has no professional staff for interpretation and presentation of exhibits. The part-time staff member employed to work with the collection is responsible for the technical preservation of specimens rather than their display and presentation. The Trotter is staffed by two full- 
time employees and is laid out in accordance with teaching objectives. Interpretation in each museum relies heavily on the needs of its host academic department. As such the arrangement and use of museum objects is dictated by teaching needs of classes and tutorials held in the museum space, or utilising museum collections off-site.

\section{Medical humanities}

The emergence of medical humanities has brought social science and humanities collections into use in medical courses, but little research has been undertaken on the importance or use of existing life science collections (Gaunt 2016; Humanities website; Corpus; Trotter website). Medical humanities have used existing collections to help medical students develop transferable skills and enhance patient care. A joint study at University College London (UCL) between UCL Hospitals Arts and UCL Museums and Collections examined the benefits of object engagement in patient care. There were three key outcomes: advanced communication skills for students, improved student-patient relationships, and increased patient mental/intellectual health (Chatterjee, Vreeland \& Noble 2009, 164; Chatterjee 2008, 5; Noble 2010, 203). Students and researchers introduced handling sessions with museum objects from UCL collections as part of a Special Study Module for first and second year medical students. Qualitative analysis of patient self assessment showed positive impact on the patients' state of mind and gave an opportunity for medical students to develop communication skills outside of normal clinical practice. Research at Yale demonstrated the benefit of art observation in enhancing general observational skills (Friedlaender 2013, 156). Students from Yale Medical School undertook observational sessions at the Yale Center for British Art to enhance their visual literacy. Students were shown an unfamiliar artwork and instructed to conduct an inventory of the painting, followed by analysis of the contents. They were then asked to suggest a differential diagnosis for a series of patient photographs. In the two years of the research project students who undertook the observational sessions in the gallery showed substantially higher results for observational diagnostic tests than control groups. These are two in a range of initiatives are being undertaken in medical humanities. The Otago Medical Humanities programme has been running for over 20 years (Humanities website).

Much of the research undertaken on medical students and museum collections has focused on the use of humanities and social science collections rather than health science 
collections, and the impact of using remains within tertiary education has focused on archaeological human remains used by biological anthropology students and dissection for medical students. Although implicit in discussions of health science collections and dissection, only Curtis-Richardson $(1997,364)$, Corradini \& Bukowski $(2012,121)$ and McClea (2008a) have made explicit the link between dissection and contemporary acquisition of remains for health science museums. McClea's comments are particularly pertinent as she works within the Otago Anatomy Department as the Bequest Administrator, directly linking the Otago bequest programme and the acquisition of human remains for the Trotter. The Anatomy Department Code of Conduct (2015) states that it is 'as relevant in the Museum as in any of the other teaching spaces' and that students are to conduct themselves in a 'dignified and respectful manner' in the Museum. This is reinforced by Course Outlines. Medical students are also explicitly told that the Code of Conduct applies in other contexts, including the Drennan (Anderson 2015). This is reinforced through attitudes of staff. During exhibition analysis staff were observed telling students that the Code of Conduct applied in the Museum.

There is a significant lack of literature on the ethics of using human remains in contemporary health science museums. However, the importance placed on ethical use of remains and the issues associated with their continued use in the Otago health science museums can be extrapolated from documentation and literature on dissection and more general health science education. The Trotter is deeply embedded within the Anatomy Department's teaching practice and, as McClea (2008a) has stated, dissection is the avenue through which contemporary acquisitions enter the Museum. Hence it is pertinent to explore dissection more fully, both for its own sake and as a vehicle of museum acquisition. The interviews referred to below relate primarily to the use of bequeathed bodies for dissection, but relate equally to students' experiences with human remains in the health science museums. Body donors are aware that parts of their body may be retained indefinitely within the museum collection.

\section{Emotional response in health science education}

As noted in the previous chapter, dissection in medical education is declining (King, Whitaker \& Jones 2014, 373; Trotman 2009b; Riederer 2016, 12; Kerby et al. 2011, 489). Documentation given to students at Otago University highlights the rarity of students 
handling human cadaveric material and frames it as a privilege (Anatomy 2015; Course Outlines). Staff at Otago emphasise how important working with real human bodies is for learning. Students at Otago and in wider research recognise the value in utilising human remains for education (Trotman 2009b; Biasutto et al. 2006, 187; Fruhstorfer et al. 2011, 249). Alongside full body dissection Otago students have access to significant collections of preserved remains in the museum collections. This allows them the opportunity to undertake independent study and to examine the variation of structures and rare specimens that they would not normally be able to see within their normal dissection classes. As interviews illustrate (Trotman 2009b), staff recognise the emotional impact working with human remains can have on students and themselves:

On the first day when the students come in, it's just the environment, the smells here, and then the body bags, they are very daunting for them. Dr Latika Samalia, Anatomy lecturer

I remember feeling extremely nervous the first time I went into a dissecting room. I remember feeling horrified the first time I saw an incision on a cadaver. Professor Mark Stringer, Anatomy lecturer

Inevitably when you start dissecting the human body you are constantly thinking about the person, what the person might have been like, what they might have done, what life they might have lived, and how they might have died. So these sort of thoughts are very real. Dr Phil Peplow, Anatomy lecturer

It was the most stressful, most traumatic I would say, experience. I still remember after thirty odd years, I still remember the cadaver, how it felt, how it smelt, everything stuck in my mind. I have to be frank, if someone at that point had given me a choice, do you want to go to med school or do something else, become an accountant, I would have said yes, I'll be an accountant if you get me out of here. Dr George Dias, Anatomy lecturer

It's just become part of my life. I have probably become a little desensitized but every year there are one or two cadavers which sort of shake you a bit. If you see specially manicured nails and something that strikes you about a dead body, it does affect you. That day becomes a bit depressing and sad. Dr Latika Samalia, Anatomy lecturer

I remember when my father died, coming back into the dissection room, having to immediately start teaching when there were bodies that were similar to the one I'd not long ago seen, before he was cremated. So I think it's not always the initial time going into the dissecting room. It's when there are other things that have happened in your life that bring death back to you. Professor Helen Nicholson, Dean of the School of Medical Sciences

For students, accepting death and mortality is an important aspect of working with human remains in the dissecting room and museums. Many students would not have previously seen a dead body and need to mentally and emotionally prepare themselves to address these issues. Working with remains allows them to face death without the emotional attachments associated with the death of someone they know or with a patient (Riederer 2016, 15-16; 
McLachlan et al. 2004, 420). At times when dissection classes are too challenging students are able to take advantage of remains in the museums for these purposes. Although these may be confronting, the distance provided by normal museum display techniques allows students to approach the remains in a different way than in the dissecting room. This inherent distance between museum object and viewer is often seen as a disadvantage and barrier to access in the wider museum sector but in the case of human remains it may provide an essential buffer to help develop clinical distance and emotional safety. Again, interviews (Trotter 2009b) illustrate the point:

As a teenager I had an obsession with my own mortality and I had quite a strong fear of death and I think dealing with dead bodies and human dissection will allow me to cross a bridge which I need to.

It's a pretty harrowing experience you know, cause I've never seen a dead body before and ... you feel like you're invading someone's privacy by looking at their body. Gareth Keat, medical student

I've never seen a dead body before and to have all these people who are dead who could be someone's mum or dad or brother or sister could be a bit full on. Elinor Millar, medical student

Looking at the body for the first time was kind of, a little bit shocking. Heather Mitcheson, medical student

It was something like I've never experienced before - it was kind of stressful. I found it really, really, difficult. Kathryn Foster, medical student

An eighteenth century construct, clinical detachment is the distancing of medical personnel from their patient in order to dispassionately diagnose and treat them (Jones \& Whitaker 2009, 5; Jenkins 2011, 111; Corradini \& Bukowski 2012, 120; Cherryson 2010, 144; Walter 2004, 464; Riederer, 2016, 15; Curlin 2011). It was commonly understood to be a latent skill developed through dissection (Capozzoli 1997, 327; Warnick 2004, 350). As a concept it has been criticised for dismissing the patients' experience and separating medical personnel from the 'lived experience of their own body' (Walter, 464; Hildebrandt 2016, 41; Jenkins, 113-14; Jones \& Whitaker, 40). The interviews again demonstrate this (Trotman 2009a; 2009b)

I'm scared that by doing these dissections it's going to make me, umm, more of a cold person, you know. That it's going to make me think that seeing a dead person is no big deal, when I know that it definitely is.

I just wanted to leave the room - it just felt like stepping over every boundary there possibly was - it was just very, very, disturbing. Victoria Blanks, medical student 
One thing that I realised was how easy it was to start seeing the body as a tool of learning rather than a person, and so after two or three times of dissecting classes I had to remind myself that this was a live person. Alfred Kwan, medical student

In the beginning ... I kind of persistently thought about what happened, and I had to go and look at all the people, and what they died of. You'd have thoughts about their family and eventually, eventually, it just becomes easier to work with it, to accept that they've given their body, and they wanted this to happen, instead of just going ... as every lab came, it just got easier to distance yourself. Got easier to learn about the anatomy, instead of every time going there thinking about how did this person die, and so I think it's something that happens passively really. Cindy Grobler, medical student

Clearly there's a practical element to the dissection but I think that there's a huge emotional element to dissection that is very hard to quantify and put your finger on. It's to do with dealing with the dead human body, coming to terms with what a privilege it is to do that and I think our students do that well on the whole. Professor Mark Stringer, Anatomy Lecturer

Criticism of clinical detachment has sparked moves to balance clinical detachment with empathy to ensure well being of medical personnel, patients, and donors (Jones 2011, 19; Hildebrandt 2016, 40-43; 2014, 834; Walter 2004, 464).

Daring to admit ones feelings does not make us "sentimental" but empathetic and worthy of living with other human beings. The balance between clinical detachment and empathy is the ultimate goal of ethical learning in the dissection room.... It is our duty as anatomical educators to help our students not only become familiar with the structure of the human body but also with the emotional repertoire available to us when dealing with the living and the dead. And it is our duty to accompany our students through the dissection course experience in a manner that keeps them safe from emotional harm (Hildebrandt, 2014, 834).

Strategies have been implemented in the Otago Anatomy Department to mediate students' emotional response to dead bodies and to working with real human remains in the dissecting room and museums. These include a whakawātea, viewing donor interviews from Donated to Science, and a thanksgiving service (Martyn et al. 2013, 43-53; Trotman 2009b; 2009e; 2009g; Hildebrandt, 2016, 40\&42). The whakawātea is a Māori ceremony conducted in the dissecting room by kaumātua. Bodies to be used in the upcoming year are laid out, water is blessed and then sprinkled on the bodies as karakia are recited. The ceremony ends with waiata and the ceremonial washing of hands to clear tapu (Martyn et al.) The ceremony is a cultural rather than religious ceremony that addresses a number of needs for incoming students. The whakawātea recognises the importance of Māori cultural elements in New Zealand society, and lifts tapu for Māori students. It also fits within Otago University's Māori Strategic Framework (2006) which aims to give 'meaningful effect' to the University's Treaty obligations by normalising Māori culture within the 
university setting. Attendance at the whakawātea is voluntary but a very high proportion of students attend. ${ }^{2}$ Non-Māori students provided a range of reasons for participating, including personal spiritual reasons, paying respect and thanking donors, getting used to the dissection space without the pressure of dissection and interest in the ceremony itself. As Martyn et al. (p.47) have reported in anonymous comments from students, this ceremony, and similar culturally appropriate ceremonies overseas, have proven beneficial for students starting dissection courses:

The clearing of the way meant to me that it was ok to be in the dissecting room and that it was all right to be dealing with the bodies, and it gave me a sense of peace about the whole thing, even though I still felt really awkward about it all.

It was very, very helpful. It was just... it was just really nice to... to kind of pay my respects to the dead people that were there in a way.

I think it was quite a good thing, even though it had nothing to do with my culture because I didn't grow up in New Zealand. It was a good way to get close to the bodies without the pressure of actually having to do anything, just observing and just getting used to the smell and getting used to the human being lying in front of you and not actually having to put a knife to it yet.

Incoming students view Donated to Science (Trotman 2009b) prior to starting their own dissection sessions (Flack \& Nicholson 2016, 7). The documentary contextualises and normalises students' emotional responses as they progress through their dissection experience. It has been very successful in helping Otago students face the realities of medical school, and it has been used in overseas medical schools. It has also prompted other medical schools to produce documentaries for use within their own cultural context (Hildebrandt 2016, 42). Further comments from students and staff illustrate reactions (Trotman 2009a; 2009b):

It is quite normal to feel sick. It is quite normal to feel sad. It is quite normal to feel unwell. Dr Latika Samalia, Anatomy lecturer

Looking at the body for the first time was kind of a little bit shocking because you weren't expecting his eyes to be open or his facial expression to be like he was in pain or anything like that. You kind of, I guess which is a bit naive, to think that they look like the person asleep, which was completely not true at all. They looked very unhealthy. Heather Mitcheson, medical student

I can't wait to get into the dissection room. I'm not too anxious about it but I guess there must be loads of emotions that you really don't anticipate. It's not something you can really prepare yourself for. Cindy Grobler, medical student

\footnotetext{
${ }^{2}$ In $201189 \%$ of students participated in the ceremony.
} 
Occasionally we have students in the first week who decide they do not want to do medicine anymore because of the stress they go through in the first week. Dr Latika Samalia, Anatomy lecturer

I hope it doesn't upset in any way. For me, I'm quite calm about the whole thing. It's a body. They can treat it with respect, which I have no doubt they will do. Apart from that, they just use it the best way they can. It's there to be used and I hope they use it and use it wisely... When you're dead, you're dead, it's not as if you're there living through something you wouldn't want to live through, and whether that is because of our active mind telling us, 'Gee Whiz, they're going to do this and they're going to do that to me', I don't know, but that part of it does not worry me. George, donor

After the initial shock you'll go through all sorts of stages of reaction. In fact, I'm just thinking, when we're confronted with death of someone we know we go through various stages, as Kübler-Ross said. There's the initial shock, and then there's anger, and there's grief and denial, and all sorts of stages that we go through. I'm wondering when you're shown your first dead body, and I don't know how long after that you start dissecting, but you too will go through a stage of reactions to it. Paula, donor

\section{Thanksgiving service}

Like many other medical schools, Otago University holds an annual thanksgiving service to acknowledge body bequests (Hildebrandt 2016, 42; McClea 2008b). It allows family and friends of donors to meet students and staff who work with their loved one's bodies. The service is a staff initiative but it is largely organised and run by students, in conjunction with the University chaplains. Photographs provided by the families are placed at the front of the room and candles are lit in remembrance. Refreshments afterwards allow students and staff to mingle with guests. Throughout the service the thankfulness of both students and staff is emphasised, as well as the special nature of the bequest (Trotman 2009e).

... pay tribute to those who decided that when they died they wanted their bodies to be used in ways that would benefit other people, and of course we also gather to pay tribute to you, their families who are left behind and who have had to live with the knowledge that the bodies of your loved ones have been used in these very special ways ... what we have here this evening then is a two-fold celebration. We are celebrating a profound gift, a precious gift by those who have died, but also of course indirectly, by those of you who are left behind, and we're also celebrating what I would describe as a distinctly countercultural act. After all, bequeathing one's body goes against the tenor of our society. It is acting in a way that is far from easy and in some ways that lies at the outer edges of society. But it is a move of immense significance and you should be proud of your relatives who are prepared to take this step. Those of us involved in the health sciences are deeply grateful for this because without this gift, this act of education in which we're involved would be much the poorer. Professor Gareth Jones, Deputy Vice-Chancellor

First and foremost I think if I had the chance to talk to the person who decided to bequeath their body for our learning experience I would say thank you. It is a privilege for us, the dental students, to be able to examine the human body in this way and from what I understand not available to many other students around the world. Nick, dental student 
We the students of Otago University would like to thank the family and friends who are here today, as your consent has given us the opportunity to learn and understand the intricate nature of human beings and this personal reflection of mine is a reminder that those who bequeath their body to the department are not forgotten, and it is by their generosity and yours that a difference has been made in our lives. Suan, student

Although I never got to know any of these generous people, they have taught me about the physical body, and the spirit of people. The act of giving their bodies for the sake of education tells me they were kind, not self seeking, and had a heart to make a difference in the lives of others. This is what I'll remember, and it has made a difference in my learning and experience of life. I not only give thanks for you and your loved ones, today I celebrate the spirit to give and love unconditionally. Thank you. Sharon Chau, physiotherapy student

Be assured that the University, Anatomy Department students, and particularly myself, remain awed by the generosity of such a gift, and are entirely cognizant of how uniquely privileged we are to have access to such a valuable and instructive resource. Luke, physiotherapy student

The memorial service came about because the staff in the Department were looking for a way that we could give back to the families. I think memorial services, or thanksgiving services, are also a way for closure for the families, and I think for them to be able to do that they need to have acknowledgement from the department. Kathryn McClea, Bequest Coordinator

As we were speaking to the relatives at the memorial service a lot of them didn't really want to know what we did. They wanted to know that we appreciate it, but didn't want to know any more details. Though I guess it depends on the person, the individual, what they want to know. It was really touching. To be honest I didn't think it would be so emotional, but as soon as all the family came up with the candles, and put candles in front of the photos, it was quite touching. I think it's a really good service to hold. Cindy Grobler, medical student

\section{Respect}

Thankfulness for body bequests is an expression of respect towards body donors.

Documentation, reinforced through verbal reminders, clearly articulates the need for respect in dealing with human material. Respect is emphasised in standardised information about the Anatomy Museum, Course Outlines, the Code of Conduct, and the Anatomy Lab Rules. As noted previously, what respect means is different to different people.

Dissection and the use of human remains in medical education and health science museums have been declining as the way in which people envisage medicine changes. With the development of new medical technologies and the discoveries of more therapies for disease and injury, students are required to learn increasing amounts of information in the same period of time (Flack \& Nicholson, 2016, 5; Fruhstorfer et al. 2011, 247). This coincides with increasing societal issues pressuring medical schools not to use real human remains in 
teaching. There are a number of reasons for this, including debate over ethical sources of cadavers; legalistic concerns over profits for donors used in commercial discoveries; and cultural and historical concerns such as slavery and national socialism.

Although many medical schools are moving away from using human remains in teaching, this is not the position at Otago (McClea 2008b). Otago University continues to embrace the use of human remains in a variety of forms, including the Trotter and Drennan, dissection, and anatomy labs. Changes to medical technologies and new therapies will continue throughout the career of all health practitioners but the fundamental basics of human anatomy will continue to be essential underpinnings of all medical advancement. Within these changing contexts a strong understanding of basic anatomy and the ability to learn and adapt to developing techniques are more important than learning specific techniques, as not all emerging technologies and therapies will be accessible in every clinical practice. A component of Otago's continuing use of human remains for teaching basic anatomy is the goodwill and generosity of the community. Staff explicitly state that students cannot learn anatomy without working with human remains, a view that is borne out by students, and this relies on the generosity of donors and their families. This goodwill and generosity is created through the University openly engaging with the community in an ethical way, and being sensitive to the needs of family members (McClea 2008b; 2008c; Riederer 2016, 16).

I didn't realise that there were so many people that donated their body, and when the medical students got up and talked they showed such respect for the bodies. Sylvia Petrie, niece of donor (Trotman 2009e)

The benefits of using human remains are borne out in Otago University's excellent reputation for its high level of health science education, reflected in QS rankings, and in student perceptions (QS website).

When I chose Otago University to fulfil a dream of converting myself into a physiotherapist it was based purely on the reputation that Otago has for delivering quality education in the medical field. Luke, physiotherapy student (Trotman 2009e)

Donated to Science highlights a number of important considerations for student use of human remains in both dissection and museums. Although specifically referring to the students' dissection experience, the use of the Trotter is so deeply embedded within teaching at Otago that a direct correlation can be drawn between the two. Because the Code of Professional Conduct specifically links the guidelines provided by the Anatomy 
Department to both case study museums the information from the documentary can be further extrapolated to apply to the Drennan (Anderson, 2015).

\section{The use of human remains at Otago University}

The Drennan and Trotter both serve the same purpose as extra educational resources for students' development of knowledge and research. However, there are significant differences in the way the museums are used. The Drennan is under-utilised for teaching purposes in comparison to the Trotter. Exhibition analysis also highlighted discrepancies in individual use. During the entire period of exhibition analysis the Trotter was in use, whereas the Drennan was empty for the entire period of its exhibition analysis. The fact that the Drennan analysis occurred during lunch periods may be a factor in this observation but does not compensate for the complete lack of use during this period. Bookings for the two museums also demonstrate differences in their use. The Trotter was heavily booked throughout the 2015-2016 period while booking records for the same period for the Drennan are nonexistent. Again, there may be reasons for the lack of evidence in this regard. Nevertheless, conclusions can be drawn from its absence.

The exploration of the situation at Otago University is important for two main reasons. Firstly, consideration of museum collections in health science tertiary programmes has been woefully under-examined internationally. Consideration of the use of remains in contemporary programmes has largely focused on the use of dissection in the curricula and its alternatives. Concurrently the use of museum collections for teaching at tertiary level is starting to be re-evaluated but this focuses primarily on art and social science collections rather than health science collections, even when it focuses on health science students. This research ties these two areas of enquiry together, providing a starting point for further exploration of these issues. Secondly, the place of museums in tertiary institutions in New Zealand is also under-examined. The development of New Zealand's major museums is linked to the establishment of universities in those places. Otago Museum has strong historical links with Otago University, including shared resourcing and staffing. The two institutions are located on adjacent sites in the centre of Dunedin City, the current Museum Director holds an honorary lecturer position at the University, and recently established scholarships allow postgraduate students to work with the Otago Museum collections in pursuit of higher degrees. 
The international standing and reputation of the Otago University health science programmes demonstrates that the pedagogical methods utilised within these programmes are effective for developing high quality graduates in line with the graduate attributes set out in the University's Teaching and Learning Plan (2013). Two of these stated attributes are 'ethics' and 'global perspective'. The development of ethically responsible graduates within health science programmes has been a matter of some debate. There is a philosophical tension between understandings of ethics-as-technique versus ethics-asidentity. Where ethics is understood as a technique that can be taught, formal structured classes in ethics have been introduced to health science programmes. Where ethics is understood as part of an individual's identity it is recognised that much of their ethical core is established before they commence study (Hafferty \& Franks 1994). However, both positions are simplistic views of ethical development which ignore considerations of personal and professional development and fail to recognise the socialisation process that occurs through induction into a professional course. Part of this socialisation is growing awareness of professional norms through the 'hidden curriculum'(Hafferty \& Franks). The hidden curriculum refers to the philosophical underpinnings of norms within the academy and professional community, including unconscious ideas about race, gender, ableism, and body-as-object. An example of this is the depiction of discrete body parts decontextualised from the rest of the body. When the existence of the hidden curriculum and its impact are acknowledged alongside the implementation of formal ethical courses, significant improvements can be made in ethical development for students. At Otago University formal lectures on ethics are delivered to students in the medical programme, and research is being undertaken on the place of the hidden curriculum within medical education (Trotman 2009c). The way in which museum objects are displayed reinforces the hidden curriculum and unconscious understanding of what is appropriate in anatomy and pathology. Staff have close associations with international colleagues, thus ensuring that international best practice is incorporated into teaching and research. Through this students have a wider and more critical perspective than merely the New Zealand context. The continuing reliance on the use of full-body dissection and museum collections at Otago University demonstrates their continued importance, both as effective pedagogical resources, and the continuation of traditions as part of the socialization process within the hidden curriculum. 
Otago University's persistence in using human remains for dissection and in museum collections goes against many international trends, and it is important to consider why Otago's usage continues. The University's ongoing reputation for excellence in health science education argues for the effectiveness of these forms of teaching. However, the lack of conclusive empirical evidence on the impact of using dissection and museums in teaching tempers these conclusions. Further research on the effectiveness of both dissection and museum use is needed to definitively state how effective these methods are. Current studies predominantly focus on case studies, which use a variety of measures for assessing efficacy. Until consistent standards are used programmes cannot be reliably measured against each other. Irrespective of the results of other studies, Otago's continuing high reputation for its health science programmes suggests that the methods employed for teaching these programmes are successful.

$* * * * *$

An examination of the history of museums in higher education illustrates the way in which use of museum collections at tertiary level has waxed and waned as pedagogical theory and technological advances have influenced teaching methods. The benefits of OBL and experiential learning at tertiary level are currently being reconsidered, and research is demonstrating its positive impact. Tertiary collections are at the centre of this form of learning as objects as sources of primary information are rediscovered. Collections are being reassessed and repurposed across a range of disciplines to embed their importance into the wider institution so they no longer need to rely on the teaching practices of a single department. Medical humanities programmes demonstrate this in practice. As departments look to expand their student base and explore ways of more effective teaching, utilisation of OBL through established and developing collections constitutes a significant opportunity to be explored.

Museum collections were historically in the forefront of medical education. They provided a fundamental understanding of human anatomy when there was insufficient supply of adequate cadavers. Working with real human remains continues to be singularly important for students undertaking study of the healthy and pathological body. Medical discoveries and technologies are dramatically broadening the field of health sciences and this information must be included within the limited span of students' degrees, while a thorough understanding of basic human anatomy remains necessary. Modern museum collections 
provide a vital resource for independent study in this ever-expanding field. Human remains held in tertiary collections are a valuable resource that benefits not only the students studying health sciences but the wider community who will become their patients. The benefit of working with remains in these contexts extends beyond the acquisition of knowledge. Growing recognition of the emotional impact of clinical detachment and working with human remains includes recognition of students' need for engagement with remains outside of scheduled classes and their inherent pressure, whether through attendance at ceremonies of thanksgiving, whakawātea, or in museum settings. Codes of ethics are essential for students working with human remains at Otago University.

This chapter has predominantly focused on material regarding the Anatomy Department but there is significant overlap within the student cohort between both departments allowing conclusions to be drawn for both museums. Students using the Drennan will predominantly be medical students who are informed that the documentation provided by the Anatomy Department applies equally within the context of other departments within their programme. This partly explains the paucity of documentation provided by the Pathology Department. However, there are significant differences between the two departments practice regarding their museums. This will be more fully discussed in the conclusion. Students are aware of the privilege and importance of working with human remains in dissection and the museums, and have demonstrated genuine thankfulness and appreciation of this. Otago University's commitment to body donation and informed consent allows balance between the needs of students, staff and medical research with autonomy of individuals and respect of their wishes. 


\section{Conclusion}

Human remains reside in museum collections throughout the world. Although this was widely accepted it has become problematic in Western society. The museum sector has reacted to this by recognising the special status of human remains and revising policies regarding their collection and retention. This thesis argues that the current focus on indigenous remains and Body Worlds plastinates has restricted examination of the broader situation of human remains in museums. It investigates whether there can be justifiable reasons for museums to collect and human remains, with specific reference to health science museums used in tertiary education. Exploring this question has involved considering three interconnected issues: what codes of ethics exist; how use of human remains has been justified; and the place of museums in tertiary education. Examining these three issues has drawn out some of the complicating factors surrounding the treatment of human remains in museums.

An exploration of literature highlighted the predominant focus on indigenous remains and Body Worlds. This narrowing of focus has artificially constrained enquiry and limited understanding of the issue. Developing a more nuanced and sophisticated understanding of human remains in museums is necessary to enhance best practice. In health science museums, collecting and holding human remains is foundational to their activities. If it is accepted that objects hold vital information that cannot be replaced by text, and that museums are valuable for teaching, then it follows that it is appropriate for museums that teach about the human body to hold and display the human body. A broadening of perspective is required to ensure appropriate treatment for all remains in museum collections, allowing that different valid perspectives exist, and that these different perspectives need not be mutually exclusive. The answer to the original research question is that it can be acceptable for museums to acquire and hold human remains, but there needs to be a wider understanding of the contexts surrounding human remains in museums for this to be more fully clarified and appreciated. There are underlying principles, such as the nature of the body and its importance to individuals and society, which underpin wider discussion of remains in museums that are not specific solely to indigenous remains or Body Worlds. 
Consideration of indigenous remains is important for any museum holding remains, especially in light of historical acquisition and racial theory. However, the use of human remains for health science education needs to be uncoupled from repatriation claims. This does not mean that indigenous perspectives should be ignored in health science collections. Instead it demonstrates the need for greater understanding regarding acquisition and the nature of collections. Claims regarding indigenous remains should be thoroughly investigated and considered in open dialogue, with good faith, between source communities and health science museums. It is necessary for museums to recognise the emotional hurt that is caused by holding indigenous remains, and for indigenous communities to recognise that not all objects of human origin were acquired under dubious circumstances, and that there are benefits for both sides in discussing these matters. Uncoupling indigenous claims from other human material allows for development of more sophisticated understanding of what is required and appropriate in how remains held by health science collections are treated. A more nuanced debate acknowledges multiple perspectives within perceived entrenched positions of indigenous groups and scientists.

Donation is a crucial consideration when separating indigenous claims from other issues relating to material in health science museums. HTANZ demonstrates how essential donation is for acquisition of human tissue. Evolving understanding of informed consent may over time show deficiencies in the current model, but it is developed with transparency and beneficence, recognising bodily autonomy and individual rights. Informed consent is essential for acquisition of human tissue but it must be remembered that it alone is insufficient. Society places limits on what can be done with human tissue even with informed consent.

This thesis has shown that the codes of ethics governing the treatment of human remains in health science museums are a mix of codified and consultative ethics. The codified component provides clear guidelines for ethical behaviour. The nature of academia ensures a high level of consultative ethics exists alongside these strict rules. Academic scholarship on issues of ethics and health science pedagogy results in continued debate on best practice and ethical behaviour, including determining whether using human remains in health science education is warranted. The Education Act (1989) states that teaching at university should be aligned with research and held to the highest ethical standards. To comply with 
legislation, health science educators must integrate debate around the treatment of human remains into their programmes, highlighting ethical concerns and promting discussion.

There is no all encompassing guideline to govern the treatment of human remains. The variety of codes exists because remains are held in a diversity of contexts. ICOM specifically establishes its Code of Ethics as base principles to be used by national organisations to develop contextually relevant codes. This explicitly acknowledges the multiplicity of acceptable practices in different cultural contexts, and the range of legal constraints under which each organisation must act. In the New Zealand context biculturalism, Māori tikanga and HTANZ are important factors that would not be applicable elsewhere. The MA Code of Ethics does not specifically detail ethical principles for the treatment of human remains. Instead, in Appendix B of the Code it refers readers to exemplars of human remains policies from Te Papa and Canterbury Museum. This allows the Code of Ethics to keep pace with professional practice as the individual exemplars are more easily revised than the full MA Code of Ethics. However, there is an issue with the examples chosen in that they focus largely on the treatment of Māori human remains. Te Papa's policy explicitly excludes all other human remains. The Canterbury Museum policy does acknowledge human remains from other cultures, but also essentially focuses on remains within the framework of indigeneity. Human remains in New Zealand museums and new archaeological discoveries of remains may be predominantly of Māori origin but by limiting examples of human remains policies to those which only refer to Māori remains other types of human remains are ignored. This limits wider understanding of human in museums and leads to simplistic understanding of the issues. Appendix $\mathrm{C}$ of the MA Code of Ethics provides terms of reference for the establishment of the Museums Aotearoa Ethics Committee. However, the establishment of a committee to advise on specific instances of ethical dilemma does not address systemic theoretical foundations and assumptions about the nature of the human body. Examining codes of ethics and professional practice from health professional organisations does not provide clarity either. The majority of these documents deal with ethical treatment towards living individuals. The rights and needs for living and deceased individuals differ greatly and so the focus of these documents is not particularly relevant to the treatment of remains from deceased individuals.

Codes which do focus on human remains often concentrate on the ethical use of remains rather than exploring the need to use them at all. HTANZ comments on the use of human 
remains for the 'public good', which it explains as 'health practitioner education, the investigation of offences, research, transplantation or other therapeutic purposes, or for other lawful purposes' (s3). In the context of health science museums the phrases 'health practitioner education' and 'research' are the most pertinent. The necessity to use human remains in education is not explored in the Act, and in many guidelines it is taken for granted that access to real objects is necessary. It is only in wider museum studies literature that the importance of real objects is considered. Taking for granted the necessity of using human remains in health science education means that alternatives are not considered. Exploring why using remains is important strengthens the case for their continued use.

Museums in tertiary education have been dependent on their teaching and research value. Where there has been continued acceptance of their value there has been continual use. Historically, health science education relied heavily on human remains, with significant collections being accumulated over time. The continued use of these collections is dependent on recognition of their teaching value across disciplinary boundaries, embedding them within core teaching activities in many departments. The recent renewal of interest in tertiary museums is part of a wider movement to engage in a variety of alternative learning techniques. Universities which already hold collections or have close links to external museums have opportunities to explore the possibilities of OBL. With emerging technologies and increasing amounts of information and specialisation to be included in basic health science education decisions must be made on what remains in the core curriculum. Museums provide alternative learning opportunities for individuals and small groups. As dissection disappears from medical programmes, health science museums offer students an opportunity to engage with human remains, providing an avenue to contemplate mortality and its emotional impact without the pressure of a clinical or classroom setting.

Using human remains in health science education continues to be important. Removing dissection from medical school curricula has proved controversial. Studies show that dissection and access to preserved remains is beneficial for learning and is preferred by many students. Otago students undertake cadaveric dissection and utilise preserved specimens in the Trotter and Drennan. The importance of human remains does not lie solely in their use as teaching aids. The emotional impact of confronting mortality cannot be underestimated. Allowing students to interact with human remains in the dissecting room and museums provides opportunities for them to develop coping mechanisms. To 
understand the importance of human remains to health science education, OBL must be more widely recognised and accepted within tertiary education. Active engagement with collections and curricula material provides new opportunities to develop individualised learning schemes.

The most significant limitation of this research has been the paucity of information available on contemporary health science museums. Information has been extrapolated from a range of existing literature, but very little has been written specifically on health science museums within the modern curricula. Contemporary human remains are acquired for health science museums through dissection. Consequently it is appropriate to view the dissecting room as a key component of the museum. The issues for students in the dissecting room and the museum are similar and information regarding the museum experience and its importance can be deduced from this data. The lack of information on contemporary health science collections, and the links between dissection and museum acquisition, has resulted in greater focus being placed on anatomy collections. While historical and contemporary links ensure that conclusions can be drawn across both types of health science museum under investigation it would have been useful to have more direct material on pathology collections. Interviews of users of the health science museums at Otago University would have been extremely useful to contrast against the dissecting room experiences used for this research. Unfortunately it was not possible to conduct this strand of investigation within this current research.

The way in which society allows human remains to be treated demonstrates its values. Historical examples from Nazi Germany and the USA show how easily vulnerable and marginalised people can be mistreated in death. Other examples from the UK show how even those ascribed high value, such as children, can be abused due to paternalistic attitudes of medical personnel. These abuses must be continually guarded against. Human remains are often given special or sacred status. This status is widely held across cultures and religions. Calls for this special status to be removed from human remains so they can be treated like all other materials are unlikely to be upheld. It is important for remains to maintain this status in order for society to uphold the importance of the living individual.

Discussions regarding human remains in museums reflect this special status but remains exist in more complicated contexts than are most commonly portrayed. When the debate is limited to consideration of indigenous remains and Body Worlds it not only restricts 
exploration of alternative contexts but also portrays the positions of indigenous groups, scientists and museum staff as homogenous entrenched dogmatic positions. To fully engage with issues around remains in museums it must be acknowledged that there is variation of opinion within each of these groups to ensure negotiation of the issues in good faith. This thesis examines the specific context of tertiary health science museums which are a small speciality within the museum sector, but its conclusions are more widely applicable as the investigation into remains within this context highlights complacency within established perspectives. Expectations that codes of ethics of professional museum organisations would include clauses specific to human remains in the small number of tertiary health science museums could be viewed as presumptuous. However, it is not specific clauses for tertiary health science museums that need to be included in the codes, but rather a broader acknowledgement that guidelines for human remains in museums cannot be limited to a single context or type of remains. By exploring a range of associated professional codes more sophisticated guidelines can be developed.

A key consideration was the way in which professional museum ethics, medical ethics and academic ethics integrated to form best practice, and how this was applied in the case study museums. There was little common ground between the three types of ethics as each discipline's ethics had different foci. The crucial point of convergence was the issue of respect. Irrespective of the disciplinary field or the particular perspective, respect was paramount. How "respect" was interpreted and who it applied to differed greatly between and within groups. Despite this lack of agreement, the impetus to show respect appeared universal, and this is a crucial point of commonality to begin discussions on best practice. All codes of ethics, whether codified or consultative, start with discussions of appropriate behaviour. By taking "respect" as the focus of discussions different perspectives and ideas can be incorporated into the fundamental tenets for treatment of human remains in museums. This was highlighted by the similarity of terminology between the various ethical codes. It was initially assumed that the different perspectives would be expressed in different terminology and it was a surprising finding of this research that similar terms were used, all denoting respect to the individual and families of the remains. Where the remains could not be identified as an individual they were shown the respect due to a member of their specific cultural group as it could be ascertained. In these instances they were referred to by culturally appropriate names, such as "koiwi tangata" to denote their associations rather than merely "human remains". 
Considering the place of human remains in museums uncovers unconscious cultural attitudes towards the living and deceased body. The raison d'être of museums is to collect and exhibit various aspects of culture, both geographically and temporally, and hence they are well placed to explore the ranges of attitudes towards bodies within and between cultures. As death is a fundamental aspect of every lived experience it is a shared point of comparison across cultures, leading to improved cross-cultural understanding. Human remains in museums also allow societal concepts of health and medicine to be explored, including the increasing medicalisation of society and the pervasiveness of empirical science within contemporary Western society.

One aspect of this is the emergence of bioethics as a disciplinary field. In the context of health science museums, a concurrent consideration of bioethics and museum ethics is necessary to find points of consensus between museum and scientific perspectives. One of the significant aspects of this research was the synthesis of these perspectives within the case study museums. This thesis has explored how two dissimilar academic positions can be integrated in practice in health science museums and contributes to the literature in both fields.

Tertiary health science museums need further recognition within their host institutions and the wider museum sector. The lack of professional training and networking opportunities for many staff working with tertiary collections results in many tertiary museums reflecting older museum models and appearing quite old-fashioned. Tertiary museums have a lot to contribute to the wider sector, such as high quality objects, assessed and researched by experts, and consequently should be abreast of museum best practice. Greater integration between tertiary museums and the wider sector would allow for new museum practices to be introduced to tertiary museums and greater opportunities for high quality research on collections in the wider sector. Another aspect of the older museum models reflected in tertiary museums is privileged access to objects for researchers and students. In the wider museum sector significant distance between object and visitor exists due to security and lack of knowledge regarding collections. However, in the tertiary environment museum visitors already demonstrate considerable interest and advanced knowledge, and are given access to objects which would be considered privileged access in other museums. Additional to this is growing interest in OBL and experiential learning techniques allowing visitors to tertiary museums to interact with objects more closely. In wider sector museums 
there may be touching sessions with objects but predominantly objects are accessed by viewing.

Greater recognition of tertiary museums would incorporate a corresponding increased recognition of the professionalism of museum staff. There has been a movement to have museum work classified as a profession, and one of the key characteristics of a profession is a code of ethics, which is why an exploration of these codes is important. The tension between professional and academic ethics and control over tertiary museums was the genesis of this present research. It is this tension and subsequent overlap and compromise in which the primary results of this research are found. These are the negotiated spaces for developing best practice for the treatment of human remains in museums.

These negotiated spaces include those at the Drennan and Trotter. Expectations for treatment of remains are clearly articulated through student guidelines, which are underpinned by academic research and debate on the nature of remains within health science education, law, bioethics, and tertiary educational pedagogy. Otago University's rankings as a tertiary education provider ensure that its research and teaching are influenced by key thinkers on these topics internationally within the cultural context of Dunedin, New Zealand. The University's demonstrated commitment to biculturalism and the Treaty of Waitangi ensures that issues of indigeneity which are paramount in the New Zealand museum sector are fully considered. The implementation of the University's Māori Strategic Framework is the embodiment of these issues within Otago University. This means that the importance placed on Māori cultural considerations in the museum sector is not as relevant to Otago University museums as they are considered through other channels more specific to the institution. The primary guidance for the treatment of human remains in both the Trotter and Drennan is HTANZ. Recognition and application of the law is integrated into course materials and departmental documents. HTANZ lists 'proper recognition' and 'respect' as part of its key purposes. Respect is a paramount consideration for staff and students which is demonstrated in the annual thanksgiving service.

Despite being used for the same purposes, for the same students, within the same institution there are significant differences between the two case study museums. The Trotter is fully embedded within the Anatomy Department's teaching and research programme, is well known throughout the University, and is effectively utilised as an educational resource. It is well supported in terms of intellectual development, staffing levels and integration into 
the curriculum, and is used extensively for the dual roles of teaching and promotion. The Drennan meanwhile is much smaller, houses only a small part of the collection, is less clearly laid out, and is under-staffed and under-used for teaching, study space or promotion. The guidelines that direct behaviour in both museums are reliant on the intellectual leadership provided by the Trotter. The Drennan's collections are a significant resource for teaching and research, but this is not realised in their current configuration. This reflects the position of many tertiary museums. As both case study museums belong within the same institution, and the same institutional framework, it must be concluded that it is leadership from within their host department that contributes most directly to their differences in utilisation. Neuman's (1993) historical outline of the Anatomy Museum demonstrates the importance of influential individual figures in the course of the Museum's development. This appears to have been largely lacking in the development of the Drennan.

This research is significant in two main ways. Firstly, it adds to the current academic debate around museological ethics, human remains in museums, and museums in tertiary education. Secondly, it has practical implications for health science instructors, medical personnel and subsequently their patients. This thesis goes part-way to filling a significant gap in the literature. As noted earlier, much of the literature surrounding human remains in museums is limited to indigenous remains, and Body Worlds. Limiting examination of human remains in museums to only these two aspects excludes other contexts and perspectives. The importance of plastination as a technique within anatomical research and teaching is often underemphasised and overlooked when compared to discussions of plastination as spectacle, again narrowing the field of discussion. While indigeneity and sensationalist plastination exhibits are important strands of enquiry they do not constitute a full picture of human remains in museums. If the status given to human remains as being akin to sacred objects is to remain, then consideration of how remains are treated in toto is justified (ICOM 2013). If object primacy is accepted then the importance of human remains for teaching about the body is also justified. The ethical guidelines for treatment of remains in museums are important because remains are conceptualised as both object and sacred, especially within a multicultural secular society where concepts of sacredness are blurred. 
Research into medical technologies and development of new therapies is ever-growing and lifelong learning and teaching are important components of practice within health professions. How students learn and are taught impacts on their understanding of learning and teaching, patient care and ethics. Examining how people interact with health science museums highlights weaknesses and strengths within programmes and fosters further consideration of pedagogy within the curriculum, including the often unconscious 'hidden curriculum' and the development of ethical thought and behaviour. While museologists may think that what museums do matters, the shaping of how health science students are taught and, hence, what they are taught, is a tangible expression of this, with real world manifestations within health care practice.

By exploring these issues this research adds to international debates regarding museum treatment of human remains, tertiary museum practices, general health science education and museum studies literature. It also speaks to the specific context at Otago University and the tertiary and museum sectors in New Zealand. The place of tertiary museums in New Zealand has been largely overlooked, aside from particular exceptions (Baines 2015; Hudson \& Legget 2000; F. Cameron 2014). By not including tertiary museums in local museum literature they disappear from the sector consciousness, emphasising isolation and limiting tertiary museum development. Tertiary collections develop independently, and may not even be viewed as a museum collection, rather just as resources for teaching and research or clutter. Without a coordinated plan across the institution, collections are managed in a variety of ways, some being more successful than others. The present differences between the two case study museums have historical and circumstantial causes, and there is a push from Pathology staff to reintegrate the Drennan into teaching. Otago has an established reputation for its museum collections alongside Oxford, Harvard and others (Stanbury 2000). It is well placed to develop its collections into vibrant and engaging parts of the tertiary experience.

The recommendations to emerge from this research fall into two broad categories: recommendations for tertiary museums, and recommendations for the treatment of human remains. They can be integrated for the treatment of human remains in tertiary museums.

There is a need for greater engagement between tertiary institutions, in-house collections, and the wider museum sector. This would provide both tertiary institutions and museums a range of opportunities. Teaching staff would be able to develop new OBL practices and 
explore experiential learning. This could result in the creation of new objects for collections and teaching. Engagement provides museums in the wider sector with access to disciplinary specialists to support collection-based research and exhibition programmes, while tertiary museums would benefit from input from specialists in museum interpretation and exhibition techniques. Access to museum collections would provide avenues for research by experts, enriching the reputations of both institutions. Otago Museum and Otago University have jointly established scholarships for postgraduate students to research objects within the Otago Museum collections as part of their higher degrees. Another benefit would be the raised profile of both institutions within each sector, and the ability of each to utilise the other institution for promotional purposes. Cross-institutional collaboration requires significant work by both parties to establish and maintain networks, and uneven power imbalances can develop. Tertiary institutions should not rely solely on relationships with external museums, but also foster the development and growth of their internal collections within established institutional policies and frameworks. Internal development should incorporate promotion of cross-disciplinary use of collections to lessen dependence on the teaching and research focus of only one department. Interdepartmental use of collections allows reinterpretation of knowledge and collections, and provides an avenue for cross-pollination of ideas.

Staff working in tertiary museums should be encouraged to increase their interaction with colleagues in the wider museum sector, especially through national professional organisations such as MA, and internationally through ICOM. There are several professional and personal benefits which would arise from this. Research has shown that tertiary museum staff often feel isolated from both academic and museum sector colleagues, which has negative consequences for both individuals and collections. Participation in professional museum organisations would help to alleviate this. It would provide networking and mentoring opportunities, minimising professional isolation and fostering collegial support. Staff would be exposed to training opportunities resulting in increased museological practice being integrated into management of tertiary collections. Further training would lead to increased professionalism and provide a route for career development. Interacting with other museum professionals would benefit the reputation of both the individual and the institution and it could be utilised as a way of promoting tertiary collections. The benefits from engaging with the wider sector could be replicated within the tertiary institution, and wider tertiary sector, by forming networking opportunities for 
staff working with different tertiary collections. In that way issues specific to the tertiary museum sector, and within specific institutions, could be addressed and a sure foundation of museum practice could be embedded within the tertiary sector. Alongside greater engagement of tertiary museum staff is greater promotion and awareness of tertiary collections through UMAC. Membership of this body would incorporate international best practice for tertiary museums into local practice, as well as having an impact on emerging developments. It would also provide promotion of tertiary museums and their wider institutions, bringing them to the attention of potential students, researchers and staff.

Other recommendations relate to the treatment of human remains. For guidelines on the treatment of human remains to be effective it is necessary for societal attitudes to human remains to be routinely considered to check the relevance of existing codes. However, the mandate for tertiary institutions to be the conscience and critic of society means that societal values cannot be taken purely at face value. This is demonstrated by current debates in the United Kingdom over moving to a presumed consent/opt out system of organ donation. ${ }^{1}$ In light of the organ retention scandals at Alder Hey and Bristol Royal Infirmary it is the role of tertiary institutions to provide historical context and critical discussion on these issues rather than merely reflect changes in the law and cultural shifts.

The use of human remains in health science education and in museums must focus on donated cadavers rather than unclaimed bodies. Otago University utilised donated cadavers well before the enactment of legislation requiring it. In other jurisdictions unclaimed bodies are still used and this can prove disquieting for some students. The development of a robust body donation programme is essential for the ongoing use of human bodies. However, it must be acknowledged that in certain cultural and religious contexts the donation of bodies is unlikely to be successful. The processes for ethical acquisition must be renegotiated within these contexts to clarify what constitutes best practice.

More research is needed to assess the efficacy of various aspects of health science education. A significant part of this is the development of standardised methodologies within case study research to ensure comparability and that convincing conclusions can be drawn. Within this research, investigation of a variety of teaching methods is necessary including OBL, digitalised resources, clinically based learning, and written text. Once the

\footnotetext{
${ }^{1}$ This is an ongoing discussion in UK media, and as such is not fully discussed or referenced here.
} 
effectiveness of these learning methods can be ascertained they can be more confidently integrated into teaching practice. It must also be recognised that students learn in a range of ways and that teaching methods are not mutually exclusive. The best approaches to teaching emerge from the specific context of staff experience and skills, and resourcing.

Where human remains continue to be used as a teaching tool their use must be clearly promoted and understood as a teaching resource rather than as sacrilege or freak show. This can be maintained by clearly articulated and publicised justifications for their use, and regular reassessment and review of their usefulness. To ensure that collections are being utilised appropriately it is necessary for collections to have professional curatorial management including being fully catalogued, digitally recorded, and kept in mediumappropriate storage.

The aim of this thesis was to explore the codes of ethics that govern the treatment of human remains, consider the justifications these codes provided, and assess the place of museums within tertiary education to judge whether or not the collection and display of human remains was ever appropriate. It was found that discussion of human remains in museum studies literature was limited largely to indigenous remains and Body Worlds plastinates. The focus on these two aspects frustrated further consideration of the issues and reinforced supposed entrenched positions of scientists versus indigenous groups. However, a greater exploration of literature from a variety of fields showed that these were not the only considerations and that the entrenched positions were not as homogenous as portrayed.

This thesis has demonstrated that more sophisticated understanding of human remains in museums is necessary, and that a blanket rule cannot be applied across all instances of remains in museums. Consultation between community groups and museums, both in tertiary institutions and the general sector, can develop more nuanced understandings not only of human remains in museums but also of other cultural objects in the collections. In the case study museums the purpose of utilsing remains is to train future health professionals and ultimately benefits, not just those students, but the wider community. Community engagement and strict transparent guidelines ensure that human remains are collected only through agreed ethical procedures. Their acquisition is treated as an immense gift and they are treated with the greatest of respect. In these circumstances it is possible to say that the acquisition, display and use of human remains is justifiable. Future consideration of these issues needs to pay greater attention to the historical and cultural 
context in which the remains exist, in order to guard against the entrenched assumption that no human remains in museums are justifiably held. 


\section{Bibliography}

This is a list of references cited in this thesis. A large number of other sources of information were also consulted in the course of researching for the thesis.

Alberti, Samuel J.M.M. 2011. Morbid Curiosities: Medical Museums in NineteenthCentury Britain. Oxford: Oxford University Press.

Alfonso, Marta P., and Joseph Powell. 2007. "Ethics of Flesh and Bone, or Ethics in the Practice of Paleopathology, Osteology, and Bioarchaeology." In Human Remains: Guide for Museums and Academic Institutions, edited by Vicki Cassman, Nancy Odegaard and Joseph Powell, 5-19. Lanham: AltaMira Press.

American Alliance of Museums. 2000. "Code of Ethics for Museums." Arlington: American Alliance of Museums.

Anatomy Act 1832 (UK)

Anderson, David, James Kisiel, and Martin Storksdieck. 2006. "Understanding Teachers' Perspectives on Field Trips: Discovering Common Ground in Three Countries." Curator 49, no. 3 (July 2006): 365-86.

Anderson, Lynley. 2015. "Code of Professional Conduct for Medical Students at the Universities of Auckland and Otago." Dunedin, Auckland: University of Otago Medical School, University of Auckland Medical and Health Sciences.

Andrews, Lori B. 1986. "My Body, My Property." The Hastings Center Report 16, no. 5: 28-38.

Arnold, Ken. 2006. Cabinets for the Curious: Looking Back at Early English Museums. Perspectives on Collecting. Aldershot, UK: Ashgate. . 2004. "Museums and the Making of Medical History." In Manifesting Medicine, edited by Robert Bud, 145-70. London: Science Museum.

Baines, Penelope. 2015. "Non-Core Business? An Examination of University Art Galleries in Aotearoa New Zealand." Master of Museum and Heritage Studies thesis, Victoria University of Wellington.

Balachandran, Sanchita. 2009. "Among the Dead and Their Possessions: A Conservator's Role in the Death, Life and Aftermath of Human Remains and Their Associated Objects." Journal of the American Institute for Conservation 48, no. 3: 199-222.

Barker, Ian. 2006. "The Protection of Cultural Heritage Items in New Zealand." In Art and Cultural Heritage: Law, Policy and Practice, edited by Barbara R. Hoffman, 14547. Cambridge: Cambridge University Press.

Beatson, Peter. 2000. The Disability Revolution in New Zealand: A Social Map. Palmerston North: Sociology Programme, Massey University.

Belling, Catherine. 2011. "Being Non-Biodegradable: The Lonely Fate of Metameat." In Controversial Bodies: Thoughts on the Public Display of Plastinated Corpses, edited by John D. Lantos, 17-24. Baltimore: Johns Hopkins University Press.

Belmont Report: Ethical Principles and Guidelines for the Protection of Human Subjects of Research. 1979. United States Department of Health, Education, and Welfare.

Bennett, Tony. 1995. The Birth of the Museum: History, Theory, Politics. London \& New York: Routledge.

Biasutto, Susana Norma, Lucas Ignacio Caussa, and Luis Esteban Criado del Rio. 2006. "Teaching Anatomy: Cadavers vs. Computers?" Annals of Anatomy 188: 187-90.

Bienkowski, Piotr. 2015. "A Critique of Museum Restitution and Repatriation Practices." In The International Handbooks of Museum Studies: Museum Practice, edited by C. McCarthy, 431-53. Chichester: John Wiley \& Sons. 
Blakely, Robert L. 1997. "A Clandestine Past: Discovery at the Medical College of Georgia and Theoretical Foundations." In Bones in the Basement: Postmortem Racism in Nineteenth-Century Medical Training, edited by Robert L. Blakely and Judith M. Harrington, 3-27. Washington \& London: Smithsonian Institution Press, . and Judith M. Harrington, 1997. "Grave Consequences: The Opportunistic Procurement of Cadavers at the Medical College of Georgia." In Bones in the Basement: Postmortem Racism in Nineteenth-Century Medical Training, edited by Robert L. Blakely and Judith M. Harrington, 162-83. Washington \& London: Smithsonian Institution Press.

Boddington, Anne, Jos Boys, and Catherine Speight, eds. 2013. Museums and Higher Education Working Together: Challenges and Opportunities. Farnham: Ashgate.

Boorse, Christopher. 1977. "Health as a Theoretical Concept." Philosophy of Science 44, no. 4: 542-73.

Boos, Grace. 2011. "The Domestic and International Protection of Māori Cultural Property." LLB(Hons) dissertation, University of Otago.

Bounia, Alexandra. 2014. "Codes of Ethics and Museum Research." Journal of Conservation \& Museum Studies 12, no. 1: 1-7.

Bourdieu, Pierre, and Alain Darbel. 1991. "Cultural Works and Cultivated Disposition." In The Love of Art, 37-70. London: Polity.

Boys, Jos, Anne Boddington, and Catherine Speight. 2013. "Conclusion: Opportunities for the Future." In Museums and Higher Education Working Together, edited by Anne Boddington, Jos Boys and Catherine Speight, 169-88. Farnham: Ashgate.

British Association for Biological Anthropology and Osteoarchaeology. 2010."Code of Ethics."

Brooks, Mary M., and Claire Rumsey. 2007. "The Body in the Museum." In Human Remains: Guide for Museums and Academic Institutions, edited by Vicki Cassman, Nancy Odegaard and Joseph Powell, 261-89. Lanham: AltaMira Press..

Bud, Robert, ed. 2004. Manifesting Medicine. Edited by Robert Bud, Bernard Finn and Helmuth Trischler, Artefacts: Studies in the History of Science and Technology. London: Science Museum.

. 2013. "Medicine at the Science Museums, London." In Medical Museums: Past, Present, Future, edited by Samuel J.M.M. Alberti and Elizabeth Hallam, 60-73. London: Royal College of Surgeons.

Burns, Robert B. 2000. Introduction to Research Methods. 4th ed. London: Sage.

Butts, David James. 2007. "Maori, Museums and the Treaty of Waitangi." In Museum Revolutions: How Museums Change and Are Changing, edited by Simon Knell, Suzanne MacLeod and Sheila Watson, 215-27. London: Routledge.

Cameron, Duncan. 1968. "A Viewpoint: The Museum as a Communications System and Implications for Museum Education." Curator XI, no. 1: 33-40.

—. 1971. The Museum, a Temple or the Forum." Curator XIV, no. 1: 11-24.

Cameron, Fiona. 2014. "From 'Dead Things' to Immutable, Combinable Mobiles: H.D.

Skinner, the Otago Museum and University and the Governance of Māori Populations." History and Anthropology 25, no. 2: 208-26.

Campbell, Alastair V. 2009. The Body in Bioethics. London \& New York: Routledge.

Canadian Museums Association. 2006. "Ethics Guidelines." Ottawa: Canadian Museums Association.

Candlin, Fiona. 2003. "Blindness, Art and Exclusion in Museums and Galleries." International Journal of Art and Design 22, no. 1: 100-110. 
. 2006. "The Dubious Inheritance of Touch: Art History and Museum Access." Journal of Visual Culture 5, no. 2: 137-54.

Canguilhem, Georges. 1978. On the Normal and the Pathological. Translated by Carolyn R. Fawcett. Dordrecht \& Boston: D.Reidel Publishing Company.

Canterbury Museum. 1998. "Koiwi Tangata/Human Remains Policy." Canterbury Museum Trust Board.

Capozzoli, Maureen McCarthy. 1997. "A Rip into the Flesh, a Tear into the Soul: An Ethnography of Dissection in Georgia." In Bones in the Basement: Postmortem Racism in Nineteenth-Century Medical Training, edited by Robert L. Blakely and Judith M. Harrington, 313-39. Washington \& London: Smithsonian Institution Press.

Case, M. 1998. "What Registrars Do All Day." In Registrar's on Record: Essays on Museum Collection Management, 13-33. Washington D.C.: American Association of Museums.

Cassman, Vicki, Nancy Odegaard, and Joseph Powell, eds. 2007. Human Remains: Guide for Museums and Academic Institutions. Lanham: AltaMira Press.

Centre for Disease Control and Prevention. "U.S. Public Health Service Syphilis Study at Tuskegee." U.S. Department of Health \& Human Services, https://www.cdc.gov/tuskegee/index.html (accessed July 17 2017)

Chatterjee, Helen. 2010. "Object-Based Learning in Higher Education: The Pedagogical Power of Museums." University Museums and Collections Journal 3: 179-82. . 2008. "Staying Essential: Articulating the Value of Object Based Learning." University Museums and Collections Journal 1: 1-6. -, Sonjel Vreeland, and Guy Noble. 2009. "Museopathy: Exploring the Healing Potential of Handling Museum Objects." Museum and Society 7, no. 3: 164-77.

Cherryson, Annia. 2010. "In the Pursuit of Knowledge: Dissection, Post-Mortem Surgery and the Retention of Body Parts in 18th- and 19th-Century Britain." In Body Parts and Bodies Whole: Changing Relations and Meanings, edited by Katharina RebaySalisbury, Marie Louise Stig Sørensen and Jessica Hughes, 135-48. Oxford: Oxbow Books.

Chief Medical Officer. 2001. "The Removal, Retention and Use of Human Organs and Tissue from Post-Mortem Examination: Advice from the Chief Medical Officer." London: Department of Health, Department for Education and Employment, Home Office.

2000. "Report of a Census of Organs and Tissues Retained by Pathology Services in England." London: Department of Health, Department for Education and Employment, Home Office.

Clarke, Chanel. 2002. "Te Ao Tūroa - a Māori View of the Natural World in Auckland Museum." Te Ara - Museums Aotearoa Journal 27, no. 1 (May 2002): 23-26.

Committee of Ministers of the Council of Europe. 2005. "Recommendation 13 of the Committee of Ministers to Member States on the Governance and Management of University Heritage." Council of Europe.

Coney, Sandra and Phillida Bunkle. 1987. "An 'Unfortunate Experiment' at National Women's." Auckland Metro 7, no. 72 (June): 46-65.

Conn, Steven. 1998. Museums and American Intellectual Life, 1876-1926. Chicago and London: University of Chicago Press.

. 2006. "Science Museums and the Culture Wars." In A Companion to Museum Studies, edited by Sharon Macdonald, 494-508. Oxford: Blackwell.

Coroners Act 2006 (NZ) 
Corradini, Elena, and Marek Bukowski. 2012. "Proposed European Anatomical Collections Network." University Museums and Collections Journal 5: 119-132.

Council of Australian University Museums and Collections. "CAUMAC: Council of Australian University Museums and Collections." https://caumac.wordpress.com/.

Curlin, Farr A. 2011. "Detachment Has Consequences: A Note of Caution from Medical Students' Experiences of Cadaver Dissection." In Controversial Bodies: Thoughts on the Public Display of Plastinated Corpses, edited by John D. Lantos, 55-62. Baltimore: Johns Hopkins University Press.

Curtis, Neil G.W. 2003. "Human Remains: The Sacred, Museums and Archaeology." Public Archaeology 3: 21-32.

Curtis-Richardson, Mieke M.F. 1997. "Corpses as Commodities: The Ethnography of Covert Medical Practices in Georgia, Circa 1835-1997." In Bones in the Basement: Postmorten Racism in Nineteenth-Century Medical Training, edited by Robert L. Blakely and Judith M. Harrington, 340-70. Washington \& London: Smithsonian Institution Press.

Darwin, Charles. 1861. On the Origin of Species by Means of Natural Selection, or the Preservation of Favoured Races in the Struggle for Life. New York: Appleton.

Davies, Martin, and Nathan Hughes. 2014. Doing a Successful Research Project: Using Qualitative or Quantitative Methods. 2nd ed. Basingstoke: Palgrave Macmillan.

de Clercq, Steven W.G. 2001. "Uniting Forces: The European Network and National Collaborative Projects." In Managing University Museums: Education and Skills, 85-102. Paris: OECD.

Deaker, Michael. 2006. "The Provision of LOETC to New Zealand Schools: A Policy Review Paper for the Ministry of Education." edited by Ministry of Education: Ministry of Education.

Dean, David. Museum Exhibition: Theory and Practice. London \& New York: Routledge, 1994.

DeCuir-Gunby, Jessica T. 2008. "Mixed Methods Research in the Social Sciences." In Best Practices in Quantitative Methods, edited by Jason W. Osborne, 125-36. Los Angeles: Sage.

Department for Culture Media and Sport. 2005. "Guidance for the Care of Human Remains in Museums." Department for Culture, Media and Sport (UK).

Department of Anatomy. n.d. "Anatomy Teaching Lab Rules." Dunedin: Department of Anatomy, University of Otago.

2012. "Body Bonation: Bequest of Bodies under the Human Tissue Act 2008:

General Information. Conditions and Restrictions." Dunedin: Department of Anatomy, University of Otago.

2015. "Code of Conduct in Relation to Working with Human Material." Dunedin: Department of Anatomy, University of Otago.

"W.D. Trotter Anatomy Museum." University of Otago, http://www.otago.ac.nz/anatomy/facilities/museum/ (accessed June 2 2017).

Duhs, Rosalind. 2010. "Learning from University Museums and Collections in Higher

Education: University College London (UCL)." University Museums and Collections Journal 3: 183-86.

Durbach, Nadha. 2014. "'Skinless Wonders': Body Worlds and the Victorian Freak Show." Journal of the History of Medicine and Allied Sciences 69, no. 1: 38-67.

Edgar, Heather J.H., and Anna L.M. Rautman. 2014. "Contemporary Museum Policies and the Ethics of Accepting Human Remains." Curator: the Museum Journal 57, no. 2: 237-47. 
Edson, Gary, ed. 1997. Museum Ethics. London \& New York: Routledge.

Education Act 1989 (NZ)

Evans, Richard J. 2005. The Third Reich in Power. London: Penguin.

Falk, John H. 1999. "Museums as Institutions for Personal Learning." Daedalus 128, no. 3: 259.

and Lynn D. Dierking. 1997. "School Field Trips: Assessing Their Long-Term Impact." Curator 40, no. 3 (September 1997): 211-18.

Fforde, Cressida. 2004. Collecting the Dead: Archaeology and the Reburial Issue. London: Duckworth.

Flack, Natasha Ams, and Helen D. Nicholson. 2016. "Historical Perspective - Anatomy Down the Ages in Australasia; Lessons for the Future." Clinical Anatomy 29: 4-10.

Foltyn, Jacque Lynn. 2008. "Dead Famous and Dead Sexy: Popular Culture, Forensics, and the Rise of the Corpse." Mortality 13, no. 2: 153-73.

Forbes, Shari, and Douglas Heaven. 2016. "Life Amid Death at the Body Farm." New Scientist 230, no. 3076 (4 June): 2.

Fox, Claudia. 1993. "The UNIDROIT Convention on Stolen or Illegally Exported Cultural Objects: An Answer to the World Problem of Illicit Trade in Cultural Property." American Universities Journal of International Law and Policy 9, no. 1: 225-67.

Friedlaender, Linda K. 2013. "Enhancing Observational Skills: A Case Study. Collaboration between a University Art Museum and Its Medical School." In Museums and Higher Education Working Together: Challenges and Opportunities, edited by Anne Boddington, Jos Boys and Catherine Speight, 147-57. Farnham: Ashgate.

Froelich, Adrienne. 2003. "Smithsonian Science: First Class on a Coach Budget." Bioscience 53, no. 4 (April 2003): 328.

Fruhstorfer, B.H., J. Palmer, S. Brydges, and P.H. Abrahams. 2011. "The Use of Plastinated Prosections for Teaching Anatomy: The View of Medical Students on the Value of This Learning Resource." Clinical Anatomy 24: 246-52.

Gaunt, Heather. "Friday Essay: Can Looking at Art Make for Better Doctors?". The Conversation (2016).

Gladstone, Mara, and Janet Catherine Berlo. 2011. "The Body in the (White) Box: Corporeal Ethics and Museum Representation." In The Routledge Companion to Museum Ethics: Redefining Ethics for the Twenty-First Century Museum, edited by Janet Marstine, 353-78. London \& New York: Routledge.

Greenfield, Jeanette. 2007. The Return of Cultural Treasures. 3rd ed. Cambridge: Cambridge University Press.

Hafferty, Frederic W., and Ronald Franks. "The Hidden Curriculum, Ethics Teaching, and the Structure of Medical Education." Academic Medicine 69, no. 11 (1994): 861-71.

Hakiwai, Arapata. 2007. "The Protection of Taonga and Māori Heritage in Aotearoa (New Zealand)." In Decolonising Conservation: Caring for Māori Meeting Houses Outside New Zealand, edited by Dean Sully, 45-58. Walnut Creek, CA: Left Coast Press.

Hallam, Elizabeth, and Samuel J.M.M. Alberti. 2013. "Bodies in Museums." In Medical Museums: Past, Present, Future, edited by Samuel J.M.M. Alberti and Elizabeth Hallam, 1-15. London: Royal College of Surgeons.

Hannan, Leonie, Rosalind Duhs, and Helen Chatterjee. 2013. "Object-Based Learning: A Powerful Pedagogy for Higher Education." In Museums and Higher Education Working Together: Challenges and Opportunities, edited by Anne Boddington, Jos Boys and Catherine Speight, 159-68. Farnham: Ashgate. 
Harper, Jenny. 2014. "Dusting Off the Code of Ethics." Museums Aotearoa Quarterly (May 2014): 12-14.

Harrison, Julia D. 2005. "Ideas of Museums in the 1990s." In Heritage, Museums and Galleries: An Introductory Reader, edited by Gerard Corsane, 38-53. London: Routledge.

Hatton, Alf. 2012. "The Conceptual Roots of Modern Museum Management Dilemmas." Museum Management and Curatorship 27, no. 2: 129-47.

Health and Disability Commissioner (Code of Health and Disability Services Consumers' Rights) Regulations 1996. (NZ)

Health Practitioners Competence Assurance Act 2003 (NZ)

Heritage New Zealand Pouhere Taonga Act 2014 (NZ)

Heritage New Zealand Pouhere Taonga, http://www.heritage.org.nz (accessed August 26 2017).

Hesse-Biber, Sharlene Nagy. 2010. Mixed Methods Research: Merging Theory with Practice. New York: Guilford Publications.

Hildebrandt, Sabine. 2009a. "Anatomy in the Third Reich: An Outline, Part 1: National Socialist Politics, Anatomical Institutions, and Anatomists." Clinical Anatomy 22: 883-93.

2009b. "Anatomy in the Third Reich: An Outline, Part 2: Bodies for Anatomy and Related Medical Disciplines." Clinical Anatomy 22 (2009): 894-905.

2009c. "Anatomy in the Third Reich: An Outline, Part 3: The Science and Ethics of Anatomy in National Socialist Germany and Postwar Consequences." Clinical Anatomy 22: 906-15.

2008. "Capital Punishment and Anatomy: History and Ethics of an Ongoing Association." Clinical Anatomy 21: 5-14.

. 2016. "Thoughts on Practical Core Elements of an Ethical Anatomical Education." Clinical Anatomy 29: 37-45.

. 2014. "What Is Happening in Our Anatomical Dissection Rooms?". Clinical Anatomy 27: 833-34.

Historic England. 2005. "Guidance for Best Practice for Treatment of Human Remains Excavated from Christian Burial Grounds in England." edited by The Church of England and English Heritage: Historic England.

Historic Places Act 1993 (NZ)

Holm, Søren. 2011. "Troublesome Bodies." New Scientist 209, no. 2803.

Hooper-Greenhill, Eilean. 1992. Museums and the Shaping of Knowledge. London:

Routledge.

1991. "A New Communication Model for Museums." In Museum Languages:

Objects and Texts, edited by G. Kavanagh, 49-61. Leicester: Leicester University Press.

Hudson, Neville, and Jane Legget. 2000. "University Collections in Aotearoa New Zealand: Active Past, Uncertain Future." Museum International 52, no. 3: 21-26.

Human Tissue Act 1961 (UK)

Human Tissue Act 2004 (UK)

Human Tissue Act 1964 (NZ)

Human Tissue Act 2008 (NZ)

Interagency Working Group on Scientific Collections. 2009. "Scientific Collections:

Mission-Critical Infrastructure for Federal Science Agencies." Washington.

D.C.:Interagency Working Group on Scientific Collections

International Council of Museums. 1996. "Code of Professional Ethics." Paris: ICOM. 
2013. "ICOM Code of Ethics for Museums." Paris: ICOM.

. "ICOM Definition of a Museum." http://ICOM.Museum/Definition.html (accessed April 20 2017).

International Federation of Associations of Anatomists. 2012. "Recommendations of Good Practice for the Donation and Study of Human Bodies and Tissues for Anatomical Examination." International Federation of Associations of Anatomists.

International Institute for the Unification of Private Law. 1995. "UNIDROIT Convention on Stolen or Illegally Exported Cultural Objects." Rome: UNIDROIT.

Jackson, Harold. 1997. "Race and the Politics of Medicine in Nineteenth-Century Georgia." In Bones in the Basement: Postmortem Racism in Nineteenth-Century Medical Training, edited by Robert L. Blakely and Judith M. Harrington, 184-205. Washington \& London: Smithsonian Institution Press.

Jahnke, R. 2006. "Māori Visual Culture on the Run." Access: Critical Perspectives on Communication, Cultural \& Policy Studies 25, no. 2: 57-65.

Jenkins, Tiffany. 2011. Contesting Human Remains in Museum Collections: The Crisis of Cultural Authority. New York: Routledge.

Jones, D. Gareth. 2016a. "Anatomy in Ethical Review." Clinical Anatomy 29: 2-3.

—. 2011. "The Centrality of the Dead Human Body for Teaching and Research Social, Cultural and Ethical Issues." South African Journal of Bioethics and Law 4, no. 1: 18-23.

. 2016b. "The Public Display of Plastinates as a Challenge to the Integrity of Anatomy." Clinical Anatomy 29: 46-54.

. 2014. "Using and Respecting the Dead Human Body: An Anatomist's

Perspective." Clinical Anatomy 27: 839-43.

— New Zealand Medical Journal 115, no. 1155 (7 June 2002): 1-5.

- R. Gear, and K.A. Galvin. 2003. "Stored Human Tissue: An Ethical Perspective on the Fate of Anonymous, Archival Material." Journal of Medical Ethics 29: 343-47. , and Robyn Harris. 1997. "Contending for the Dead." Nature 386 (6 March 1997): $15-16$.

and Maja I. Whitaker. 2013. "The Contested Realm of Displaying Dead Bodies." Journal of Medical Ethics 39, no. 10: 652-53. and Maja I. Whitaker. 2009. Speaking for the Dead: The Human Body in Biology and Medicine. Medical Law and Ethics. 2nd ed. Farnham: Ashgate .

Keene, Suzanne. 2005. Fragments of the World. Uses of Museum Collections. London: Elsevier Butterworth Heinemann.

Kelly, Melanie. 2001. "Introduction." In Managing University Museums: Education and Skills, 7-15. Paris: OECD.

Kennedy, Ian. 2001. "Learning from Bristol: The Report of the Public Inquiry into Children's Heart Surgery at the Bristol Royal Infirmary 1984-1995." The Bristol Royal Infirmary Inquiry, Presented to Parliament by the Secretary of State for Health by Command of Her Majesty.

Kerby, Jane, Zena N. Shukur, and Joseph Shalhoub. 2011. "The Relationships between Learning Outcomes and Methods of Teaching Anatomy as Perceived by Medical Students." Clinical Anatomy 24: 489-97.

Kershaw, Ian. 2008. Hitler. London: Penguin Books.

King, Mike R., Maja I. Whitaker, and D. Gareth Jones. 2014. "I See Dead People: Insights from the Humanities into the Nature of Plastinated Cadavers." Journal of Medical Humanities 35: 361-76. 
Knell, Simon. 2003. "The Shape of Things to Come: Museums in the Technological Landscape." Museum and Society 1, no. 3: 132-46.

Lantos, John D., ed. 2011. Controversial Bodies: Thoughts on the Public Display of Plastinated Corpses. Baltimore: Johns Hopkins University Press.

Larson, Frances. 2009. An Infinity of Things: How Sir Henry Wellcome Collected the World. Oxford: Oxford University Press.

Lenzner, Nina R. 1994. "The Illicit International Trade in Cutlural Property: Does the UNIDROIT Convention Provide an Effective Remedy for the Shortcomings of the UNESCO Convention." University of Pennsylvania Journal of International Business Law 15, no. 3: 469-507.

Mack, Vanessa. 2001. "The Dual Role of University Museums: Its Influence on Management." In Managing University Museums: Education and Skills, 29-35. Paris: OECD.

Mackenzie v Attorney General [2015] NZHC19.

Manfredi, Leanne, and Rebecca Reynolds. 2013. "Tales from the Coalface." In Museums and Higher Education Working Together: Challenges and Opportunities, edited by Anne Boddington, Jos Boys and Catherine Speight, 135-45. Farnham: Ashgate.

Manning, Joanna. 2015. "Determining Breach of the Standard of Care." In Health Law in New Zealand, edited by P.D.G. Skegg and R. Paterson, 135-84. Wellington: Thomson Reuters.

Marreez, Yehia M. A-H., Luuk N.A. Willems, and Michael R. Wells. 2010. "The Role of Medical Museums in Contemporary Medical Education." Anatomical Sciences Education 3, (Sept-Oct): 249-53.

Marshall, Christopher. 2005. "When Worlds Collide: The Contemporary Museum as Art Gallery." In Reshaping Museum Space: Architecture, Design, Exhibitions, edited by S. MacLeod, 170-84. London: Routledge.

Marstine, Janet, Jocelyn Dodd, and Ceri Jones. 2015. "Reconceptualizing Museum Ethics for the Twenty-First Century: a View from the Field." In The International Handbooks of Museum Studies: Volume 2 : Museum Practice, edited by Conal McCarthy, 69-96. Chichester: John Wiley \& Sons.

Martyn, H., A. Barrett, J. Broughton, Paul Trotman, and Helen D. Nicholson. 2013. "Exploring a Medical Rite of Passage: A Clearing of the Way Ceremony for the Dissection Room." Focus on Health Professional Education: a Multi-Disciplinary Journal 15, no. 1: 43-53.

Mason, Kenyon, and Graeme Laurie. 2001. "Consent or Property? Dealing with the Body and Its Parts in the Shadow of Bristol and Alder Hey." The Modern Law Review 64, no. 5: 710-29.

Mataatua Declaration on Cultural and Intellectual Property Rights of Indigenous People. 1993. First International Conference on the Cultural \& Intellectual Property Rights of indigenous Peoples. Whakatane, NZ.

Matthews, Geoff. 1991. Museums and Art Galleries: A Design and Development Guide. Edited by Fred Lawson. Oxford: Butterworth Architecture.

Maykut, Pamela, and Richard Morehouse. 2002. Beginning Qualitative Research: A Philosophical and Practical Guide. London: Taylor and Francis.

McCarthy, Conal. 2011. Museums and Māori: Heritage Professionals, Indigenous Collections, Current Practice. Wellington: Te Papa Press.

McClea, Kathryn. 2008a. "The Bequest Programme at Otago University." Poster displayed in Department of Anatomy and Structural Biology, School of Medical Sciences, University of Otago. 
2008b. "The Bequest Programme at the University of Otago: Cadavers Donated for Clinical Anatomy Teaching." The New Zealand Medical Journal 121, no. 1274: 7278.

. 2008c. "Body Bequest Programme: Building Relationships with Next-of-Kin." Poster displayed in Department of Anatomy and Structural Biology, School of Medical Sciences, University of Otago.

McIntosh, Susan Keech. 2002. "Reducing Incentives for Illicit Trade in Antiquities: The US Implementation of the 1970 UNESCO Convention." In Illicit Antiquities: The Theft of Culture and the Extinction of Archaeology, edited by Neil Brodie and Kathryn Walker Tubb, 241-49. London: Routledge.

McLachlan, John C., John Bligh, Paul Bradley, and Judy Searle. 2004. "Teaching Anatomy without Cadavers." Medical Education 38: 418-24.

and Debra Patten. 2006. "Anatomy Teaching: Ghosts of the Past, Present and Future." Medical Education 40: 243-53.

Medical Council of New Zealand Te Kaunihera Rata o Aotearoa. 2004. "Definitions of Risk of Harm and Risk of Serious Harm." New Zealand: Medical Council of New Zealand Te Kaunihera Rata o Aotearoa.

Medical Laboratory Science Board. 2009. Code of Competencies and Standards for the Practice of Medical Laboratory Science. New Zealand: Medical Laboratory Science Board Te Poari Mātai Oranga.

Medical Sciences Council of New Zealand. 2014. Guide for Registered: Medical Laboratory Scientists and Medical Laboratory Technicians. Wellington: Medical Sciences Council of New Zealand.

Moreland, Judy, Clive McGee, Alister Jones, Louise Milne, Ariana Donaghy, and Thelma Miller. 2006. "Effectiveness of Programmes for Curriculum-Based Learning Experiences Outside the Classroom: A Summary." Ministry of Education.

Morris, Alan G. 2007. "Documentation: History and the Sources of Skeletons in Collections." In Human Remains: Guide for Museums and Academic Institutions, edited by Vicki Cassman, Nancy Odegaard and Joseph Powell, 151-61. Lanham: AltaMira Press.

Museum Ethnographers' Group. 1994. "Museum Ethnographers' Group Guidelines on Management of Human Remains."

Museum of New Zealand Te Papa Tongarewa. 2010. "Draft Kōiwi Tangata Policy." Wellington: Museum of New Zealand Te Papa Tongarewa.

Museums Aotearoa. 2013. "Code of Ethics \& Professional Practice: For Governing Bodies, Managers and Staff of Museums and Art Galleries in Aotearoa New Zealand." Wellington: Museums Aotearoa.

. 2017. "New Zealand Museums and Galleries 2017." Wellington: Museums Aotearoa

Museums Association. 2008. "Code of Ethics for Museums: Ethical Principles for All Who Work for or Govern Museums in the UK." London: Museums Association.

Museums Australia Inc. 1999. "Code of Ethics." Civic Square, ACT: Museums Australia.

Nafziger, James A.R. 2007-2008. "The Principles for Cooperation in the Mutual Protection and Transfer of Cultural Material." Chicago Journal of International law 8, no. 1: 147-67.

National Services Te Paerangi, and J. Legget. 1999. Towards a New Zealand Museums Standards Scheme. Wellington: Te Papa National Services.

Native American Graves Protection and Repatriation Act. 1990 (USA) 
Neuman, Fieke. 1993. "Pots and Pieces: The Anatomy Museum of the Otago Medical

School and How It Came to Be." New Zealand Museums Journal 23, no. 1: 17-22.

New Zealand Historic Places Trust Pouhere Taonga. 2010. Kōiwi Tangata Human

Remains. Archaeological Guidelines Series. [Wellington]: New Zealand Historic

Places Trust.

Newman, Andrew. 2005. "Understanding the Social Impact of Museums, Galleries and

Heritage through the Concept of Capital." In Heritage, Museums and Galleries: An

Introductory Reader, edited by Gerard Corsane, 228-37. London: Routledge.

Nicholson, Emily G., and Stephen L. Williams. 2002. "Professional Ethics Revisited."

Curator 45, no. 3: 173-78.

Noble, Guy. 2010. "Heritage in Hospitals: Using Museum Objects to Teach

Communications Skills." University Museums and Collections Journal 3: 203-06.

O'Hara, Coralie. 2012 "Repatriation in Practice: A Critical Analysis of the Repatriation of

Human Remains in New Zealand Museums." Master of Museum and Heritage

Studies thesis, Victoria University of Wellington.

O'Neill, Mark. 1999. "Museums and Their Communities." In The Manual of Museum

Planning, edited by Gail Dexter Lord and Barry Lord, 21-37. London: The

Stationery Office.

Organisation for Economic Co-operation and Development. 2001. Managing University

Museums: Education and Skills. Paris: OCED.

Otago Museum Trust Board Act 1955 (NZ)

Page, Dorothy. 2008. Anatomy of a Medical School: A History of Medicine at the

University of Otago 1875-2000. Dunedin: Otago University Press.

Palmer, Norman. 2003. "The Report of the Working Group on Human Remains."

Department for Culture, Media and Sport, United Kingdom.

Paquette, Jonathan. 2012. "From Decolonization to Postcolonial Management: Challenging

Heritage Administration and Governance in New Zealand." Public Organization

Review 12: 127-38.

Paterson, Ron. 2015. "The Code of Patients' Rights." In Health Law in New Zealand, edited by P.D.G. Skegg and Ron Paterson, 27-66. Wellington: Thomson Reuters.

Peart, Nicola. 2015. "Human Tissue." In Health Law in New Zealand, edited by P.D.G.

Skegg and Ron Paterson, 705-35. Wellington: Thomson Reuters.

Peräkylä, Anssi. 2005. "Analyzing Talk and Text." In The Sage Handbook of Qualitative

Research, edited by Norman K. Denzin and Yvonna S. Lincoln. Thousand Oaks:

Sage.

Peters, Ann H., Vicki Cassman, and Monica Gustafsson. 2007. "Associated Artifacts." In

Human Remains: Guide for Museums and Academic Institutions, edited by Vicki

Cassman, Nancy Odegaard and Joseph Powell, 129-50. Lanham: AltaMira Press.

Posner, Eric A. 2006. "The International Protection of Cultural Property: Some Skeptical

Observations," Chicago Public Law and Legal Theory Working Paper 141.

Protected Objects Act 1975 (NZ)

Prott, Lyndel V. 2012. "The Fight against the Illicit Traffic of Cultural Property: The 1970

Convention: Past and Future, 15-16 March 2011." International Journal of Cultural

Property 18, no. 4: 437-42.

Qamar, Khadija, Amina Ahmad, and Abid Ashar. 2014. "Comparison of Learning Anatomy with Cadaveric Dissection and Plastic Models by Medical Students." Pakistan

Armed Forces Medical Journal 64, no. 2: 219-24.

Quigley, Christine. 2001. Skulls and Skeletons: Human Bone Collections and Accumulations. Jefferson (NC): McFarland. 
QS World University Rankings by Subject.

https://www.topuniversities.com/university-rankings/2016. (accessed May 13 2017).

Radin, Joanna. 2014. "Collecting Human Subjects: Ethics and the Archive in the History of Science and the Historical Life Sciences.". Curator: the Museum Journal 57, no. 2: 249-58.

Redfern, Michael, Jean W. Keeling, and Elizabeth Powell. 2001. "The Royal Liverpool Children's Inquiry Report." London: House of Commons.

Rees, Geoffrey. 2011. "More Wondrous and More Worthy to Behold: The Future of Public Anatomy." In Controversial Bodies: Thoughts on the Public Display of Plastinated Corpses, edited by John D. Lantos, 36-47. Baltimore: Johns Hopkins University Press.

Richardson, Ruth. 1988. Death, Dissection and the Destitute. London: Penguin Books.

Riederer, Beat M. 2016. "Body Donations Today and Tomorrow: What Is Best Practice and Why?". Clinical Anatomy 29: 11-18.

Royal Australasian College of Physicians. 2013. "Code of Conduct." The Royal Australasian College of Physicians.

Royal College of Pathologists of Australasia. 2014. "Code of Ethics." Surry Hills: Royal College of Pathologists of Australasia.

Sandell, Richard. 2007. "Displaying Difference." Chap. 6 In Museums, Prejudice and Reframing Difference, 138-72. London: Routledge.

Second-Year Dental Class. 2007. "Our Reflections on the Bequest Programme." Poster dispayed in Department of Anatomy and Structural Biology, University of Otago.

Sharp, Lesley A. 2000. "The Commodification of the Body and Its Parts." Annual Review of Anthropology 29: 287-328.

Shirer, William L. 1998. The Rise and Fall of the Third Reich: A History of Nazi Germany. London: Arrow.

Simpson, Andrew. 2012. "Cinderella Collections Fifteen Years after the Ball: Australia's University Museums Reviewed." Museums Australia Magazine 21, no. 2: 18-20.

Skegg, P.D.G. 2015. "Death". In Health Law in New Zealand, edited by P.D.G. Skegg and Ron Paterson, 689-702. Wellington: Thomson Reuters. . 1991. "The Uses of Corpses for Medical Education and Research: The Legal Requirements." Medicine, Science and the Law 31, no. 4: 345-54.

Skloot, Rebecca. 2010. The Immortal Life of Henrietta Lacks. New York: Crown Publishers.

Sofaer, Joanna R. 2006. The Body as Material Culture: A Theoretical Osteoarchaeology. Cambridge: Cambridge University Press.

Soubiran, Sébastien. 2010. "Is Research and Teaching a Key for Preserving University Collections and Museums?". University Museums and Collections Journal 3: 21-30.

Speight, Catherine, Anne Boddington, and Jos Boys. 2013. "Introduction." In Museums and Higher Education, edited by Anne Boddington, Jos Boys and Catherine Speight, 326. Farnham: Ashgate.

Stafford, Barbara Maria. 2011. "The Creeping Illusionizing of Identity from Neurobiology to Newgenics." In Controversial Bodies: Thoughts on the Public Display of Plastinated Corpses, edited by John D. Lantos, 105-14. Baltimore: Johns Hopkins University Press.

Stanbury, Peter. 2001. "Managing the Visibility of University Museum Collections. " In Managing University Museums: Education and Skills, 69-77. Paris: OECD. 
2000. "University Museums and Collections." Museums International 52, no. 2: 49.

Stewart, Denis Tiffin. 1994. Pathology in Dunedin: Academic and Hospital 1885-1970:

Private 1960-1991. Christchurch: Philson.

Suarez, Andrew V., and Neil D. Tsutsui. 2004. "The Value of Museum Collections for Research and Science." Bioscience 54, no. 1: 66-74.

Sully, Dean, ed. Decolonising Conservation: Caring for Māori Meeting Houses Outside New Zealand. Walnut Creek,CA: Left Coast Press, 2007.

Swain, Hedley. 2002. "The Ethics of Displaying Human Remains from British Archaeological Sites." Public Archaeology 2: 95-100.

Tapsell, Paul. 2011. "'Aroha Mai: Whose Museum?': The Rise of Indigenous Ethics within Museum Contexts." In The Routledge Companion to Museum Ethics: Redefining Ethics for the Twenty-First-Century Museum, edited by Janet Marstine, 85-111. New York: Routledge.

Thomson, Keith Stewart. 2002 Treasures on Earth. London: Faber.

Thomson, Keith W. 1981. Art Galleries and Museums in New Zealand. Wellington: Reed. Tolich, Martin, and Carl Davidson. 1999. Starting Fieldwork. An Introduction to Qualitative Research in New Zealand. Auckland: Oxford University Press.

Trials of War Criminals before the Nuremberg Military Tribunals under Control Council Law No.10. 1949. In Nuremberg Code. Washington: U.S. Government Printing Office.

Trotman, Paul. 2009a. Another Voice. DVD. Dunedin: PRN Films. . 2009b. Donated to Science. DVD. Dunedin: PRN Films. . 2009c. Helen's Complete Bequest Lecture. DVD. Dunedin: PRN Films. 2009d. Meeting the Donor. DVD. Dunedin: PRN Films. 2009e. Otago Medical School Service of Thanksgiving Dunedin: DVD. PRN Films. 2012. Practising Medicine. DVD. Dunedin: PRN Films. 2009f. Roma Visits the Museum. DVD. Dunedin: PRN Films, 2009. 2009g. Whakawatea or Clearing of the Way Ceremony. DVD. Dunedin: PRN Films.

Turner, Trudy R. 2014. "Large Scale Collections of Biological Material and Ethical First Principles." Curator 57, no. 2: 259-67.

United Nations. 2007. "United Nations Declaration on the Rights of Indigenous Peoples." New York: United Nations. . 2010. "United Nations Global Plan of Action to Combat Trafficking in Persons." New York: United Nations .

United Nations Educational, Scientific and Cultural Organization. 1970. "Convention on the Means of Prohibiting and Preventing the Illicit Import, Export and transfer of Ownership of Cultural Property." Paris: UNESCO.

University Museums and Collections Committee of ICOM. "UMAC Database." http://umac.icom.museum/database. (accessed 10 Sept. 2017).

University of Otago. "Corpus: conversations about Medicine and Life." Medical Humanitites, University of Otago. http://corpus.nz/ (accessed June 11 2017) 2011. "Disciplinary Statute." Dunedin: University of Otago. . "Department of Pathology" University of Otago. http://www.otago.ac.nz/dsmpathology/index.html (accessed April 20 2017). 
"Drennan Pathology Museum." Division of Health Sciences, University of Otago, http://www.otago.ac.nz/healthsciences/hunter-centre/facilities/otago041291.html. (accessed April 6 2017).

. 2010. "Ethical Behaviour Policy." Dunedin: University of Otago.

. "Health Sciences First Year." University of Otago, http://www.otago.ac.nz/hsfy/index.html.

2006. "Māori Strategic Framework 2007-2012." Dunedin: University of Otago.

"Humanities in Health Sciences and Medicine at Otago." Division of Humanities, University of Otago, http://www.otago.ac.nz/humanities/study/otago618436.html. (accessed June 11 2017)

. 2012. "Pacific Strategic Framework 2013-2020." Dunedin: University of Otago.

. "Trotter Anatomy Museum."

http://www.otago.ac.nz/healthsciences/research/facilities/otago083134.html (accessed June 2 2017).

_. 2013. "University of Otago Teaching and Learning Plan 2013-2020." Dunedin: University of Otago.

Vernon, M. Catherine. 1994. "Common Cultural Property: The Search for Rights of Protective Intervention." Case Western Reserve Journal of International Law 26, no. 2/3 (Spring/Summer): 435-79.

Verschelde, Dominick. 2013. "The University Museum: Respecting Old Values, Embracing New Directions." University Museums and Collections Journal 6: 69-74.

Wakefield, Denis. 2007. "The Future of Medical Museums: Threatened but Not Extinct." Medical Journal of Australia 187, no. 7: 380-81.

Walter, Tony. 2004. "Body Worlds: Clinical Detachment and Anatomical Awe." Sociology of Health \& Illness 26, no. 4: 464-88.

Warnick, Bryan R. 2004. "Cadaver Dissection and the Limits of Simulation." The Journal of Clinical Ethics 15, no. 4: 350-62.

Watt, Robin J. 1995. "Museums Can Never Own the Remains of Other People but They Can Care for Them." UBC Law Review: 77-89.

Waugh, Douglas. 1990. "The Decline and Fall of Our Medical Museums." Canadian Medical Association Journal 142, no. 3: 236.

Weeks, Jane. 2000. "The Loneliness of the University Museum Curator." Museum International 52, no. 2: 10-14.

Weis, Elizabeth. 2008. Reburying the Past: The Effects of Repatriation and Reburial on Scientific Inquiry. New York: Nova Science Publishers, Inc.

Were, Graeme. 2010. "Re-Engaging the University Museum: Knowledge, Collections and Communities and University College London." Museum Management and Curatorship 25, no. 3: 291-304.

Wikler, Daniel, and Jeremiah Barondess. 1993. "Bioethics and Anti-Bioethics in Light of Nazi Medicine: What Must We Remember?". Kennedy Institute of Ethics Journal 3, no. 1: 39-55.

Wilkinson, Timothy M. 2014. "Respect for the Dead and the Ethics of Anatomy." Clinical Anatomy 27: 286-90.

Willumson, Glenn. 2000. "The Shifting Audience of the University Museum." Museum International 52, no. 2: 15-18.

Winkelmann, Andreas. 2007. "Anatomical Dissection as a Teaching Method in Medical School: A Review of the Evidence." Medical Education 41: 15-22. . 2016. "Consent and Consensus - Ethical Perspectives on Obtaining Bodies for Anatomical Dissection." Clinical Anatomy 29: 70-77. 
Winstanley, Carrie. 2013. "'Museums and Galleries? No Thanks, Not for Me.' A Critical Review of Attitudes to Museum and Gallery Visits among University Students on an Education Degree Programme." In Museums and Higher Education Working Together: Challenges and Opportunities, edited by Anne Boddington, Jos Boys and Catherine Speight, 123-33. Farnham: Ashgate.

Witcomb, Andrea. 2003. Re-Imagining the Museum: Beyond the Mausoleum. London: Routledge.

World Archaeological Congress. 2006. "The Tamaki Makau-Rau Accord on the Display of Human Remains and Sacred Objects." World Archaeological Congress. . 1989. "The Vermillion Accord on Human Remains." World Archaeological Congress.

World Medical Association. 2013 "WMA Declaration of Helsinki - Ethical Principles for Medical Research Involving Human Subjects." World Medical Association, Inc.

Yerbury, Di. 2001. "The Cinderella Collections: An Australian Fairy Story." In Managing University Museums: Education and Skills, 55-67. Paris: OECD.

\section{University of Otago course outlines}

Course outlines for 2015 and 2016 were consulted for the following papers:

ANAT (Anatomy) 241, 242, 243, 250, 331, 332, 333, 334, 335, 336.

BIOA (Biological Anthropology) 101, 201, 301;

DENT (Dentistry) 262.

HUBS (Human Body Systems) 191, 192.

MICN (Medicine) 201, 301

PHTY (Physiotherapy) 250

"Reproduction Development and Aging: Early Learning in Medicine: Year 3 Block Module Handbook." (Anatomy).

University of Otago. "Subjects and Papers." www.otago.ac.nz/courses/subjects/. (accessed July 30 2017). 